\title{
Constraint-Based Fracture Mechanics Analysis of Cylinders with Circumferential Cracks
}

\author{
By \\ Michael Bach, B.Eng. \\ a thesis submitted to \\ the Faculty of Graduate Studies and Research \\ in partial fulfillment of \\ Master of Applied Science (Engineering)
}

Ottawa-Carleton Institution for

Mechanical and Aerospace Engineering

\author{
Department of \\ Mechanical and Aerospace Engineering \\ Carleton University \\ Ottawa, Ontario
}

August 2008

(C) Copyright

2008, Michael Bach 


$\begin{array}{ll}\begin{array}{l}\text { Library and } \\ \text { Archives Canada }\end{array} & \begin{array}{l}\text { Bibliothèque et } \\ \text { Archives Canada }\end{array} \\ \begin{array}{l}\text { Published Heritage } \\ \text { Branch }\end{array} & \begin{array}{l}\text { Direction du } \\ \text { Patrimoine de l'édition }\end{array} \\ \begin{array}{l}\text { 395 Wellington Street } \\ \text { Ottawa ON K1A 0N4 } \\ \text { Canada }\end{array} & \begin{array}{l}\text { 395, rue Wellington } \\ \text { Ottawa ON K1A 0N4 } \\ \text { Canada }\end{array}\end{array}$

Your file Votre référence ISBN: 978-0-494-44028-5

Our file Notre référence

ISBN: 978-0-494-44028-5

NOTICE:

The author has granted a nonexclusive license allowing Library and Archives Canada to reproduce, publish, archive, preserve, conserve, communicate to the public by telecommunication or on the Internet, loan, distribute and sell theses worldwide, for commercial or noncommercial purposes, in microform, paper, electronic and/or any other formats.

The author retains copyright ownership and moral rights in this thesis. Neither the thesis nor substantial extracts from it may be printed or otherwise reproduced without the author's permission.
AVIS:

L'auteur a accordé une licence non exclusive permettant à la Bibliothèque et Archives Canada de reproduire, publier, archiver, sauvegarder, conserver, transmettre au public par télécommunication ou par l'Internet, prêter, distribuer et vendre des thèses partout dans le monde, à des fins commerciales ou autres, sur support microforme, papier, électronique et/ou autres formats.

L'auteur conserve la propriété du droit d'auteur et des droits moraux qui protège cette thèse. $\mathrm{Ni}$ la thèse ni des extraits substantiels de celle-ci ne doivent être imprimés ou autrement reproduits sans son autorisation.
In compliance with the Canadian Privacy Act some supporting forms may have been removed from this thesis.

While these forms may be included in the document page count, their removal does not represent any loss of content from the thesis.
Conformément à la loi canadienne sur la protection de la vie privée, quelques formulaires secondaires ont été enlevés de cette thèse.

Bien que ces formulaires aient inclus dans la pagination, il n'y aura aucun contenu manquant.

\section{Canada}




\begin{abstract}
In this thesis, the fracture behavior of a hollow cylinder with internal circumferential crack under uniform tensile loading is examined. Complete finite element analysis of the cracked cylinder is conducted to determine key fracture parameters such as $K$, T-stress, and J-integral. The finite element method is used to determine these fracture parameters using both linear elastic analysis to obtain $K$ and T-stress and elastic plastic analysis to obtain fully plastic $\mathrm{J}$-integral. The cylinder thickness ratio studied is $r_{i} / r_{o}=0.2,0.4,0.6$, and 0.8 with crack depth ratio of $a / t=0.2,0.4,0.6$, and 0.8 . The fracture parameters are applied to conventional and constraint-based failure assessment diagrams to determine the maximum load carrying capacities of the cracked cylinders. The fracture mechanics parameter solutions of T-stress, J-integral obtained and the constraint-based failure assessment procedures demonstrated in this thesis will enable a more realistic fracture assessment for circumferentially cracked hollow cylinders.
\end{abstract}




\section{Acknowledgements}

I would firstly like to thank Professor Xin Wang, my thesis supervisor. I want to show my appreciation to Professor Wang who gave me the opportunity to get into the masters program. His supervision in the past two years have allowed me to acquire a heightened appreciation for engineering and research particularly in the field of fracture mechanics. Working with Professor Wang has been a great intellectual experience. His enthusiasm for knowledge, experienced guidance, patience, and continuous encouragement has enabled me to complete my thesis.

I would like to also thank Carleton University for giving me my university education and financially supporting me throughout my undergraduate and graduate studies.

Finally, I would like to dedicate this thesis to my parents. I would like to thank my parents for bringing me to Canada so that I could have the opportunity to obtain an enriched education and make a better life for myself. I am very grateful to my parents for their unwavering support throughout the years. I also want to thank my parents for instilling valuable qualities in me such as the utmost importance of education. They taught me that I should never stop learning and that there are no limits to what I can achieve. 


\section{Table of Contents}

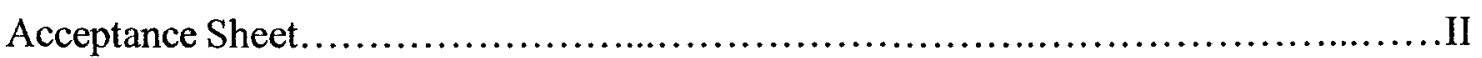

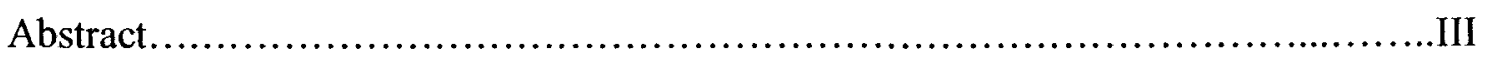

Acknowledgements.................................................................

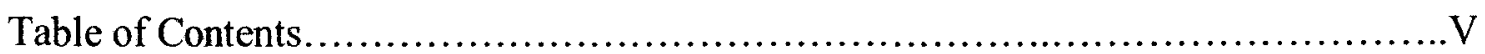

List of Tables.......................................................................

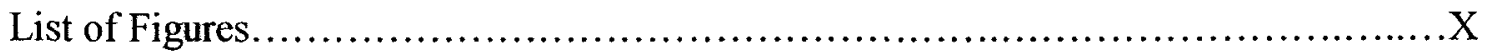

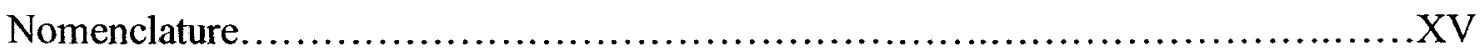

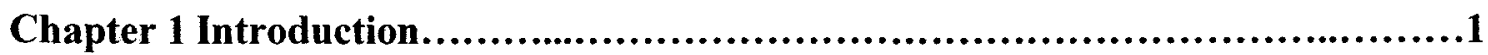

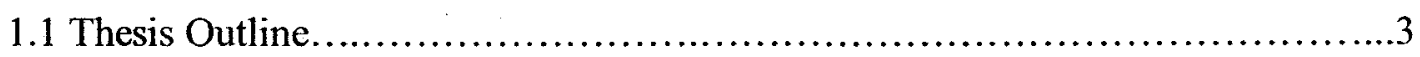

Chapter 2 Literature Review...........................................................

2.1 Fracture Mechanics..............................................................

2.2 Linear Elastic Fracture Mechanics.......................................... 8

2.2.1 Conventional One-Parameter Fracture Mechanics...........................

2.2.2 Constraint-Based Linear Elastic Fracture Mechanic...................... 12

2.3 Elastic Plastic Fracture Mechanics..........................................14

2.3.1 Elastic Plastic J-integral................................................. 15

2.3.2 Constraint-Based Elastic Plastic Fracture Mechanics.......................19

2.4 Failure Assessment Diagrams............................................20

2.4.1 Conventional Failure Assessment Diagrams.............................20

2.4.2 Constraint-Based Failure Assessment Diagrams...........................23

2.5 Finite Element Method in Fracture Mechanics..................................25 
2.5.1 Modeling Crack Tip Singularity..........................................26

2.5.2 Determination of K from Finite Element Methods...........................31

2.5.3 Determination of T-stress from Finite Element Methods......................31

2.5.4 Determination of J-integral from Finite Element Methods......................34

2.6 Hollow Cylinder with Circumferential Crack...................................35

Chapter 3 Solution of Elastic T-Stress for Hollow Cylinder..........................51

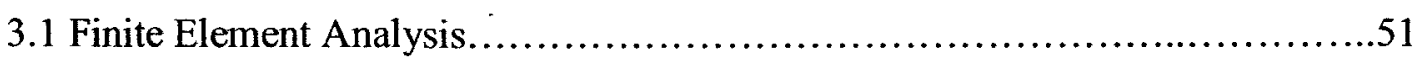

3.1.1 Cracked Geometry ................................................ 51

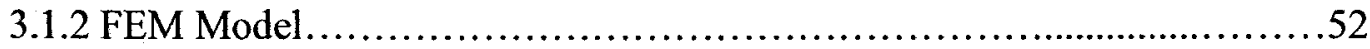

3.1.3 Verification of $\mathrm{K}$ from Established Results...............................53

3.1.4 Verification of Elastic T-stress Solutions.................................54

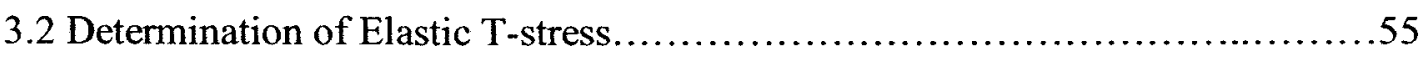

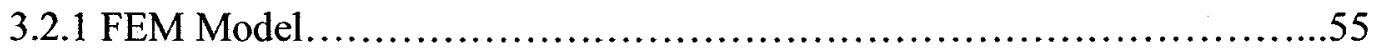

3.2.2 Results of Elastic T-stress Solutions.......................................56

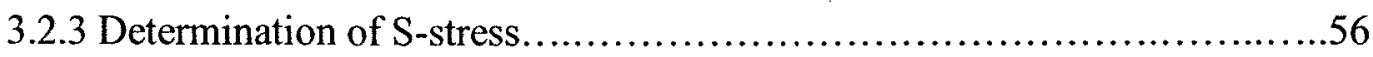

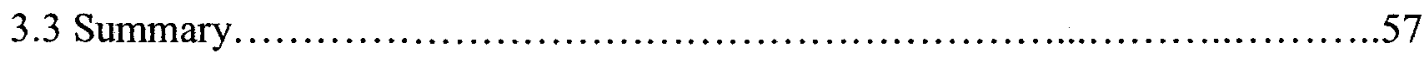

Chapter 4 Solution of Fully Plastic J-Integral for Hollow Cylinder...................71

4.1 Finite Element Analysis.................................................... 71

4.1.1 Cracked Geometry.................................................. 71

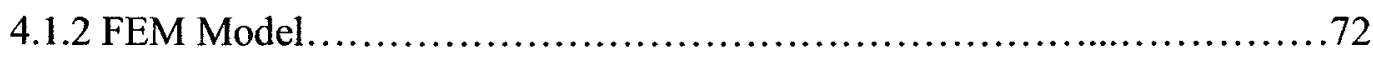

4.1.3 Verification of Fully Plastic J-Integral for Cracked Cylinders...............75

4.2 Determination of Fully Plastic J-Integral Solution.............................76

4.2.1 Discussion of Results.............................................. 77

4.3 Application of the EPRI J-Integral Estimation Scheme............................77

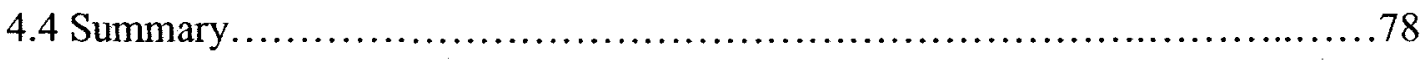


Chapter 5 Failure Assessment Diagrams............................................95

5.1 Constraint-Based Failure Assessment Diagrams...............................95

5.1.1 Constraint-Base Lower Bound FADs..................................95

5.1.2 J-T Constraint-Base Failure Assessment Diagrams.......................101

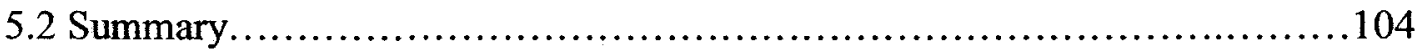

Chapter 6 Conclusions and Recommendations....................................117

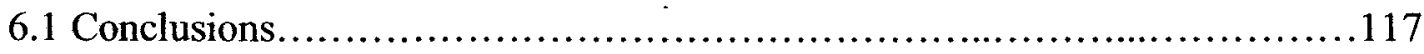

6.2 Recommendations...................................................... 118

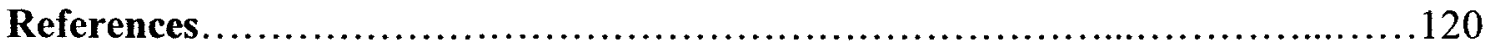




\section{List of Tables}

\section{Chapter 3}

Table 3.1: Verification of boundary correction factor for cracked cylinder, $r_{i} / r_{o}=0.2 \ldots .58$

Table 3.2: Verification of boundary correction factor for cracked cylinder, $r_{i} / r_{o}=0.4 \ldots .58$

Table 3.3: Verification of boundary correction factor for cracked cylinder, $r_{i} / r_{o}=0.6 \ldots .59$

Table 3.4: Verification of boundary correction factor for cracked cylinder, $r_{i} / r_{o}=0.8 \ldots .59$

Table 3.5: Normalized T-stress solutions for cracked cylinder under tension

Table 3.6: Normalized S-stress solutions for cracked cylinder under tension .60

\section{Chapter 4}

Table 4.1: Verification of fully plastic $h_{l}$ factor for penny-shaped crack, $a / t=0.5 \ldots \ldots .79$

Table 4.2: Verification of fully plastic $h_{1}$ factor for cracked cylinder with $r_{i} / r_{0}=0.83$,

$$
a / t=0.5
$$

Table 4.3: Results of normalized fully plastic $h_{l}$ factor for cracked cylinder with

$$
r_{i} / r_{o}=0.2 \text {. }
$$


Table 4.4: Results of normalized fully plastic $h_{l}$ factor for cracked cylinder with

$$
r_{i} / r_{o}=0.4
$$

Table 4.5: Results of normalized fully plastic $h_{l}$ factor for cracked cylinder with

$$
r_{i} / r_{o}=0.6 \text {. }
$$

Table 4.6: Results of normalized fully plastic $h_{l}$ factor for cracked cylinder with

$$
r_{i} / r_{o}=0.8
$$

\section{Chapter 5}

Table 5.1: Maximum load carrying capacity for cracked cylinder, $r_{i} / r_{o}=0.2$ using lower bound FAD methods.

Table 5.2: Maximum load carrying capacity for cracked cylinder, $r_{i} / r_{o}=0.8$ using lower bound FAD methods.

Table 5.3: Maximum load carrying capacity for cylinder, $r_{i} / r_{o}=0.8, n=10$ using J-

Based FAD 106 


\section{List of Figures}

\section{Chapter 1}

Figure 1.1: Cross-Sectional View of Internal Circumferential Crack in Cylinder.

\section{Chapter 2}

Figure 2.1: Three Basic Fracture Modes.

Figure 2.2: Stress Field at Vicinity of 3D Crack Front..................................................38

Figure 2.3: Direction of Elastic T-stress .39

Figure 2.4: Direction of Elastic S-stress . .40

Figure 2.5a: Stress Strain Curve for Linear Elastic Material.

Figure 2.5b: Stress Strain Curve for Non-linear Elastic Material.

Figure 2.6: J-integral as a Line Integral. . .42

Figure 2.7a: Closed Contour ABCDEF Around Crack Tip. .43

Figure 2.7b: Path Independent Contour. .43

Figure 2.8: Failure Assessment Diagram. .44 
Figure 2.9: 8-node Quadrilateral Element.

Figure 2.10: Collapse of 8-node Element To Model Elastic Crack Tip Singularity.......46

Figure 2.11a: 3D Crack Front with Continuous Turning Tangent...................47

Figure 2.11b: Line-load Applied to Crack Front.................................47

Figure 2.11 c: A Volume $V(s)$ Enclosing the Crack Front Segment...................47

Figure 2.12: J-integral used in for Two-Dimensional Domain Integral Method.........48

Figure 2.13: Three Dimensional View of Circumferentially Cracked Hollow Cylinder.

Figure 2.14: Cross-Sectional View of Cracked Geometry. .50

\section{Chapter 3}

Figure 3.1: Three Dimensional View of Circumferentially Cracked Hollow Cylinder. 61

Figure 3.2: Cross-Sectional View of Cracked Geometry. .62

Figure 3.3: Axisymmetric Element CAX8 .63

Figure 3.4: ABAQUS FEM Model of Cracked Cylinder Under Tension. . .64 
Figure 3.5: Close-Up View of FEM Model of Crack Tip................................65

Figure 3.6: Nodal Position of Collapsed Quadrilateral at Vicinity of Crack Tip..........66

Figure 3.7: Verification of Boundary Correction Factor for Cracked Cylinder From

Established Results (Tada, 1985)........................................67

Figure 3.8: Geometry of Penny-Shaped Crack.......................................68

Figure 3.9: Normalized T-stress Solutions for Cracked Hollow Cylinder Under Uniform

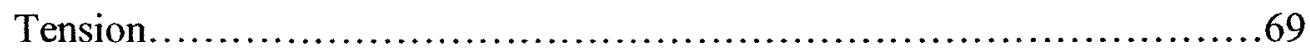

Figure 3.10: S-stress Solutions for Cracked Hollow Cylinder Under Uniform

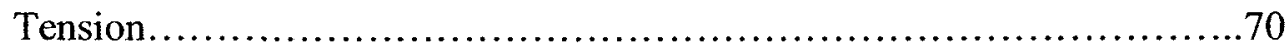

\section{Chapter 4}

Figure 4.1: Cross-Sectional View of Cracked Geometry

Figure 4.2: Location of Gauss Points in Quadrilateral Element with Reduced Integration.

Figure 4.3: Collapse of 8-node Element to Model Plastic Crack Tip Singularity...... .84 
Figure 4.4: Quarter FEM Model of Elastic Plastic Cracked Cylinder Under Tensile

Load.

Figure 4.5: Stress Strain Curves for Strain Hardening Material $n=3,5$, and 10

Figure 4.6: Verification of $h_{1}$ Factor for Cracked Cylinder, $r_{i} / r_{o}=0.83, a / t=0.5$, and $n=3$ with Established Results (Anderson, 1991).

Figure 4.7: $h_{l}$ for Cracked Cylinder, $r_{i} / r_{o}=0.2, n=3,5$, and $10 \ldots \ldots \ldots \ldots \ldots \ldots \ldots \ldots 8$

Figure 4.8: $h_{1}$ for Cracked Cylinder, $r_{i} / r_{o}=0.4, n=3,5$, and 10

Figure 4.9: $h_{l}$ for Cracked Cylinder, $r_{i} / r_{o}=0.6, n=3,5$, and 10

Figure 4.10: $h_{l}$ for Cracked Cylinder, $r_{i} / r_{o}=0.8, n=3,5$, and 10

Figure 4.11: Application of EPRI Estimation for J-integral with Cracked Cylinder, $n=3$

Figure 4.12: Application of EPRI Estimation for J-integral with Cracked Cylinder, $n=5$.

Figure 4.13: Application of EPRI Estimation for J-integral with Cracked Cylinder, $n=10$. 


\section{Chapter 5}

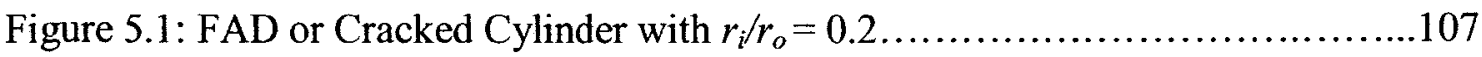

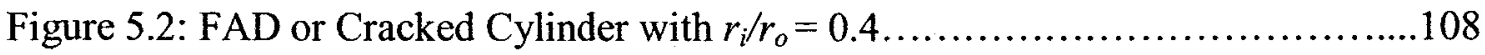

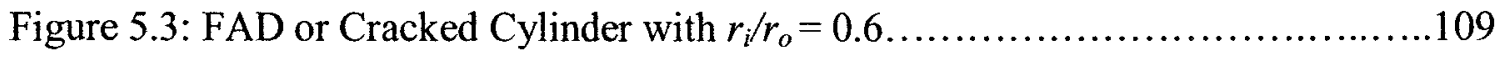

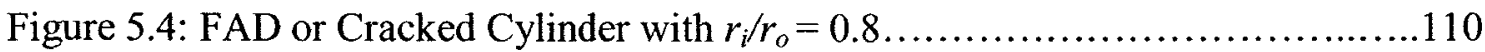

Figure 5.5: Failure Assessment Line Used To Determine Maximum Load Carrying Capacity.

Figure 5.6: Comparison of Conventional FAD and Constraint-Based FAD Cracked

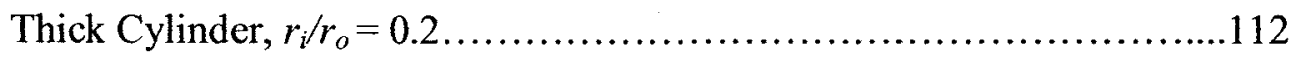

Figure 5.7: Comparison of Conventional FAD and Constraint-Based FAD Cracked Thick Cylinder, $r_{i} / r_{o}=0.8$. 113

Figure 5.8: J-Based FAD of Cracked Cylinder with $r_{i} / r_{o}=0.8, a / t=0.2, n=10$.

Figure 5.9: J-Based FAD of Cracked Cylinder with $r_{i} / r_{o}=0.8, a / t=0.6, n=10 \ldots \ldots \ldots .115$

Figure 5.10: Comparison of Increase in $P_{n}$ for K-based and J-based FAD, $r_{i} / r_{o}=0.8$, $a / t=0.2, n=10$ 116 
Figure 5.11 Comparison of Increase in $P_{n}$ for K-based and J-based FAD, $r_{i} / r_{o}=0.8$,

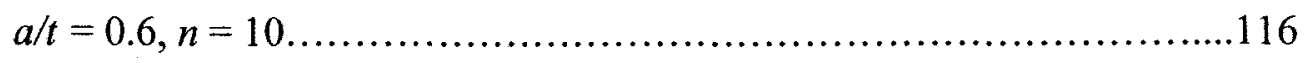




\section{Nomenclature}

\begin{tabular}{|c|c|}
\hline LEFM & Linear elastic fracture mechanics \\
\hline EPFM & Elastic plastic fracture mechanics \\
\hline$\sigma_{i j}$ & Stress tensor \\
\hline$K_{I}$ & Mode 1 Stress intensity factor \\
\hline$r$ & Radius of polar coordinate centered at crack tip \\
\hline$\theta$ & Angle of polar coordinate centered at crack tip \\
\hline$f_{i j}$ & Dimensionless function of geometry \\
\hline$T_{11}$ & Elastic T-stress \\
\hline$V$ & Normalized T-stress \\
\hline$T_{33}$ & S-stress \\
\hline$Y$ & Geometry factor \\
\hline$a$ & Crack length \\
\hline$K_{I C}$ & Fracture toughness \\
\hline$G$ & Energy release rate \\
\hline$G_{I C}$ & Critical energy release rate \\
\hline$C O D$ & Crack tip opening displacement \\
\hline$\Pi$ & Potential energy \\
\hline$A$ & Crack area \\
\hline$E$ & Young's modulus \\
\hline$v$ & Poisson's ratio \\
\hline$J$ & $\mathrm{~J}$-integral \\
\hline$W$ & Strain energy density \\
\hline$T$ & Traction vector \\
\hline$d s$ & Length increment along $\Gamma$ \\
\hline$u$ & Displacement vector \\
\hline
\end{tabular}




\begin{tabular}{ll}
$\Gamma$ & Arbitrary counter-clockwise path around crack tip \\
$J_{I C}$ & Critical J-integral \\
$Q$ & Hydrostatic Q-stress \\
$\left(\sigma_{\theta \theta}\right)_{H R R}$ & Hoop stress from HRR stress field \\
FEM & Finite element method \\
$N_{i}$ & Element shape function \\
$r, s$ & Natural coordinate system \\
$x_{i} y_{i}$ & Global coordinate system \\
$u_{i}, v_{i}$ & Cartesian components of displacement \\
{$[J]$} & Jacobian matrix \\
{$[$ B] } & Strain-displacement matrix \\
{$[\mathrm{D}]$} & Stress strain matrix \\
{$[k]$} & Stiffness matrix \\
$\sigma$ & Applied Stress \\
$\sigma_{o}$ & Yield stress \\
$\alpha$ & Dimensionless constant of Ramberg-Osgood equation \\
$I_{n}$ & Integration constant dependent on $n$ \\
$\bar{\sigma}_{i j}$ & Dimensionless function of $n$ and $\theta$ \\
$\bar{\varepsilon}_{i j}$ & Dimensionless function of $n$ and $\theta$ \\
$\varepsilon$ & Strain \\
$\varepsilon_{o}$ & Yield strain \\
$n$ & Strain hardening coefficient \\
$J_{e l}$ & Elastic J-integral \\
$J_{p l}$ & Plastic J-integral \\
$c$ & Remaining uncracked length \\
\hline & \\
\hline & Fully plastic factor \\
\hline &
\end{tabular}




\begin{tabular}{|c|c|}
\hline$P_{o}$ & Limit load \\
\hline$\sigma_{i j}^{L}$ & Auxiliary stress components \\
\hline$u_{i}^{l}$ & Auxiliary displacement components \\
\hline$f$ & Point force \\
\hline$u_{i}$ & Cartesian component of displacement \\
\hline$d$ & Reference distance \\
\hline$s$ & Point along crack front \\
\hline$I(s)$ & Interaction integral \\
\hline$V(s)$ & Domain, which enclosed crack front segment \\
\hline$f \mu_{k}$ & Line load normal to crack front \\
\hline$A_{c}$ & Increase in crack area by virtual crack advance \\
\hline$A^{*}$ & Area bounded by contours $\Gamma_{l}$ and $\Gamma_{0}$ \\
\hline$W \delta_{l j}$ & Virtual work \\
\hline$n_{j}$ & Unit vector \\
\hline$q$ & Function of $A^{*}$ \\
\hline$S$ & Normalized S-stress \\
\hline$L$ & Cylinder Length \\
\hline$\sigma_{\infty}$ & Remote tensile stress \\
\hline$\varepsilon_{i j}$ & Cartesian components of strain \\
\hline$t$ & Cylinder thickness \\
\hline$F$ & Boundary correction factor \\
\hline$a / t$ & Crack depth ratio \\
\hline$r_{i} / r_{o}$ & Cylinder thickness ratio \\
\hline$K_{r}$ & Stress intensity factor ratio \\
\hline$L_{r}$ & Stress ratio \\
\hline$\sigma_{L}$ & Limit stress solution based on yield stress \\
\hline$K_{m a t}^{C}$ & Fracture Resistance due to constraint effects \\
\hline
\end{tabular}


$P_{n}$

$\sigma_{f}$

$\sigma_{u}$

Material dependent constant related to level of constraint

Normalized constraint parameter

Material dependent constant related to level of constraint

Maximum stress ratio cut-off value

Limit load solution

Normalized maximum load carrying capacity

Flow stress

Ultimate strength 


\section{Chapter 1}

\section{Introduction}

Engineering structures such as pipelines and pressure vessels that fail by fracture can lead to considerable economic losses and damage to human lives. It is extremely important for these structures to be built fracture safe. It wasn't until the mid 1900's that design based on fracture mechanics became common practice. The study of fracture mechanics was introduced as a way of characterizing the fracture behavior of cracks and flaws in engineering structures based on the stress analysis in the vicinity of the crack.

Since cracks can lower the strength of a structure below its design strength, fracture mechanics quantifies the maximum service loading condition for a given crack size. Fracture mechanics can be divided into two categories: linear elastic fracture mechanics and elastic plastic fracture mechanics (Anderson, 1991).

Linear elastic fracture mechanics or LEFM, was developed to quantify the crack fracture under primarily elastic conditions where the plastic zone around the crack tip is confined to a very small region. LEFM examines the stress fields ahead of the crack characterized by a single parameter called the stress intensity factor, $K$.

For ductile materials, fracture often occurs after substantial plasticity develops around the crack tip. Elastic plastic fracture mechanics or EPFM, extends the description of fracture behaviour beyond the elastic regime. The commonly used elastic plastic fracture parameter is the J-integral associated with describing the crack tip stress fields for these elastic plastic materials. 
However, the above mentioned conventional single-parameter, linear elastic and elastic plastic fracture mechanics based on $K$ or J-integral could be overly conservative in failure assessments (Ainsworth and O'Dowd, 1995). These failure assessments use a low bound fracture toughness taken from highly constrained test specimens. Conventional fracture mechanics is not able to accurately characterize the stress fields of low constrained cracks, which have a higher value of fracture resistance. This approach could translate to unnecessary economical loss in maintenance and replacement of these cracked structures well before they actually need to be replaced.

Over the past 15 years, the two-parameter, constraint-based fracture mechanics has been developed to account for this increase in fracture resistance of low constrained cracks to provide a more realistic stress analysis of these crack geometries (Du and Hancock, 1991 and Betegon and Hancock, 1991). Two-parameter, constraint-based fracture mechanics as the name suggests uses an additional constraint parameter along with the stress intensity factor for LEFM, and J-integral for EPFM to accurately describe the stress fields of a crack. Rice (1974) suggested that the elastic T-stress be used as the constraint parameter. The elastic T-stress is the second term of the Williams (1957) series expansion and is defined as the stress parallel to the crack plane. Larsson and Carlsson (1973) and Rice (1974) demonstrated that the magnitude of the T-stress affects the size and shape of the plastic zone surrounding the crack tip. In addition, Bilby et al. (1986) stated that the T-stress could affect the magnitude of the stress triaxality near the elasticplastic crack tip field. A positive T-stress strengthens the crack tip triaxality and results in a high crack tip constraint while a negative $T$-stress reduces the crack tip triaxality and lowers the crack tip constraint. Another commonly used constraint parameter is the hydrostatic Q-stress, which is closely related to T-stress (O'Dowd and Shih, 1991).

Commonly used failure assessment procedures in industrial applications such as PD 6493 (1991) are found in the British Standards Publication. The procedure describes methods of how to generate failure assessment diagrams (FAD) based on the conventional one- 
parameter fracture mechanics of $K$ or $\mathrm{J}$-integral. Therefore, overly conservative assessments results will be obtained for low constraint crack geometries. It has been demonstrated that by adding the $T$-stress term to the conventional failure assessment diagram, the low constraint effect can be accounted for, which results in the increase of maximum load carrying capacity of the cracked structure (Ainsworth and O'Dowd, 1995).

An area of engineering that relies heavily on fracture mechanics is the pipeline and pressure vessel industry. Each year millions of dollars are spent on the maintenance and repair of damaged pipelines (Kannappan, 1986). Due to the nature of their operations, these pipelines are subjected to a range of static and dynamic loading conditions, which add stresses to the pipes. The combination of loading conditions and effects of the surrounding environment can cause corrosion and cracks to form. Under the right conditions, the pipelines can fail by fracture. The consequences of these failures equal to a tremendous economical loss as well as possible damage to human lives and the environment. Therefore, it is important for engineers to have a realistic and reliable failure assessment of these cracked structures. Cracks formed in these pipelines and pressure vessels can vary in size, shape and orientation. A common crack geometry is a circumferential crack that originates on the internal wall of the pipe and grows towards the outer wall. A uniform circumferentially cracked hollow cylinder as seen in Figure 1.1 , is a simplified model that can be used to study the fracture behaviour of real cracks found in pipelines. Pipelines in operation are under a wide range of loading. Uniaxial tensile loading is applied to the crack geometry of Figure 1.1 as a study of a common loading condition experienced by real cracked pipes. For remote tensile loading, these cracked cylinders are under low constraint conditions. An accurate fracture assessment of these cracked cylinders using two-parameter, constraint-based fracture mechanics can give engineers the information needed to design pipelines without overstressing or overloading them. Compared to conventional FAD methods, constraint-based assessments will provide a more realistic load carrying capacity for a given crack size. 
This means that life extensions can be given to cracked and aging pipelines on a rational technical basis.

The stress intensity factor for this crack geometry has been extensively studied and published in handbooks by Tada et al. (1985) for a wide rage of cylinder thickness ratios, $r_{i} / r_{o}$, and crack depth ratios, a/t. Sherry et al. (1995) presented T-stress solutions for cracks in thin cylinders with $r_{i} / r_{o}$ less than 0.83 under uniform tensile loading. Similarly, for the elastic plastic analysis, there are limited solutions of J-integral for very thin cracked pipes with $r_{i} / r_{o}$ less than 0.82 (Anderson, 1991). However, no T-stress and Jintegral solutions are determined for circumferential cracks in thicker cylinders. Therefore it is necessary to evaluate the stress intensity, T-stress, and J-integral using FEM for a wide range of $r_{i} / r_{o}$ and $a / t$ ratios in order to conduct a realistic constraint-based fracture assessment of these cracked cylinders encountered in engineer applications.

\subsection{Thesis Outline}

The objective of this thesis is to study the fracture behaviour of a hollow cylinder with internal circumferential crack under uniform tensile loading. A complete finite element analysis of the cracked cylinder is conducted to determine key fracture parameters such as $K$, T-stress, and $\mathrm{J}$-integral. The finite element method will be used to determine these fracture parameters using both linear elastic analysis to obtain $K$ and T-stress and elastic plastic analysis to obtain fully plastic J-integral. The geometry of the hollow cylinder is shown in Figure 1.1. The cylinder thickness ratio that will be studied are $r_{i} / r_{o}=0.2,0.4$, 0.6 , and 0.8. Each thickness ratio has a crack depth ratio of $a / t=0.2,0.4,0.6$, and 0.8 that will also be examined. Tensile loads are applied at the ends of the cylinder. The fracture parameters will be applied to conventional and constraint-based failure assessment diagrams to determine the maximum load carrying capacities of the cracked cylinders. 
The thesis is divided into six Chapters. Chapter 1 is the introduction. In Chapter 2, a literature review of linear elastic and elastic plastic fracture mechanics is presented. The background theory on the finite element method to calculate $K, \mathrm{~T}$-stress, and $\mathrm{J}$-integral will also be discussed as well as failure assessment methods. Chapter 3 will present the FEM analysis to calculate the elastic T-stress. Chapter 4 will present the FEM analysis to determine the fully plastic J-integral (the fully plastic factor, $h_{l}$ ). The application of the Electric Power and Research Institution (EPRI) estimation scheme will also be presented. The purpose of Chapter 5 is to present the conventional and constraint-based failure assessment diagrams using the fracture parameters determined in Chapters 3 and 4 to determine the maximum load carrying capacities. Finally, Chapter 6 will be the conclusions as well as recommendations. 


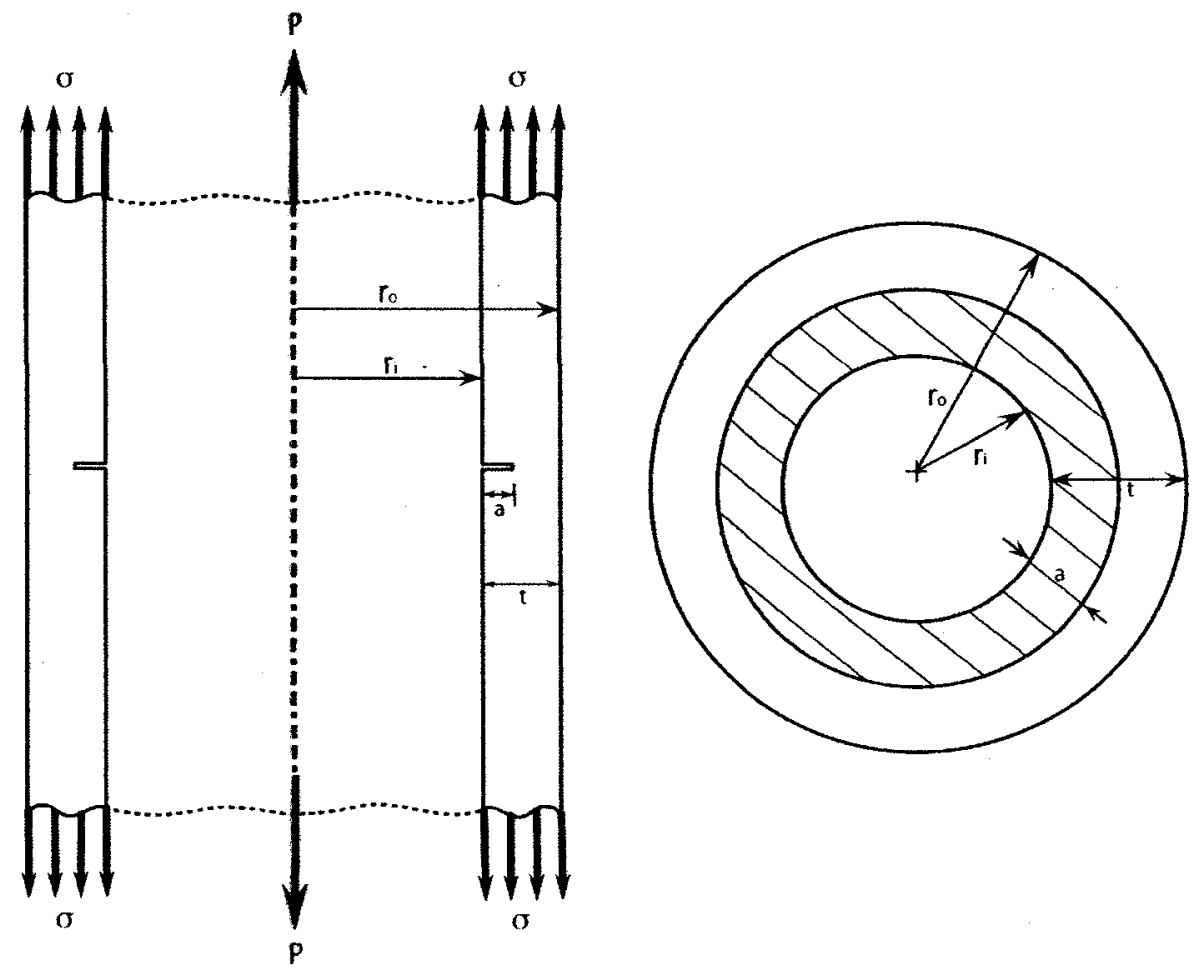

Figure 1.1: Cross-Sectional View of Internal Circumferential Crack in Cylinder 


\section{Chapter 2}

\section{Literature Review}

The purpose of this chapter is to conduct a literature review of the fundamental concepts of fracture mechanics. Section 2.1 will define the basic concepts of fracture mechanics. In section 2.2, the theories of linear elastic fracture mechanics such as the stress intensity factor and elastic T-stress will be discussed. Section 2.3 will summarize elastic plastic fracture mechanics and the J-integral concept. In section 2.4 , both conventional and constraint-based failure assessment diagrams will be introduced. Section 2.5 will look at using the finite element method to model axisymmetric crack geometries, and calculate the basic fracture mechanics parameters. Section 2.6 will examine the circumferential cracked hollow cylinder geometry studied in this thesis.

\subsection{Fracture Mechanics}

The study of fracture mechanics entails looking at the mechanisms that control the separation between parts of the body and developing fracture criteria and predictions to help reduce the chances of fracture that could lead to catastrophic failure of structures. Fracture mechanics comprises theories that are used to examine how cracks grow and how the cracks affect the strength of the structure. Depending on the level of plasticity involved around the crack tip, fracture mechanics can be further classified as linear elastic fracture mechanics (LEFM) and elastic plastic fracture mechanics (EPFM) (Janssen et al. 2004). 


\subsection{Linear Elastic Fracture Mechanics}

Linear elastic fracture mechanics attempts to characterize the fracture behavior of linear elastic materials. LEFM is only valid for non-linear material deformation that is restricted to a very small region around the crack tip.

To understand LEFM, it is important to examine the loading conditions or fracture modes that cause cracks to propagate. Fracture modes describe the separation of bodies geometrically. All stresses in the vicinity of the crack tip may be categorized into three main loading modes. Figure 2.1 shows the separation geometries of the three types of fracture modes. Mode I loading as seen in Figure 2.1a, occurs when two parts of the body separate perpendicularly away from one another in opposite directions. Mode I is the most common loading scenario and is primarily used by engineers as the design conditions in fracture mechanics. Mode II, is characterized by a sliding or in-plane shear mode where the crack surfaces slide over one another, perpendicular to the leading edge shown in Figure 2.1b. Mode III, Figure 2.1c, is characterized by tearing motions where the crack surfaces move relative to one another and parallel to the leading edge of the crack. For this thesis, only mode I loading will be considered.

\subsubsection{Conventional One-Parameter Fracture Mechanics}

There are two analytical approaches to LEFM. The two approaches are based on the stress intensity factor method and the energy release rate method. Both methods will be described in this section. Conventional linear elastic fracture mechanics is based on the concept that the stress fields at the vicinity of the crack are characterized by a single parameter called the stress intensity factor. 


\section{Stress Intensity Factor}

For cracked configurations subjected to external forces, it is possible to derive a closedform expression for the stresses in the body if the material is isotropic linear in behavior. Williams (1957) was the first to obtain the stress fields in any isotropic linear elastic three-dimensional cracked body, as shown in Figure 2.2 for mode I loading. The basic terms of the Williams series expansion are given as

$$
\left[\begin{array}{lll}
\sigma_{11} & \sigma_{12} & \sigma_{13} \\
\sigma_{21} & \sigma_{22} & \sigma_{23} \\
\sigma_{31} & \sigma_{32} & \sigma_{33}
\end{array}\right]=\frac{K_{l}}{\sqrt{2 \pi r}}\left[\begin{array}{ccc}
f_{11}(\theta) & f_{12}(\theta) & 0 \\
f_{21}(\theta) & f_{22}(\theta) & 0 \\
0 & 0 & f_{33}(\theta)
\end{array}\right]+\left[\begin{array}{ccc}
T_{11} & 0 & 0 \\
0 & 0 & 0 \\
0 & 0 & T_{33}
\end{array}\right]
$$

where $\sigma_{i j}$ is the stress tensor, $K_{I}$ is the stress intensity factor of mode I loading, $r$ and $\theta$ are polar coordinates at the crack tip, and $f_{i j}$ is a dimensionless trigonometric function of $\theta$.

After substituting the function $f_{i j}$, the stresses at the crack tip for a three-dimensional cracked body can be further described as

$$
\begin{aligned}
& \sigma_{11}=\frac{K_{I}}{\sqrt{2 \pi r}} \cos \frac{\theta}{2}\left(1-\sin \frac{6}{2} \sin \frac{6}{2}\right)+T_{11} \\
& \sigma_{22}=\frac{K_{1}}{\sqrt{2 \pi r}} \cos \frac{6}{2}\left(1+\sin \frac{6}{2} \sin \frac{36}{2}\right)
\end{aligned}
$$




$$
\begin{aligned}
& \sigma_{33}=\frac{K_{I}}{\sqrt{2 \pi r}} 2 v \cos \frac{6}{2}+T_{33} \\
& \sigma_{12}=\frac{K_{I}}{\sqrt{2 \pi r}} \cos \frac{6}{2} \sin \frac{6}{2} \cos \frac{36}{2} \\
& \sigma_{13}=\sigma_{31}=0
\end{aligned}
$$

Equations 2.2 to 2.6 shows that the stress components become infinite at the crack tip as $r$ goes to zero; this phenomenon is called the $1 / V_{\mathrm{r}}$ singularity. The intensity of the singularity is given by the stress intensity factor, $K_{I}$. Each stress component in the first term is proportional to $K_{I}$. The $T_{I I}$ is called the T-stress while the $T_{33}$ term is also called the S-stress, which will be discussed later in this chapter.

In conventional one-parameter fracture mechanics, the effects of the non-singular Tstress terms are ignored. $K_{I}$ is used alone to predict the stress state or stress intensity near the vicinity of a crack tip due to remote loading. It is assumed that the stress intensity factor completely defines and characterizes the crack tip condition for linear elastic materials. $K_{I}$ is defined as

$$
K_{I}=Y \sigma \sqrt{\pi a}
$$

where $Y$ is a dimensionless parameter that is related to the specimen and crack geometry. $\sigma$ is the applied stress and $a$ is the crack length. The stress intensity factor has been extensively used in describing crack growth and fracture behaviour of materials provided the stress field remains predominately elastic. 


\section{Fracture Toughness}

If a material fails at a certain stress condition, then fracture is defined as occurring at a critical stress intensity factor, it is commonly called the fracture toughness (Ewalds, 1984). $K_{I C}$ is the low bound, plane strain fracture toughness obtained by standard material fracture testing (ASMT E399) of highly constrained crack geometries. This fracture test ensures that a low bound fracture toughness is obtained. $K_{I C}$ is a unique material property that is related to brittle materials because with the presence of a crack, the material could rapidly fail by brittle fracture. For the assessment of defective engineering components, the values of $K_{I C}$ can be used to determine the allowable load that can be applied on a specific material and crack geometry. To prevent failure from occurring, $K_{I}$ should be less than $K_{I C}$.

\section{Stress Intensity Factor and Energy Release Rate}

Another linear elastic fracture mechanics method is based on the energy balance. Griffiths (1920) first proposed the theory of energy balance which states that a crack will grow and fracture will occur if the energy available for crack growth is greater than that of the material resistance. The resistance of the material is defined as any energy dissipation in the form of surface energy and plastic work. Griffith's theory was developed for brittle materials. Irwin (1957) elaborated on Griffith's energy balance theory and modified it to extend the theory for ductile materials. Irwin developed an energy approach to fracture called the energy release rate, $G$. Irwin stated that $G$ is the rate of change in potential energy, $\Pi$ with crack area, $A$ and is given as

$$
G=-\frac{\partial \Pi}{\partial A}
$$


Both stress intensity factor and energy release rate have been used as parameters to describe the behaviour of cracks. The stress intensity factor can be related to the energy release rate through

$$
G=\frac{K_{I}^{2}}{E^{\prime}}
$$

where

$$
\begin{array}{ll}
E^{\prime}=E & \text { for plane stress } \\
E^{\prime}=\frac{E}{\left(1-v^{2}\right)} & \text { for plane strain }
\end{array}
$$

where, $E$ is the Young's modulus and $v$ is the Poissons's ratio. At the instance of fracture, $G$ is equal to $G_{c}$, the critical energy release rate that is a measure of the fracture toughness. Therefore, to prevent fracture from occurring, $G$ should be less than $G_{c}$. Through the relationship shown in Eq. (2.9), the stress intensity factor approach is equivalent to the energy release rate approach.

\subsubsection{Constraint-Based Linear Elastic Fracture Mechanics}

Conventional methods of failure assessments are based on the theory that the stresses at the vicinity of a crack tip are characterized by the single parameter, $K_{I}$. Studies have shown that a single parameter is not sufficient to accurately describe the stress state and the onset of fracture (Larsson and Carlsson, 1973).

Material fracture tests are typically done on compact tension specimens with highly constrained crack tips. The test results give a low bound estimate of fracture toughness, 
$K_{I C}$. These low estimates of fracture toughness are used in design as a safety against the cracked bodies. The problem is that cracked geometries in reality may have a lower crack tip constraint and thus the conventional methods of failure assessment become too conservative.

The constraint-based fracture mechanics methodology is to apply a two-parameter fracture mechanics analysis of cracked bodies in order to determine a more realistic, and lower level of constraint at the crack tip for a given geometry. The most commonly used constraint parameter is the elastic $\mathrm{T}$-stress.

\section{The Elastic T-stress}

The $T_{I l}$ term or the elastic T-stress is the second term of the Williams series expansion as given in Eq. (2.2) (Rice, 1973). It is the amplitude of the crack front stress field parallel to the crack plane as seen in Figure 2.3. The elastic T-stress has been found to be an important parameter in characterizing the near crack tip elastic plastic stress state of 2D and 3D crack problems. Larson and Carlsson (1973) and Rice (1973) all show that the magnitude and sign of the T-stress can influence the size and shape of the plane strain crack-tip plastic zone at a finite load level.

Bilby et al. (1986) demonstrated that the elastic T-stress could strongly affect the magnitude of the hydrostatic triaxality in the near crack tip elastic fields. The importance of this concept is that the magnitude of the T-stress can change the level of stress triaxality, which affects the crack tip constraint. A positive value of T-stress will strengthen the level of stress triaxality and increase the crack tip constraint, while a negative value of $T$-stress will lower the level of stress triaxality and decrease the crack 
tip constraint. Similar to the stress intensity factor, the elastic T-stress solution is dependant on the type of loading, size of crack and geometry.

The $T_{33}$ term in the Williams series expansion given in Eq. (2.4) is also called S-stress. It is the amplitude of the second term in the three-dimensional series expansion of the crack front stress in the $\mathrm{x}_{3}$ direction as seen in Figure 2.4. There are very few studies on the S-stress however, Rice (1973) discussed that the S-stress could be used as an additional fracture parameter in three dimensional crack geometries.

\subsection{Elastic Plastic Fracture Mechanics}

Elastic plastic fracture mechanics assumes an isotropic elastic plastic material, which is a characteristic of ductile metals. Figure 2.5 shows the difference between linear elastic materials and elastic plastic materials. Figure 2.5a shows the stress strain curve for a linear elastic material, the stress and strain follow Hooke's law and is linear. Figure 2.5b shows the stress strain curve for non-linear elastic materials.

For ductile materials, substantial plastic deformation occurs before cracking. The stress intensity factor that normally characterizes the stress at the crack tip is no longer valid. Instead the stresses inside the plastic zone are characterized by an elastic-plastic parameter called the J-integral. The crack opening displacement or COD is another parameter that is used in EPFM, which will not be discussed in this thesis. 


\subsubsection{Elastic Plastic J-Integral}

The J-integral was first introduced by Rice (1968). The J-integral is based on the energy method and is a path-independent line integral with a value equal to the decrease in potential energy per increment of crack extension in linear or nonlinear elastic materials. The $\mathrm{J}$-integral is defined as

$$
J=\int_{\Gamma}\left(W d x_{2}-T \cdot \frac{\partial u}{\partial x_{1}}\right) d s
$$

where $W$ is the strain energy density, $T$ is the traction vector acting on $\Gamma, u$ is the displacement vector at $\Gamma$, and $d s$ is the length increment along $\Gamma$, as shown in Figure 2.6.

The J-integral is represented as a line integral to be evaluated as a line integral along an arbitrary path $\Gamma$ surrounding the crack tip, starting somewhere on the lower crack surface and ending on the upper crack surface. The integration is performed in the counterclockwise direction as seen in Figure 2.6.

The J-integral is proven to be path-independent. If a closed contour ABCDEF around that crack tip is taken as shown in Figure $2.7 \mathrm{a}$, the integral along this contour must equal zero.

$$
\int_{\Gamma_{1}}+\int_{C D}+\int_{\Gamma_{2}}+\int_{F A}=0
$$


Since $T=0$ and $d x_{2}=0$ along $\mathrm{CD}$ and FA, these contributions equal zero (Broek, 1986).

$$
\int_{\Gamma_{1}}+\int_{\Gamma_{2}}=0 \text { or } \int_{\Gamma_{1}}=-\int_{\Gamma_{2}}
$$

Therefore the contributions of $\mathrm{ABC}$, which is clockwise, must be equal to the contribution of DEF, which is counterclockwise. This means that the integral, if taken in the same direction along $\Gamma_{1}$ and $\Gamma_{2}$ will have the same value and the J-integral is said to be path independent as shown in Figure 2.7b The path independence implies that the $\mathrm{J}$ integral can be used as a measure of the stresses and strains at the tip of the crack. Therefore, the J-integral can be used as a stress intensity parameter similar to $K_{I}$ in linear elastic analysis. Failure of the material will occur if the J-integral reaches a value that is greater than the critical J-integral, $J_{I C}$.

$$
J>J_{I C}
$$

From works presented by Hutchinson (1968) and Rice and Rosengren (1968), the Jintegral could be used to characterize the crack tip conditions of nonlinear elastic materials. A power-law relationship between plastic strain and stress was assumed and given by the Ramberg-Osgood equation

$$
\frac{\varepsilon}{\varepsilon_{o}}=\frac{\sigma}{\sigma_{o}}+\alpha\left(\frac{\sigma}{\sigma_{o}}\right)^{n}
$$


where $\alpha$ is a dimensionless constant, $\varepsilon_{0}$ is the yield strain, $\sigma_{0}$ is the yield stress, and $n$ is the material-hardening coefficient. The $n$ for many materials are given in design handbooks. The crack tip stresses and strains can be expressed in terms of J-integral by

$$
\begin{gathered}
\sigma_{i j}=\sigma_{o}\left(\frac{E}{\alpha \sigma_{o}^{2} I_{n}} \frac{J}{r}\right)^{\frac{1}{n+1}} \overline{\sigma_{i j}}(\theta, n) \\
\varepsilon_{i j}=\alpha \frac{\sigma_{o}}{E}\left(\frac{E}{\alpha \sigma_{o}^{2} I_{n}} \frac{J}{r}\right)^{\frac{1}{n+1}} \overline{\varepsilon_{i j}}(\theta, n)
\end{gathered}
$$

where $I_{n}$ is a dimensionless constant depending on the strain hardening exponent $n$ and the stress state, $\bar{\sigma}_{i j}$ and $\bar{\varepsilon}_{i j}$ are dimensionless functions of $n$, the angle $\theta$, and the stress state.

Equations (2.16) and Eq. (2.17) are called the Hutchinson and Rice and Rosengren (HRR) singularity and imply that the stresses and strains at the vicinity of the crack tip are completely characterized by a single parameter $J$ similar to the stress intensity factor. Therefore, J-integral can be considered as a single fracture mechanics parameter for the elastic plastic materials.

For linear elastic analysis, the J-integral is identical to the strain energy; $G$ and therefore the J-integral can be related to the stress intensity factor by

$$
J_{e l}=\frac{K^{2}}{E^{\prime}}
$$


where

$$
\begin{array}{ll}
E^{\prime}=E & \text { for plane stress } \\
E^{\prime}=\frac{E}{\left(1-v^{2}\right)} \text { for plane strain }
\end{array}
$$

\section{The EPRI J-Integral Estimation Scheme}

Shih and Hutchinson (1976) proposed an advanced method to compute fracture driving force taking into account of strain hardening. The method was developed and published by the Electric Power Research Institute or (EPRI) in 1981.

The estimation method states that the applied J-integral can be computed under elastic plastic and fully plastic conditions. The elastic and plastic components of $J$ are computed separately and added together to obtain the total J-integral given as

$$
J=J_{e l}+J_{p l}
$$

The equation for the plastic $\mathrm{J}$-integral is defined as

$$
J_{p l}=\alpha \sigma_{o} \varepsilon_{o} c h_{\mathrm{I}}\left(\frac{P}{P_{o}}\right)^{n+1}
$$


where $\alpha$ is a dimensionless constant of the Ramberg-Osgood equation, $P$ is the applied load and $P_{o}$ is the load at collapse. The term $c$ is the remaining uncracked segment. The $h_{1}$ is a geometry factor and is only dependent on the geometry and material hardening coefficient, $n$ once normalized. The elastic J-integral component can be calculated using Eq. (2.18). Finite element methods are used to determine both components of the Jintegral.

\subsubsection{Constraint-Based Elastic Plastic Fracture Mechanics}

Conventional EPFM assumes that the J-integral alone characterizes the crack tip fields. Betegon and Hancock (1991) and Du and Hancock (1991) suggested that the J-integral along with the $\mathrm{T}$-stress could be used as a two-parameter characterization of the elasticplastic crack tip fields in a wide range of crack geometries and loading conditions.

Also, studies by Dodds et al. (1991) introduced a hydrostatic Q-stress that can be used in addition with the J-integral to characterize the crack tip fields at the onset of fracture for elastic plastic materials. The Q-stress is defined as the difference in the near crack tip field and the relative stress in small-scale-yielding for the same $J$ value and given as

$$
Q=\frac{\left(\sigma_{\theta \theta}\right)_{H R R}-\sigma_{\theta \theta}}{\sigma_{o}}
$$

where $\left(\sigma_{\theta \theta}\right)_{H R R}$ is the stress from the HRR stress field and $\sigma_{o}$ is the yield stress of the material. It has been shown by Dodds et al. (1991) that the J-integral described the crack tip field while the Q-stress described the stress state of the crack relative to the triaxality 
stress. Ainsworth and O'Dowd (1995) demonstrated that the elastic plastic Q-stress is related to the elastic T-stress by

$$
Q=\frac{T}{\sigma_{o}}
$$

Therefore it is possible to obtain the Q-stress from FEM calculations of T-stress. Using the two fracture parameters of J-integral and Q-stress are similar to J-integral and Tstress which helps lower the crack tip constraint and give a more realistic, and less conservative characteristic of the elastic plastic crack tip fields.

\subsection{Failure Assessment Diagrams}

Based on the linear elastic fracture mechanics and elastic plastic fracture mechanics, failure assessments can be conducted for engineering components. The most commonly used failure assessment method is the failure assessment diagram method (PD 6493, 1991). In this section, the conventional failure assessment diagrams based on one-

parameter fracture mechanics are reviewed as well as the constraint-based failure assessment diagrams.

\subsubsection{Conventional Failure Assessment Diagrams}

The first failure assessment diagrams were first introduced in the R6 procedures of 1976 as a method of assessing the integrity of a cracked structure (Harrison, 1976). The failure 
assessment methods have been further developed and revised and is in the third stage of revision (Ainsworth and O'Dowd, 1995).

\section{Lower Bound Conventional FAD}

Conventional lower bound FADs are based on a single-parameter fracture mechanics. The conventional failure assessment methods are described in the PD 6493 (1991) procedures. The conventional lower bound FAD is given by the curve

$$
K_{r}=f\left(L_{r}\right)
$$

$K_{r}$ is the stress intensity ratio given by

$$
K_{r}=\frac{K_{I}}{K_{I C}}
$$

where $K_{I}$ is the stress intensity factor for a given load and $K_{I C}$ is the fracture toughness of the material. $L_{r}$ is the load ratio given by

$$
L_{r}=\frac{\sigma}{\sigma_{L}}
$$


where $\sigma$ is the applied stress and $\sigma_{L}$ is the limit stress taken from the limit load for the given cracked geometry. Failure is avoided if the calculated point $\left(K_{r}, L_{r}\right)$ lies within the region bounded by the failure assessment curve, $K_{r}=f\left(L_{r}\right)$ as seen in a typical conventional FAD in Figure 2.8. The lower bound level 3 curve, $K_{r}=f\left(L_{r}\right)$ of PD 6493, is defined as

$$
K_{r}=\left(1-0.14 L_{r}^{2}\right)\left[\left(0.3+0.7 \exp \left(-0.65 L_{r}^{6}\right)\right)\right]
$$

There is a cut-off value of $L_{r}$ that cannot be exceeded called the $L_{r}^{\max }$ also shown in Figure 2.8. The cut-off value is designed to ensure that plastic collapse does not occur.

\section{J-Based Conventional FAD}

Lower bound FADs are independent of specific geometry and material strain-hardening properties so the approximation of maximum load carrying capacity has been shown to be overly conservative compared to the J-based FAD presented in the R6 (1997) procedures. Similar to lower bound conventional FAD, The failure assessment curve can be related to the solutions from the J-integral estimated based on the EPRI procedures and given as

$$
K_{r}=f\left(L_{r}\right)=\sqrt{\frac{J_{e l}}{J}}
$$


where $J_{e l}$ and $J_{p l}$ are values of J-integral obtained from elastic and elastic-plastic FEM analysis respectively. Failure is assumed to be prevented if the calculated $\left(K_{r}, L_{r}\right)$ point lies within the failure assessment curve and less than the cut-off value of $L_{r}{ }^{\max }$.

\subsubsection{Constraint-Based Failure Assessment Diagrams}

Constraint-based FADs were first introduced in the R6 procedures of 1997. Constraintbased failure assessment is based on the concept that the fracture toughness in conditions of low constraint, $K_{\text {mat }}^{C}$ can be higher than the conventional fracture toughness, $K_{I C}$ under conditions of high constraint. The following section will look at two constraintbased failure assessment diagrams. The first is the constraint-based lower bound FAD consisting of $K_{I}$ and T-stress and the second is the FAD based on J-integral and T-stress.

\section{Constraint-Based Lower Bound FAD}

The conventional failure assessment diagram is modified to account for the constraint effects with

$$
K_{r}=f\left(L_{r}\right)\left(\frac{K_{m a t}^{c}}{K_{I C}}\right)
$$

The increased in fracture resistance was determined by Betegon and Hancock (1991) and O'Dowd and Shih (1991) and can be expressed as 


$$
\begin{array}{ll}
K_{m a t}^{C}=K_{I C}\left[1+\alpha\left(-\beta L_{r}\right)^{m}\right] & \text { for } \beta<0 \\
K_{m a t}^{C}=K_{I C} & \text { for } \beta \geq 0
\end{array}
$$

where $\alpha$, and $m$ are material dependent constants which relates the dependence of fracture toughness on constraint. $\beta$ is a normalized constraint parameter relating to the Tstress as

$$
\beta=\frac{T}{\sigma_{o} L_{r}}
$$

where $T$ is the elastic T-stress and $\sigma_{o}$ is the yield stress of the material. Substituting the first equation of Eq. (2.30) into Eq. (2.29), the failure assessment parameter, $K_{r}$ becomes

$$
\begin{array}{ll}
K_{r}=f\left(L_{r}\right)\left[1+\alpha\left(-\beta L_{r}\right)^{m}\right] & \text { for } \beta<0 \\
K_{r}=f\left(L_{r}\right) & \text { for } \beta \geq 0
\end{array}
$$

where the lower bound FAD curve is given in Eq. (2.27). The constraint-based failure assessment diagrams are based on the first equation of Eq. (2.32). Similar to the conventional FAD, failure will not occur if the calculated $\left(K_{r}, L_{r}\right)$ point lies inside the failure assessment curve and is less than the cut-off value of $L_{r}{ }^{\max }$. A typical constraintbased FAD curve is shown in Figure 2.8. The generation of a constraint-based lower bound failure assessment diagram entails calculating the stress intensity factor for incrementing loads along with determining the normalized elastic T-stress. 


\section{Constraint-Based J-T FAD}

In the J-T based FAD using T-stress, $K_{r}$ is given in terms of the square root of the Jintegral ratio (Ainsworth and O'Dowd, 1995). The constraint-based failure assessment diagrams are generated similar to that of Eq. (2.32) except the first part of Eq. (2.32) is substituted with Eq. (2.28) and is given as

$$
\begin{array}{ll}
K_{r}=\sqrt{\frac{J_{e l}}{J}}\left[1+\alpha\left(-\beta L_{r}\right)^{m}\right] & \text { for } \beta<0 \\
K_{r}=\sqrt{\frac{J_{e l}}{J}} & \text { for } \beta \geq 0
\end{array}
$$

$\mathrm{J}-\mathrm{T}$ based fracture assessment proves to further increase the J-based FAD curve because it is generated based on material property, geometry, and the constraint parameter, $\mathrm{T}$ stress.

\subsection{Finite Element Method in Fracture Mechanics}

The finite element method used to determine crack-tip stress fields has been studied widely. The method has allowed the analysis of complex two-dimensional and threedimensional problems, and the use of elastic plastic elements to include crack tip plasticity (Broek, 1986). In this thesis, FEM is used to calculate fracture parameters such as $K_{I}, \mathrm{~T}$-stress, and $\mathrm{J}$-integral for the cracked cylinder. The FE method is reviewed in this section. 


\subsubsection{Modeling of Crack Tip Singularity}

The main purpose of using FEM in the linear elastic and elastic plastic fracture analyses of this thesis is the modeling of the crack tip singularity. Equations (2.2) to (2.5) shows that the stress components become infinite at the crack tip as $r$ goes to zero; this phenomenon is called the crack tip singularity. Linear elastic materials exhibit a $1 / \sqrt{ } r$ singularity in strain at the crack tip while elastic plastic materials exhibit a $1 / r$ singularity. A singular element technique is presented to model the crack tip singularity, help increase accuracy and reduce the computational cost. This technique is based on modification of the isoparametric elements at the crack tip suggested by Barsoum (1977). A regular 8-node isoparametric element is shown in Figure 2.9. Barsoum suggested that the 8-node quadrilateral element be collapsed at one side into a single point. The quadrilateral forms a triangular shape as seen in Figure 2.10. Collapsing the nodes of the quadrilateral at one side and constraining them to move together can account for the $l / \sqrt{ } r$ singularity in linear elastic materials. It was also suggested that a more accurate analysis could be conducted by moving the mid-point nodes to onequarter points closer to the crack tip. For elastic plastic materials, the nodes of the quadrilateral are also collapsed at one side but the nodes are not constrained to move together which produce a $1 / r$ singularity (Barsoum, 1977).

\section{Isoparametric Elements}

In FEM, the elastic continuum is replaced by a finite number of structural elements of finite size, interconnected by nodal points. The forces between elements are transmitted through these nodal points. The displacements of the nodal points are the fundamental concepts of FEM. The following section will discuss the basic concepts of FEM isoparametric elements and nodal displacements. The type of element that is used in the work of this thesis is an 8-node quadrilateral element as seen in Figure 2.9. The shape 
functions will map the element geometry and the element nodal displacements, a key idea in FEM. Elements in the models are mapped from natural coordinates to global coordinates through the element shape functions given as

$$
\left\{\begin{array}{l}
x \\
y
\end{array}\right\}=\sum_{i=1}^{8} N_{i}(r, s)\left\{\begin{array}{l}
x_{i} \\
y_{i}
\end{array}\right\}
$$

The nodal coordinate in the natural coordinate system is given by $r$ and $s$ while the nodal coordinates in the global system is given by $x_{i}$ and $y_{i} N_{i}$ represents the shape function. For an 8-node quadrilateral, the shape functions are given as

$$
\begin{aligned}
& N_{1}=\frac{1}{4}(1-r)(1-s)(-1-r-s) \\
& N_{2}=\frac{1}{4}(1+r)(1-s)(-1-r-s) \\
& N_{3}=\frac{1}{4}(1+r)(1+s)(-1-r+s) \\
& N_{4}=\frac{1}{4}(1-r)(1+s)(-1-r+s) \\
& N_{5}=\frac{1}{2}\left(1-r^{2}\right)(1-s) \\
& N_{6}=\frac{1}{2}\left(1-r^{2}\right)\left(1-s^{2}\right) \\
& N_{7}=\frac{1}{2}\left(1-r^{2}\right)(1+s) \\
& N_{8}=\frac{1}{2}(1-r)\left(1-s^{2}\right)
\end{aligned}
$$


The element nodal displacement equation is given as

$$
\left\{\begin{array}{l}
u \\
v
\end{array}\right\}=\sum_{i=1}^{8} N_{i}(r, s)\left\{\begin{array}{l}
u_{i} \\
v_{i}
\end{array}\right\}
$$

It is important to note that the shape functions are given in terms of the natural coordinates. The Jacobian matrix given as

$$
[J]=\left|\begin{array}{ll}
\frac{\partial x}{\partial r} & \frac{\partial y}{\partial r} \\
\frac{\partial x}{\partial s} & \frac{\partial y}{\partial s}
\end{array}\right|
$$

The Jacobian matrix relates the natural and global coordinates system as

$$
\left\{\begin{array}{l}
\frac{\partial N_{i}}{\partial x} \\
\frac{\partial N_{i}}{\partial y}
\end{array}\right\}=[J]^{-1}\left\{\begin{array}{l}
\frac{\partial N_{i}}{\partial r} \\
\frac{\partial N_{i}}{\partial s}
\end{array}\right\}
$$


The strains are related to the nodal displacements by the following equations

$$
\left.\left\{\begin{array}{c}
\varepsilon_{x} \\
\varepsilon_{y} \\
\gamma_{x y}
\end{array}\right\}=\left\{\begin{array}{c}
\frac{\partial u}{\partial x} \\
\frac{\partial u}{\partial y} \\
\frac{\partial}{\partial x}+\frac{\partial u}{\partial y}
\end{array}\right\}=[B]\right\}\left[\begin{array}{c}
u_{1} \\
v_{1} \\
u_{2} \\
v_{2} \\
\vdots \\
\vdots \\
u_{8} \\
v_{8}
\end{array}\right\}
$$

where

$$
[B]_{i}=\left|\begin{array}{cc}
\frac{\partial N_{i}}{\partial x} & 0 \\
0 & \frac{\partial N_{i}}{\partial y} \\
\frac{\partial N_{i}}{\partial y} & \frac{\partial N_{i}}{\partial x}
\end{array}\right|
$$

The stress-strain relationship is given by

$$
\left.\left\{\begin{array}{l}
\sigma_{x} \\
\sigma_{y} \\
\tau_{x y}
\end{array}\right\}=\frac{E}{(1+v)(1-2 v)}\left[\begin{array}{ccc}
1-v & v & 0 \\
v & 1-v & 0 \\
0 & 0 & 1-2 v
\end{array}\right] \begin{array}{c}
\varepsilon_{x} \\
\varepsilon_{y} \\
\gamma_{x y}
\end{array}\right\}
$$

where 


$$
\frac{E}{(1+v)(1-2 v)}\left|\begin{array}{ccc}
1-v & v & 0 \\
v & 1-v & 0 \\
0 & 0 & 1-2 v
\end{array}\right|=[D]
$$

Equation (2.42) is called the constitutive matrix for plane strain and is written as $[D]$. Now that all of the variables have been defined, the stiffness matrix is given as

$$
[k]=\int_{-1}^{t}[B][D][B] \operatorname{det}|J| d r d s
$$

\section{Contour Integral Evaluation}

Contour integrals are used in two-dimensional as well as three-dimensional FEM to determine the fracture parameters of stress intensity factor, elastic T-stress, and $\mathrm{J}$ integral. In FEM model, elements surrounding the crack tip form contours. Each contour is seen as a virtual motion of block of material covering the crack tip. A block of elements is then defined as a contour. Various contour integrals can be evaluated to determine of stress intensity factor, elastic T-stress, and J-integral.

Contour integral evaluation uses the domain integral method and the divergence theorem based on works presented by Shih (1981). The divergence theorem is used to expand the contour integral into an area integral in two dimensions and a volume integral in three dimensions over a finite domain around the crack tip. In ABAQUS, the domain integral method is used to evaluate the contour integrals. The equation for the J-integral is 


$$
J=\int_{A}\left[\sigma_{i j} \frac{\partial u_{i}}{\partial x_{1}}-W \delta_{i j}\right] \frac{\partial q_{1}}{\partial x_{1}} d A
$$

Details of the J-integral as a contour integral will be discussed in further section of this chapter.

\subsubsection{Determination of $\mathbf{K}$ from Finite Element Methods}

There are two methods of determining the stress intensity factor using FEM. The first method involves calculating the stress intensity directly using Eq. (2.2) to Eq. (2.5). The technique calculates the stress and displacement at a small distance from the crack tip and solving for the stress intensity factor. This method however required a very large number of very small elements near the crack tip. The most commonly used method is the second method of deriving the stress intensity factor from the J-integral presented by Shih et al. (1981).

For linear elastic analysis, $J$ is equal to $G$, and therefore, the $K$ is derived using Eq. (2.18). The contour integral method is used to integrate the contours surrounding the crack tip, the J-integral is determined as shown in Eq. (2.44) and the $K_{I}$ is extracted from the relationship between J-integral and $K_{I}$.

\subsubsection{Determination of Elastic T-Stress from Finite Element Methods}

The elastic T-stress can be calculated using several methods such as the weight function method by Wang (2002), the boundary element method by Sladeck (2000) and finite 
element method by Nakamura and Parks (1992). Determination of the elastic T-stress by finite element method using the interaction integral will be discussed.

Nakamura and Parks (1992) suggested extracting the elastic T-stress for threedimensional fracture problems by introducing the interaction integral method (Kfouri, 1986). Figure 2.11a shows a three-dimensional crack front with a continuous turning tangent. A line-load with a magnitude of $f_{k}=f \mu_{k}(s)$ is applied along the crack front as showing in Figure $2.11 \mathrm{~b}$. The term $\mu_{k}$ represents the direction normal to the crack front and in the plane of the crack at the point $s$. Introduction of the superscript ' $L$ ' is used to identify the stresses, strains and displacements fields. The analytical solution is given as

$$
\begin{aligned}
\sigma_{11}^{L} & =-\frac{f}{\pi r} \cos ^{3} \theta \\
\sigma_{22}^{L} & =-\frac{f}{\pi r} \cos \theta \sin ^{2} \theta \\
\sigma_{33}^{L} & =-\frac{f}{\pi r} v \cos \theta \\
\sigma_{12}^{L} & =-\frac{f}{\pi r} \cos ^{2} \theta \sin \theta \\
\sigma_{13}^{L} & =\sigma_{23}^{L}=0
\end{aligned}
$$

and

$$
\begin{aligned}
& u_{1}^{L}=-\frac{1-v^{2}}{E} \frac{f}{\pi}\left\{\ln \left(\frac{r}{d}\right)+\frac{\sin ^{2} \theta}{2(1-v)}\right\} \\
& u_{2}^{L}=-\frac{1-v}{2 E} \frac{f}{\pi}\{(1-2 v)-\cos \theta \sin \theta\} \\
& u_{3}^{L}=0
\end{aligned}
$$


The near tip field was superimposed with the field due to the line-load approximation and the interaction integral is determined as

$$
I(S)=\frac{1}{A_{c} \int_{(s)}}\left\{\left(\sigma_{i j} \frac{\partial u_{i}^{L}}{\partial x_{k}}+\sigma_{i j}^{L}\right) \frac{\partial q_{k}}{\partial x_{j}}-\sigma_{i j}^{L} \varepsilon_{i j} \frac{\partial q_{k}}{\partial x_{k}}\right\} d V
$$

where $V(s)$ is the domain that encloses the crack from segment from s- $\varepsilon$ and $s+\varepsilon$ as seen in Figure $2.11 \mathrm{c}$ where the integral is evaluated. $V(s)$ surrounds the crack front at $s$ and lies in the plane perpendicular to the crack front as $s . A_{c}$ is the increase in crack area generated by the virtual crack advance, $\sigma_{i j}, \varepsilon_{i j}$, and $u_{i}$ are the stress, strain and displacement components of the 3D crack problem, $\sigma_{i j}{ }^{L}, \varepsilon_{i j}{ }^{L}$, and $u_{i}{ }^{L}$ are the line-load solutions given in Eq. (2.45) and Eq. (2.46). With the interaction integral defined, the Tstress can be calculated as

$$
T_{11}(s)=\frac{E}{1-v^{2}}\left\{\frac{I(s)}{f}+v \varepsilon_{33}(s)\right\}
$$

where $\varepsilon_{33}(s)$ is the extensional strain at point $s$ in the direction tangential to the crack front. Once the T-stress term is determined, $T_{33}$ or the S-stress can be obtained by the relationship with $\mathrm{T}$-stress as

$$
T_{33}=E \varepsilon_{33}+v T_{11}
$$


where $T_{33}$ is the S-stress, $E$ is Young's modulus, $\varepsilon_{33}$ is the strain in the 33-direction, $v$ is the Poisson's ratio and $T_{l l}$ is the elastic T-stress.

\subsubsection{Determination of J-Integral from Finite Element Methods}

For elastic plastic materials, the J-integral is determined from FEM by contour integral evaluation based on the domain integral method. Figure 2.12 shows the closed contour used in the two-dimensional domain integral method. In the domain integral method, the $\mathrm{J}$-integral is integrated over an area of a closed contour given by $A^{*}$ and bounded by $\Gamma_{l}$ and $\Gamma_{0}$. Shih et al. (1981) presented the J-integral to include the inertia effects of the crack growth in the $x_{I}$ direction. The elastic plastic J-integral is defined as a contour integral and is given as

$$
J=\int_{\mathrm{r}}\left[\sigma_{i j} \frac{\partial u_{j}}{\partial x_{1}}-W \delta_{1 j}\right] h_{j} q_{1} d s
$$

where $W \delta_{l j}$ is the virtual work, $n_{j}$ is the unit vector which is negative on the $\Gamma_{0}$ curve and positive on the $\Gamma_{l}$ curve. The $q_{l}$ term is a function of $A^{*}$ that is 1 on $\Gamma_{0}$ and 0 on $\Gamma_{l}$. Applying the divergence theorem to Eq. (2.50), the contour integral is expanded into an area integral, integrated over and area given by

$$
J=\int_{A}\left[\sigma_{i j} \frac{\partial u_{i}}{\partial x_{1}}-W \delta_{1 j}\right] \frac{\partial q_{1}}{\partial x_{j}} d A
$$


Equation (2.51) is the same as that of Eq. (2.44) used to determine the stress intensity factor. If the first contour lies on the node at the crack tip, then the first few contours may be inaccurate and therefore should be ignored. The J-integral for the various contours may be slightly different because of the approximate nature of the finite element method. The value of the J-integral is typically taken from the average of the three outer most contours where the values have converged. Creating a finer mesh can reduce variation in contours. Variations in estimates are called domain dependence and are a result of the error in the contour integral definition. It is important to note that since the stress intensity factor is calculated based on the J-integral; it will have the same domain dependence as the J-integral.

\subsection{Hollow Cylinder with Internal Circumferential Crack}

Circumferential cracks are one of the most common yet dangerous flaws found in pipelines and pressure vessels. The simplified, uniform circumferential cracked cylinder represents an excellent model for tensile loaded cracked cylindrical structures such as pipelines with internal pressure. The geometry and dimensions of the hollow cylinder with circumferential crack are shown in Figure 2.13. The cracked cylinder under remote tension is a basic model of three-dimensional analysis that can be determined from axisymmetric analysis as shown in Figure 2.14. The stress intensity factor for hollow cylinders with circumferential crack under uniform tension has already been well studied and determined analytically (Tada et al., 1985).

The fully plastic J-integral solution (fully plastic $h_{l}$ factor) for hollow cylinders under remote tension has been studied for geometries of $r_{i} / r_{o}=0.82,0.9$, and 0.92 . These geometries represent very thin hollow cylinders (Anderson, 1991). Further studies of cracked thicker cylinders are required. 
There have been limited solutions of T-stress for thin hollow cylinder geometry under uniform tensile loading (Sherry et al. 1995). The purpose of a two-parameter constraintbased failure assessment is to determine the values of $K$, T-stress and $\mathrm{J}$-integral to be used in two-parameters failure assessment. Therefore the values of T-stress, and $\mathrm{J}$ integral are first determined. Constraint-based assessments for the crack geometry will then be conducted for the purpose of this thesis. 


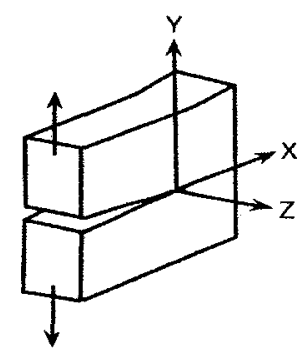

a: Mode I

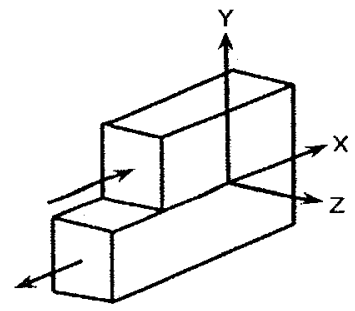

b: Mode II

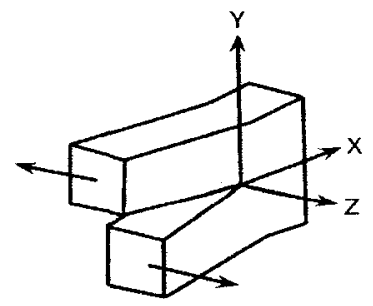

c: Mode III

Figure 2.1: Three Basic Fracture Modes 


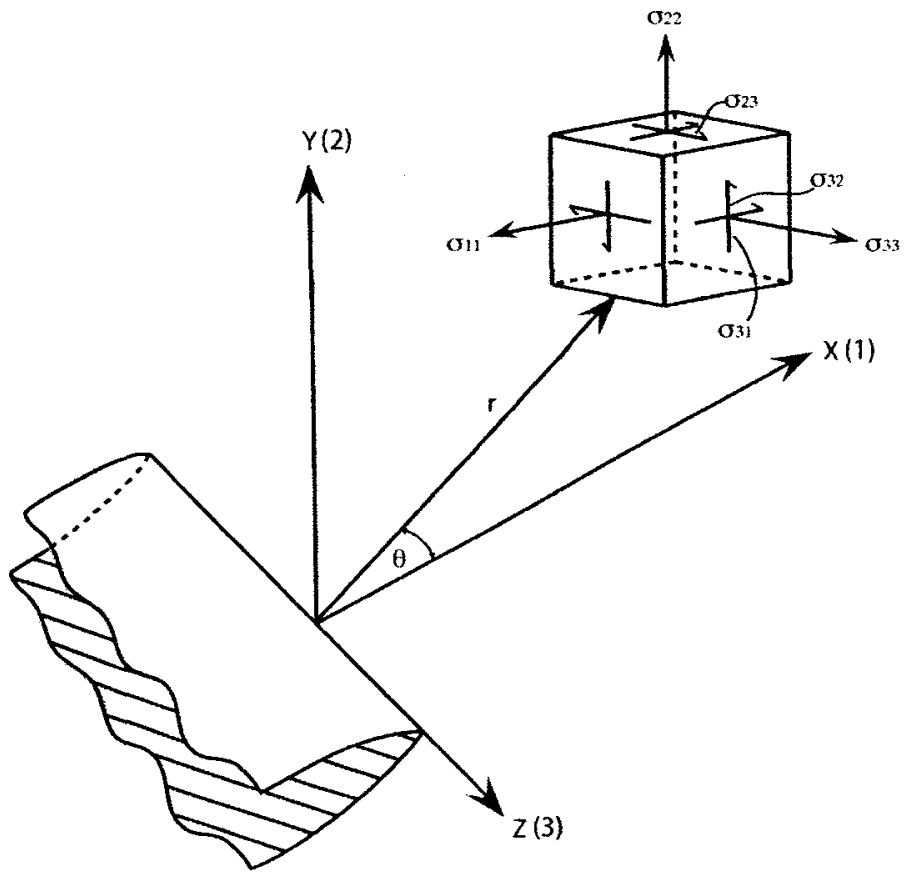

Figure 2.2: Stress Field at Vicinity of 3D Crack Front 


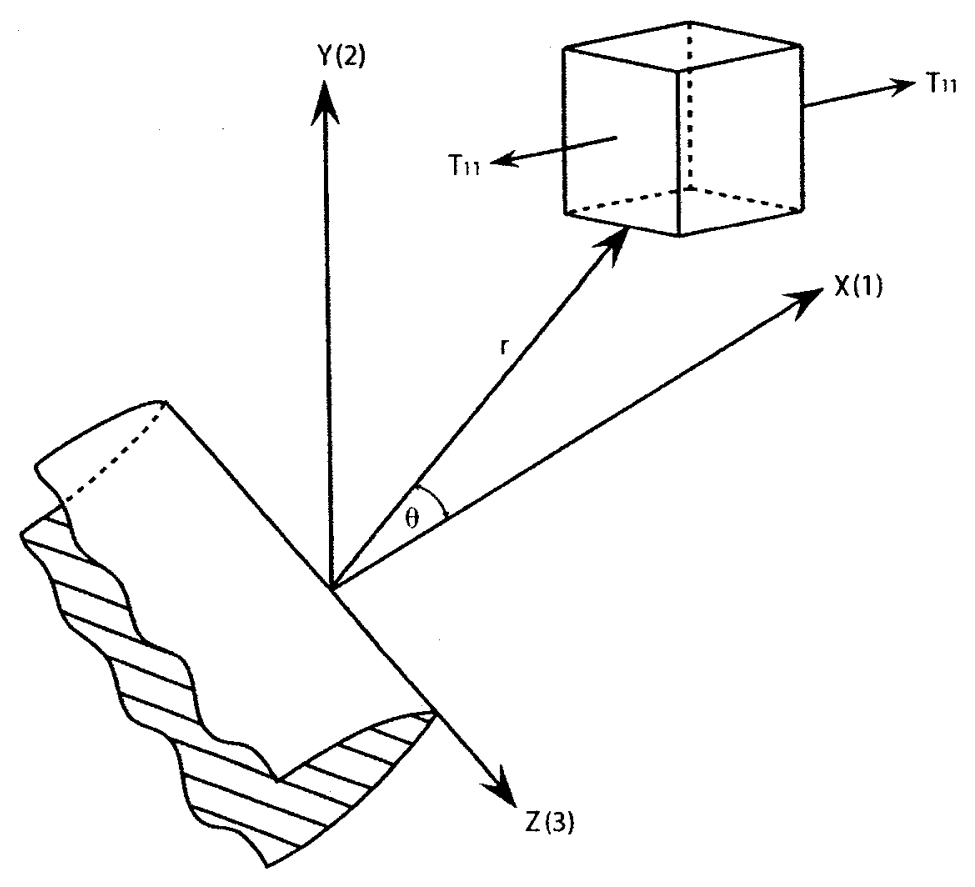

Figure 2.3: Direction of Elastic T-stress 


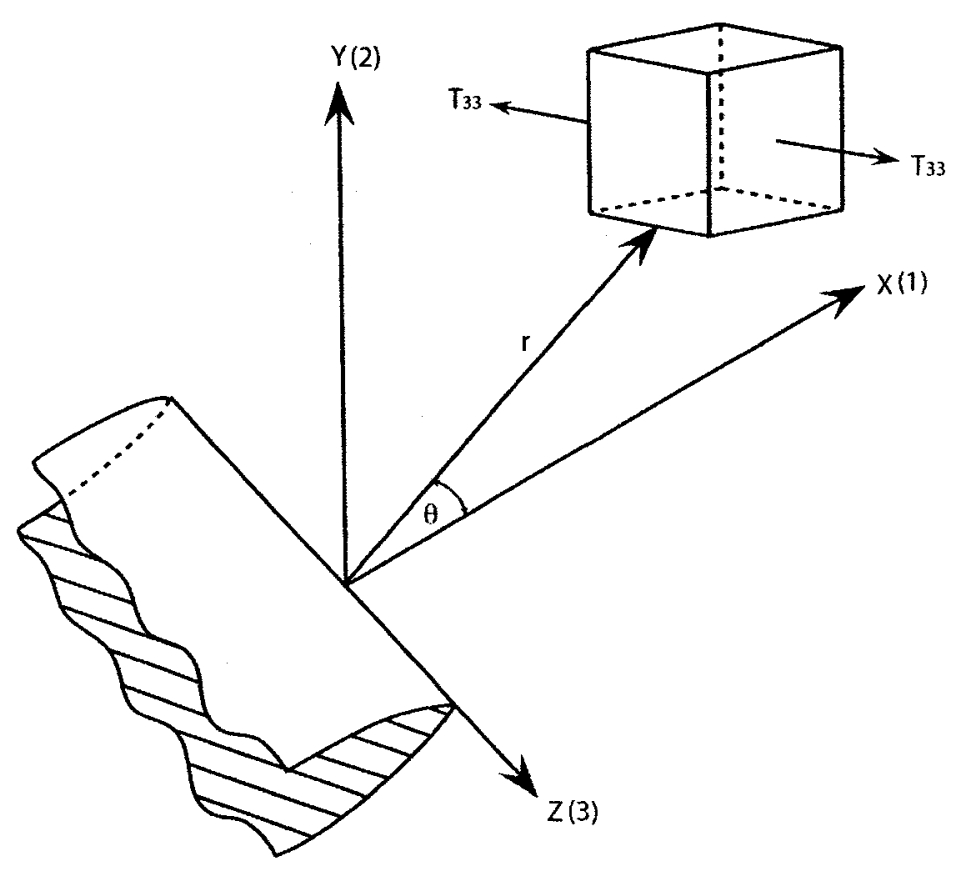

Figure 2.4: Direction of Elastic S-stress 


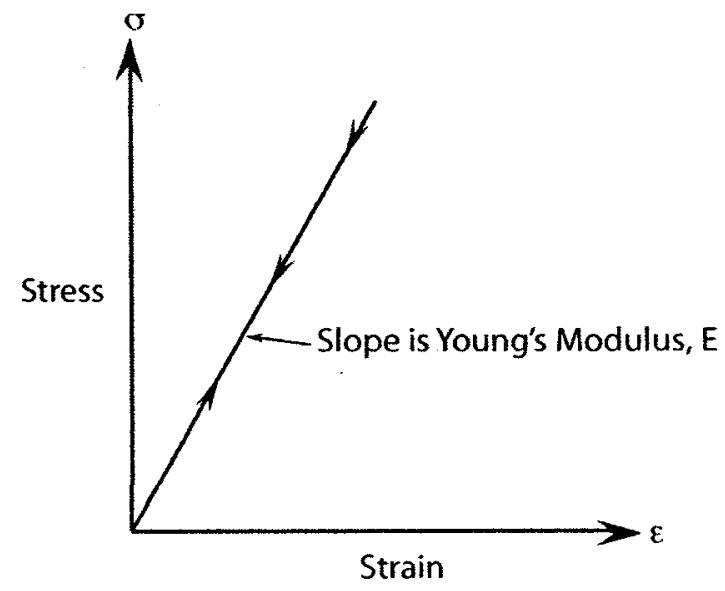

Figure 2.5a: Stress Strain Curve for Linear Elastic Material

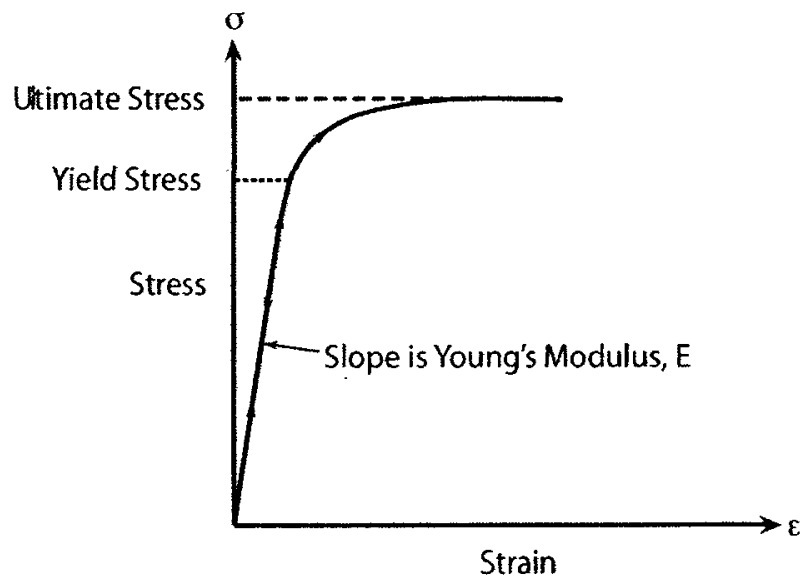

Figure 2.5b: Stress Strain Curve for Non-linear Elastic Material 


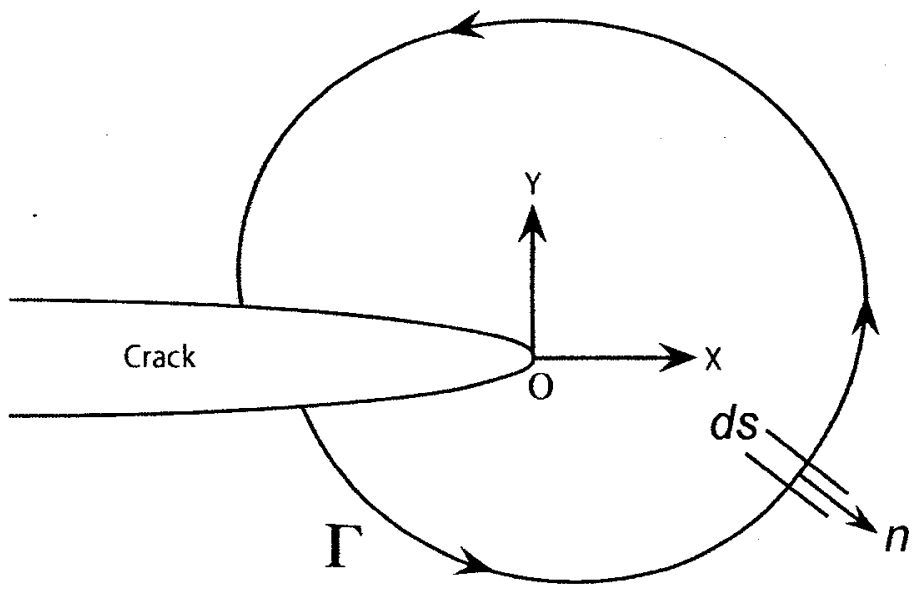

Figure 2.6: J-integral as a Line Integral 


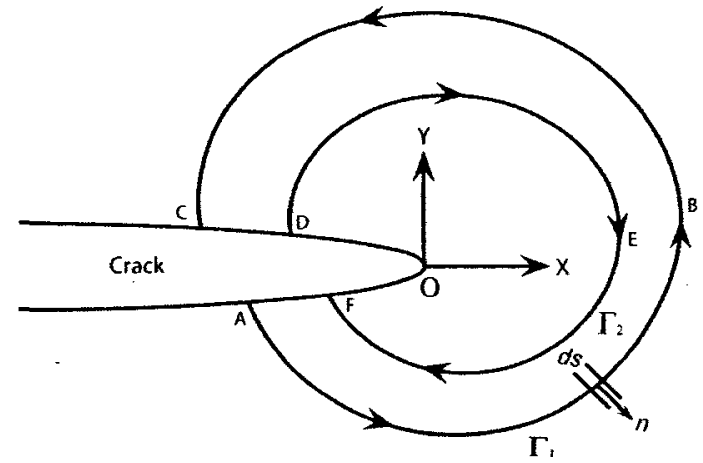

Figure 2.7a: Closed Contour ABCDEF Around Crack Tip

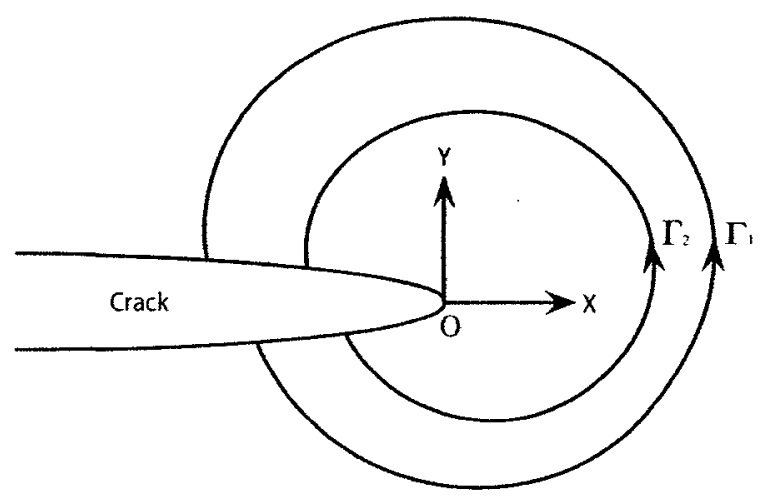

Figure 2.7b: Path Independent Contour 


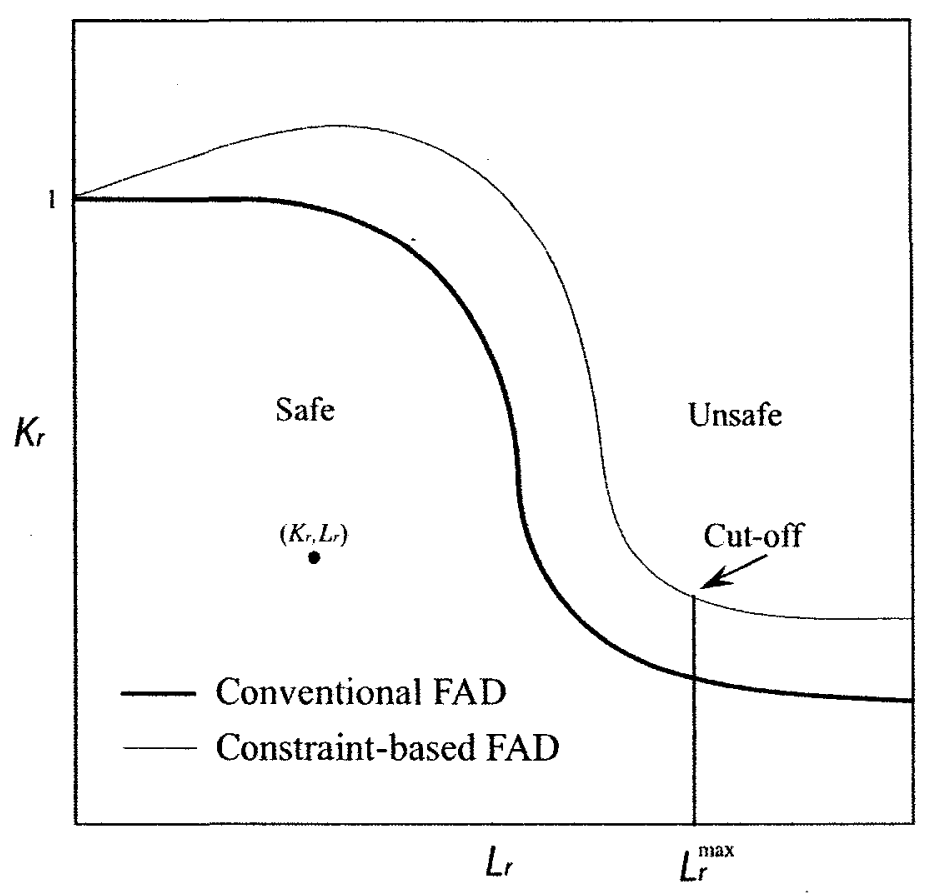

Figure 2.8: Failure Assessment Diagram 


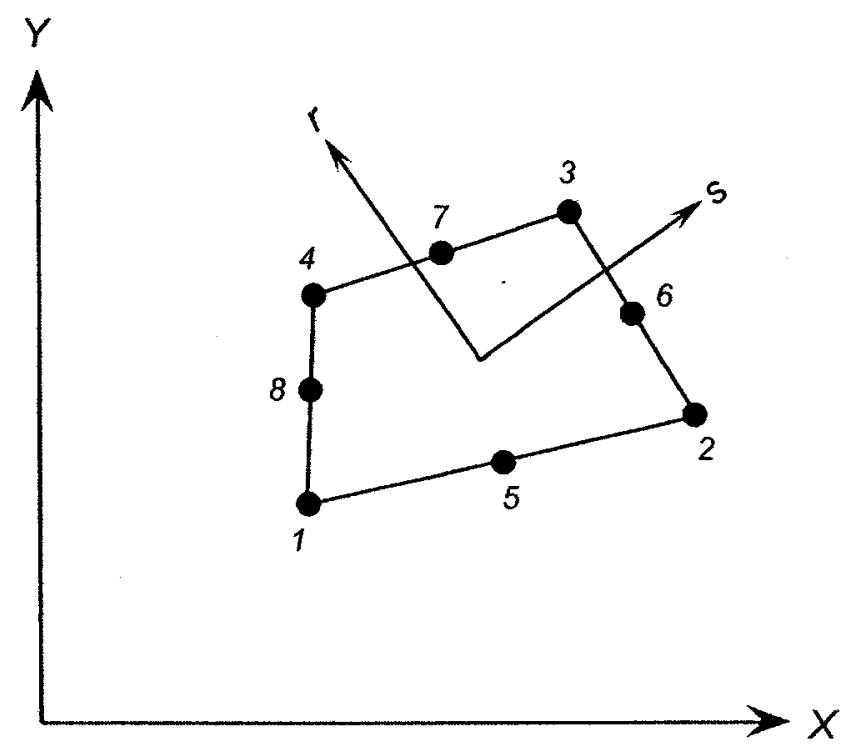

Figure 2.9: 8-node Quadrilateral Element 

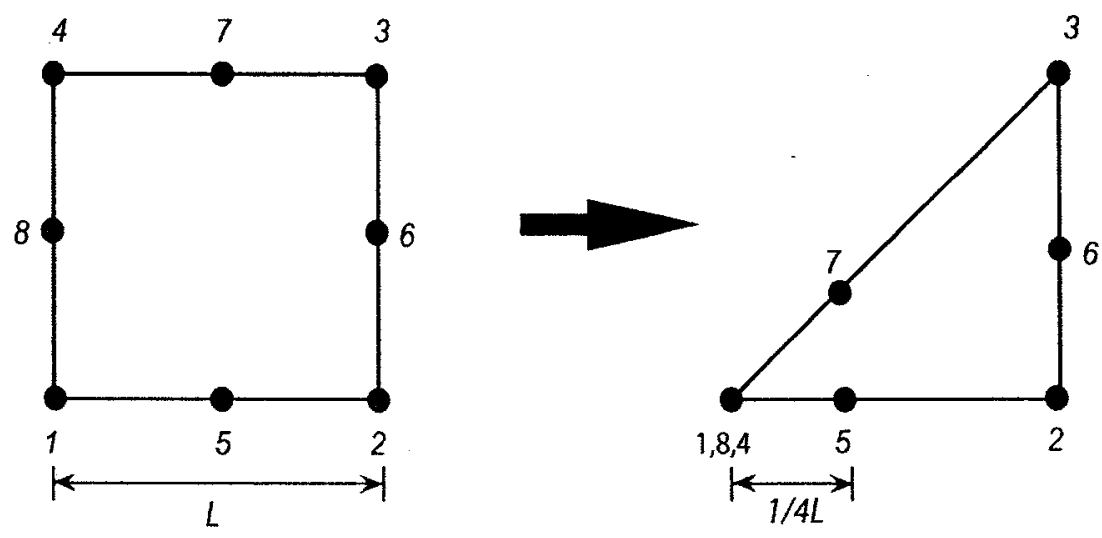

Figure 2.10: Collapse of 8-node Element To Model Stress Tip Singularity 


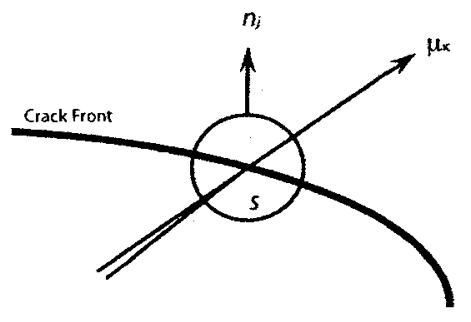

Figure 2.11a: 3D Crack Front with Continuous Turning Tangent

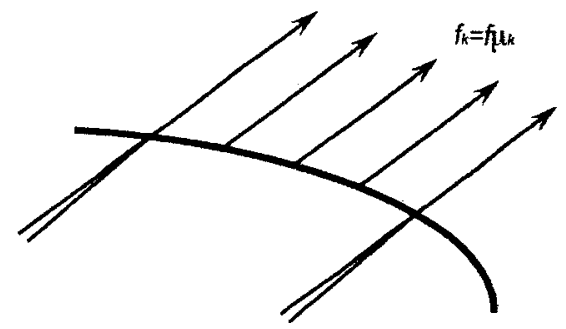

Figure 2.11b: Line-load Applied to Crack Front

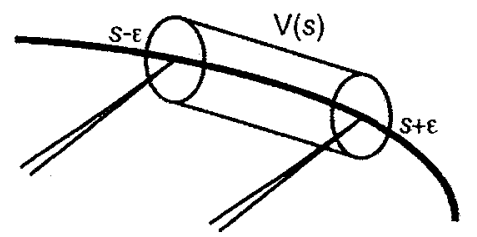

Figure 2.11c: A Volume $V(s)$ Enclosing the Crack Front Segment 


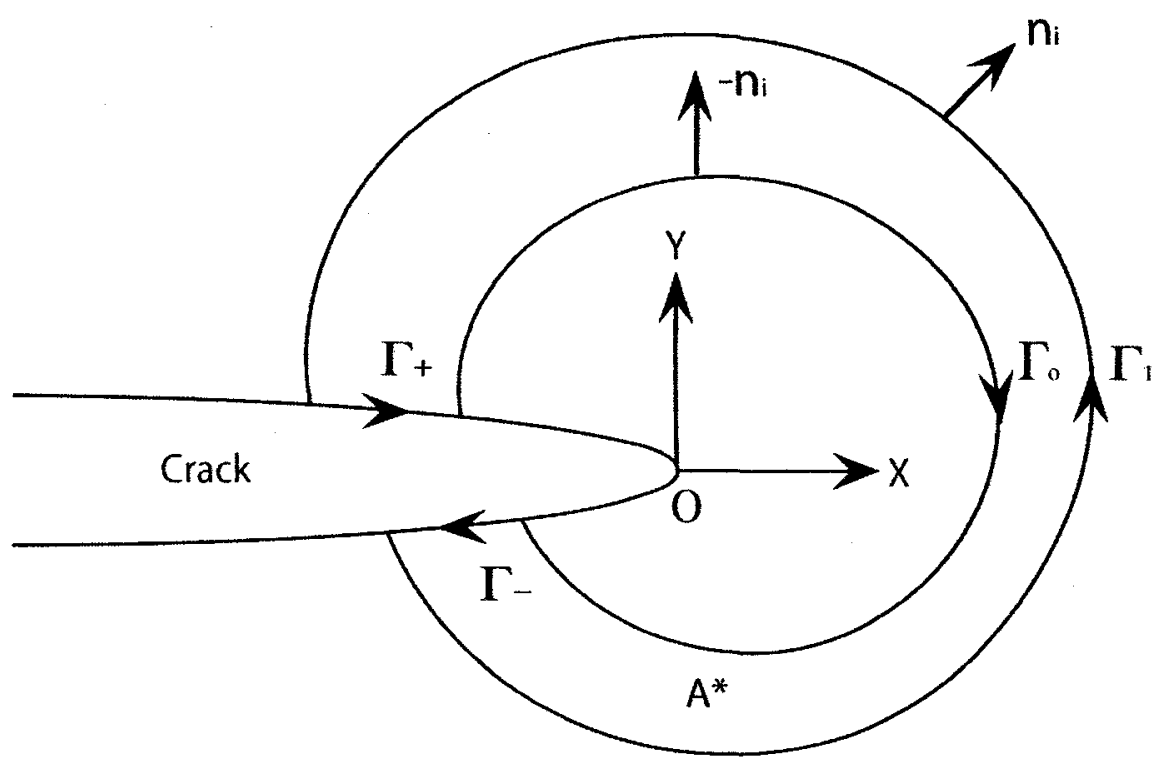

Figure 2.12: Closed Contour used for Two-Dimensional Domain Integral Method 


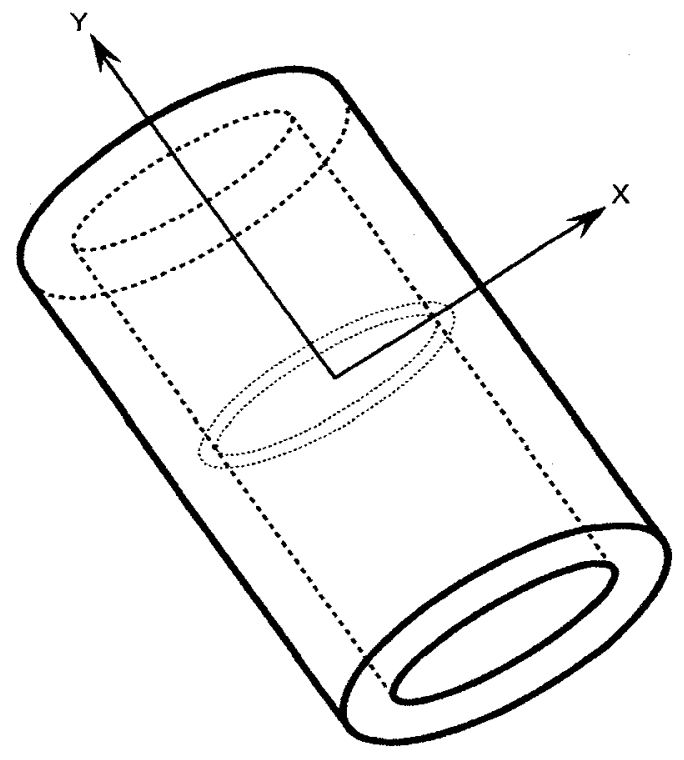

Figure 2.13: Three Dimensional View of Circumferentially Cracked Hollow Cylinder 


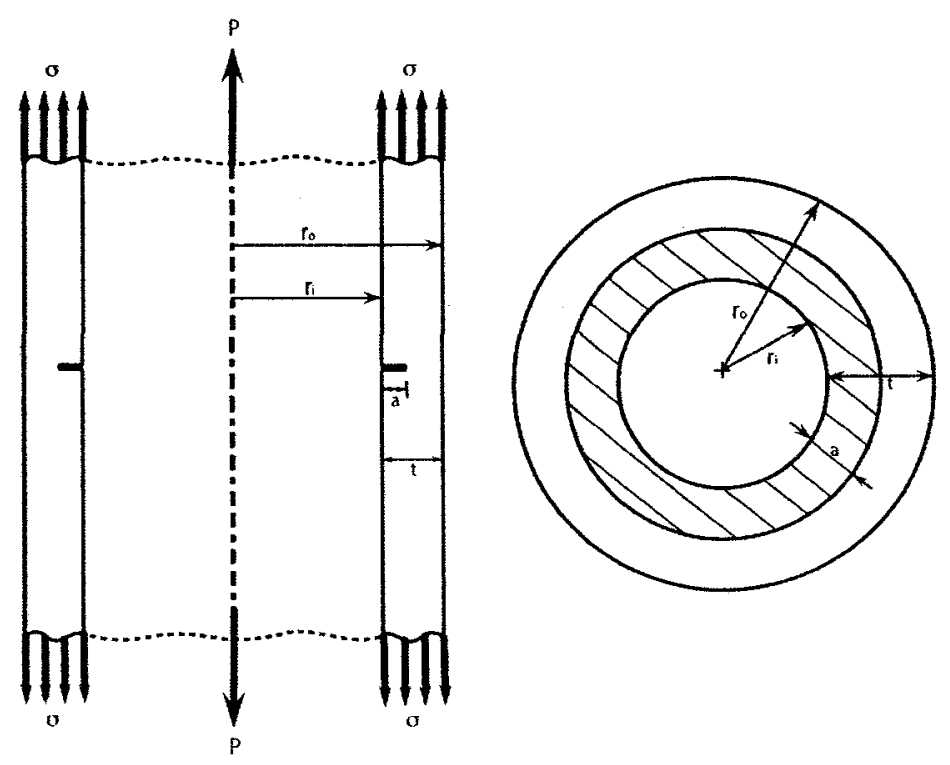

Figure 2.14: Cross-Sectional View of Cracked Geometry 


\section{Chapter 3}

\section{Solutions for Elastic T-stresses for Hollow Cylinders}

The purpose of Chapter 3 is to determine the elastic T-stresses for circumferential cracks in hollow cylinders under uniform tension. These crack geometries are common in engineering problems yet only limited T-stress solutions have been determined. Sherry et al. (1995) have determined the T-Stress solutions for very thin cylinders with circumferential cracks ranging from $r_{i} / r_{o}=0.85$ to 0.95 . This thesis will determine the elastic T-stress solutions for cracked hollow cylinders with $r_{i} / r_{o}=0.2,0.4,0.6$ and 0.8 . The domain integral method is used to numerically determine the $K$ and elastic T-stress (Shih et al. 1981).

\subsection{Finite Element Analysis}

\subsubsection{Cracked Geometry}

The cracked geometry that is being studied is a finite hollow cylinder with an internal circumferential crack as showing in Figure 3.1. Figure 3.2 shows the cross-section view of the crack geometry. The cylinder has an outer radius, $r_{o}$, an internal radius of $r_{i}$. The thickness of the cylinder is given as $t$. The circumferential crack is present on the internal surface of the cylinder and the crack length is given as $a$. The geometry has varying $r_{i} / r_{o}$ $=0.2,0.4,0.6,0.8$, and 0.9. Each $r_{i} / r_{o}$ ratio has varying $a / t=0.2,0.4,0.6$, and 0.8 . The length of the cylinder in the longitudinal direction is larger compared to the thickness of the cylinder so that the free boundary effects are negligible. Uniform tensile loading is applied to the ends of the cylinder. 


\subsubsection{FEM Model}

The modeling of the cracked geometry was carried out using a finite element software, ABAQUS 6.7.3. ABAQUS is an engineering simulation program that allows structures to be analyzed base on the finite element method. The program is able to model both linear and nonlinear structural problems (ABAQUS User Manual, 2004).

Since the geometry is an axisymmetric circumferential crack in a hollow cylinder, there are two planes of symmetry and so the problem is modeled in two-dimensions using axisymmetric elements as shown in Figure 3.3. Only one quarter of the cylinder is modeled because of simplification in the symmetry as seen in Figure 3.4. The entire model uses 8-node quadrilateral elements but at the tip of the crack, a sweeping fan shaped mesh was used as seen in Figure 3.5. The elements surrounding the crack tip were collapsed on one side to form a triangular shape. The nodes at the crack tip were constrained to move together. The midside nodes are moved to the $1 / 4$ point nearest the crack tip to help improve modeling of the stress singularity as seen in the close-up view of crack tip of Figure 3.6. The nodes on the horizontal plane of symmetry were restricted from displacement in the vertical direction.

\section{Mesh Refinement}

The size of the elements in the vicinity of the crack tip influences the accuracy of the solutions. The more refined the mesh is close to the crack tip, the better the stress and strains results will be and the better the contour integrations will be. The region around the crack tip is partitioned and a sweeping mesh with elements having a quad-dominated shape is used. The mesh was refined closer to the crack tip to ensure accurate results for the stress intensity factor shown in Figure 3.5. 


\section{Defining the Material Properties}

The material properties for the model is that of a linear elastic isotropic material with $E=$ $30,000 \mathrm{lbf} / \mathrm{in}^{2}(207 \mathrm{GPa})$, and $v=0.3$. The test model has a uniform tensile load, $\sigma$, applied to the ends of the cylinder.

\subsubsection{Verification of $\mathbf{K}$ from Established Results}

The stress intensity factor for many three-dimensional geometries including the hollow cylinder with circumferential cracks have been well established and summarized (Tada et al., 1985). The purpose of this section is to model a cracked hollow cylinder shown in Figure 3.2, and use FEM to calculate the stress intensity factors. The stress intensity factors will then be compared to the stress intensity factors of established results to verify the model being used is acceptable. Since the stress intensity factor is dependent on the geometry and loading, it is normalizes as

$$
K_{I}=F\left(\frac{r_{i}}{r_{o}}, \frac{a}{t}\right) \sigma \sqrt{\pi a}
$$

where $\sigma$ is the nominal stress given as

$$
\sigma=\frac{\mathrm{P}}{\pi\left(\mathrm{r}_{\mathrm{o}}^{2}-\mathrm{r}_{\mathrm{i}}^{2}\right)}
$$


$F$ is the normalized stress intensity factor called the boundary correction factor or the geometry correction factor for different crack geometries (Anderson, 1991). For verification purpose the geometry that will be studied is the hollow cylinder thickness of $r_{i} / r_{o}=0.2,0.4,0.6,0.8$, and 0.9 . The crack depth ratio is varied with $a / t=0.2,0.4,0.6$, and 0.8 for each geometry. The boundary correction factor is then determined. For the verification calculation of the stress intensity factors, the domain integral is used. Seven integrals were calculated starting at the crack tip. The stress intensity factor showed good contour independence and so the outer three contours were averaged and taken as the stress intensity factor.

\section{Results of $K_{I}$ Calculations}

The calculated boundary correction factors are presented in Tables 3.1, 3.2, 3.3, and 3.4. The boundary correction factors determined from established results of Tada et al. (1985) are compared with the calculated boundary correction factors shown in Figure 3.7. The calculated boundary correction factors show good agreement with the established results with maximum differences of less than $1 \%$ for $r_{i} / r_{o}<0.6$ and less than $2 \%$ for $r_{i} / r_{o}>0.6$. This indicated that the finite element models are acceptable for linear elastic crack analysis of determining stress intensity factors.

\subsubsection{Verification of Elastic T-stress Solutions}

To further verify the finite element procedure in determining the T-stress, calculations were performed on a geometry of a solid cylinder containing a penny-shaped crack as seen in Figure 3.8. The penny-shaped crack geometry is similar to the circumferential cracked cylinder in that they are both axisymmetric problems. The T-stress solution was verified for the crack length of $a / t=0.1$ and $v=0.3$. Established results of the T-stress 
solutions for penny-shaped crack were taken from Wang (2002). The penny-shaped crack was modeled using ABAQUS. The material properties was set to a linear elastic material with $E=30,000 \mathrm{lbf} / \mathrm{in}^{2}$, and $v=0.3$. A uniform tensile load was applied at the ends of the cylinder. Since the penny-shaped crack model is symmetric about the axis of rotation, only one quarter of the geometry was modeled. The nodes on the horizontal plane were constrained from moving in the vertical direction while the nodes along the vertical plane were constrained from moving in the horizontal direction.

The calculated normalized T-stress from the FEM model was -0.81 compared to the results from Wang (2002) of -0.80 . The difference is less than $0.1 \%$. Therefore, the finite element procedures are verified for both $K$ and T-stress calculations.

\subsection{Determination of Elastic T-Stress}

\subsubsection{FEM Model}

The FEM model is similar to the FEM model of the hollow cylinder used to determine the stress intensity factors. All boundary conditions, material properties and loading conditions are identical to that of the test model in section 3.1. Since there are two planes of symmetry only one-quarter of the plate is modeled. The nodes along the horizontal plane of symmetry are constrained from moving in the vertical direction. A uniform tensile load, $\sigma$, is applied to the end of the cylinder. The analysis was performed for four crack lengths of a/t $=0.2,0.4,0.6$, and 0.8 for each cylinder thickness ratios of $r_{i} / r_{o}=$ $0.2,0.4,0.6,0.8$, and 0.9 . The contour integral method was used to determine the Tstress. Excellent contour independence was obtained in these calculations. Seven contours were taken around the tip of the crack and the outer three contours were averaged and used as the T-stress value. 


\subsubsection{Results of Elastic T-stress Solutions}

Once the T-stress solutions were determined, it was normalized. The normalized T-stress is given as

$$
V=\frac{T}{\sigma}
$$

where $\sigma$ is the nominal tensile stress. The tabulated results of the T-stresses are found in Table 3.5. Results of the normalized T-stress solutions are shown in Figure 3.9. The Tstress results show consistent trends for all $r_{i} / r_{o}$ ratios and $a / t$ ratios. The T-stresses calculated were all negative. The negative $\mathrm{T}$-stresses indicate a crack geometry under low constrained condition. The trend for all test cases was that the magnitude of the Tstresses increased as the thickness of the crack increased. The magnitude of the T-stress was generally larger for thicker cylinders except for thin cylinders with large cracks in which the magnitude were larger than those of the thick cylinders.

\subsubsection{Determination of S-stress}

The S-stresses $\left(T_{33}\right)$ were determined from the relationship between the calculated elastic T-stress and the S-stress and given by

$$
T_{33}(s)=E \varepsilon_{33}(s)+v T_{11}(s)
$$


where $T_{33}$ is the S-stress, $E$ is Young's modulus, $\varepsilon_{33}$ is the strain in the 33-direction, $v$ is the Poisson's ratio and $T_{11}$ is the elastic T-stress.

The S-stress value was calculated for each $r_{i} / r_{o}$ ratio and $a / t$ ratio. ABAQUS generated the $\varepsilon_{33}$ for the crack tip in the output data file. Substituting $\varepsilon_{33}$ and T-stress results into Eq. (49), the S-stress was then calculated. The values of the S-stresses are tabulated in Table 3.6. Figure 3.10 shows the plotted values of the S-stress solutions. The trends of the S-stresses are similar to those of the T-stresses. All S-stress values were negative.

\subsection{Summary}

The purpose of this chapter was to determine the elastic T-stresses for the circumferentially cracked cylinders. The finite element procedures were verified by calculating the stress intensity factor and T-stress and comparing them with established results. The T-stress solutions were calculated using FEM and presented in Tables and Figures. 


\begin{tabular}{|c|c|c|c|}
\hline \multicolumn{4}{|c|}{ Boundary Correction Factor, $F$ for $r_{i} / r_{0}=0.2$} \\
\hline$a / t$ & $F$, Present & $F$, Tada (1985) & $\begin{array}{c}\text { Difference } \\
(\%)\end{array}$ \\
\hline 0.2 & 0.871 & 0.861 & 1.16 \\
\hline 0.4 & 0.859 & 0.846 & 1.54 \\
\hline 0.6 & 0.938 & 0.920 & 1.96 \\
\hline 0.8 & 1.201 & 1.178 & 1.92 \\
\hline
\end{tabular}

Table 3.1: Verification of boundary correction factor for cracked cylinder, $r_{i} / r_{o}=0.2$

\begin{tabular}{|c|c|c|c|}
\hline \multicolumn{4}{|c|}{ Boundary Correction Factor, $F$ for $r_{i} / r_{o}=0.4$} \\
\hline$a^{\prime} t$ & $F$, Present & $F$, Tada (1985) & $\begin{array}{c}\text { Difference } \\
(\%)\end{array}$ \\
\hline 0.2 & 1.008 & 0.989 & 1.84 \\
\hline 0.4 & 1.022 & 1.007 & 1.47 \\
\hline 0.6 & 1.128 & 1.107 & 1.88 \\
\hline 0.8 & 1.443 & 1.420 & 1.62 \\
\hline
\end{tabular}

Table 3.2: Verification of boundary correction factor for cracked cylinder, $r_{i} / r_{o}=0.4$ 


\begin{tabular}{|c|c|c|c|}
\hline \multicolumn{4}{|c|}{ Boundary Correction Factor, $F r_{i} / r_{0}=0.6$} \\
\hline a/t & $F$, Present & $F$, Tada $(1973)$ & $\begin{array}{c}\text { Difference } \\
(\%)\end{array}$ \\
\hline 0.2 & 1.104 & 1.101 & 0.20 \\
\hline 0.4 & 1.180 & 1.175 & 0.45 \\
\hline 0.6 & 1.341 & 1.328 & 1.00 \\
\hline 0.8 & 1.723 & 1.722 & 0.05 \\
\hline
\end{tabular}

Table 3.3: Verification of boundary correction factor for cracked cylinder, $r_{i} / r_{o}=0.6$

\begin{tabular}{|c|c|c|c|}
\hline \multicolumn{4}{|c|}{ Boundary Correction Factor, $F$ for $r_{i} / r_{o}=0.8$} \\
\hline \multirow{2}{*}{$a / t$} & $F$, Present & $F$, Tada $(1973)$ & $\begin{array}{c}\text { Difference } \\
(\%)\end{array}$ \\
\hline 0.2 & 1.196 & 1.194 & 0.13 \\
\hline 0.4 & 1.392 & 1.381 & 0.81 \\
\hline 0.6 & 1.681 & 1.676 & 0.28 \\
\hline 0.8 & 2.162 & 2.158 & 0.22 \\
\hline
\end{tabular}

Table 3.4: Verification of boundary correction factor for cracked cylinder, $r_{i} / r_{o}=0.8$ 


\begin{tabular}{|c|c|c|c|c|c|}
\hline \multicolumn{2}{|c|}{ Normalized T-stress, $V$} \\
\hline$a / t$ & $r_{i} / r_{o}=0.9$ & $r_{i} / r_{o}=0.8$ & $r_{i} / r_{o}=0.6$ & $r_{i} / r_{o}=0.4$ & $r_{i} / r_{o}=0.2$ \\
\hline 0.2 & -0.56 & -0.57 & -0.57 & -0.60 & -0.69 \\
\hline 0.4 & -0.63 & -0.65 & -0.69 & -0.74 & -0.84 \\
\hline 0.6 & -0.87 & -0.92 & -0.98 & -1.01 & -1.04 \\
\hline 0.8 & -1.90 & -1.91 & -1.94 & -1.84 & -1.69 \\
\hline
\end{tabular}

Table 3.5: Normalized T-stress solution for cracked cylinder under tension

\begin{tabular}{|c|c|c|c|c|c|}
\hline \multirow{2}{*}{} & & & & & \\
\hline$a / t$ & $r_{i} / r_{o}=0.9$ & $r_{i} / r_{o}=0.8$ & $r_{i} / r_{o}=0.6$ & $r_{i} / r_{o}=0.4$ & $r_{i} / r_{o}=0.2$ \\
\hline 0.2 & -0.54 & -0.58 & -0.65 & -0.73 & -0.81 \\
\hline 0.4 & -0.72 & -0.79 & -0.88 & -0.92 & -0.92 \\
\hline 0.6 & -1.08 & -1.16 & -1.20 & -1.15 & -1.09 \\
\hline 0.8 & -1.82 & -1.87 & -1.83 & -1.71 & -1.54 \\
\hline
\end{tabular}

Table 3.6: Normalized S-stress solution for cracked cylinder under tension 


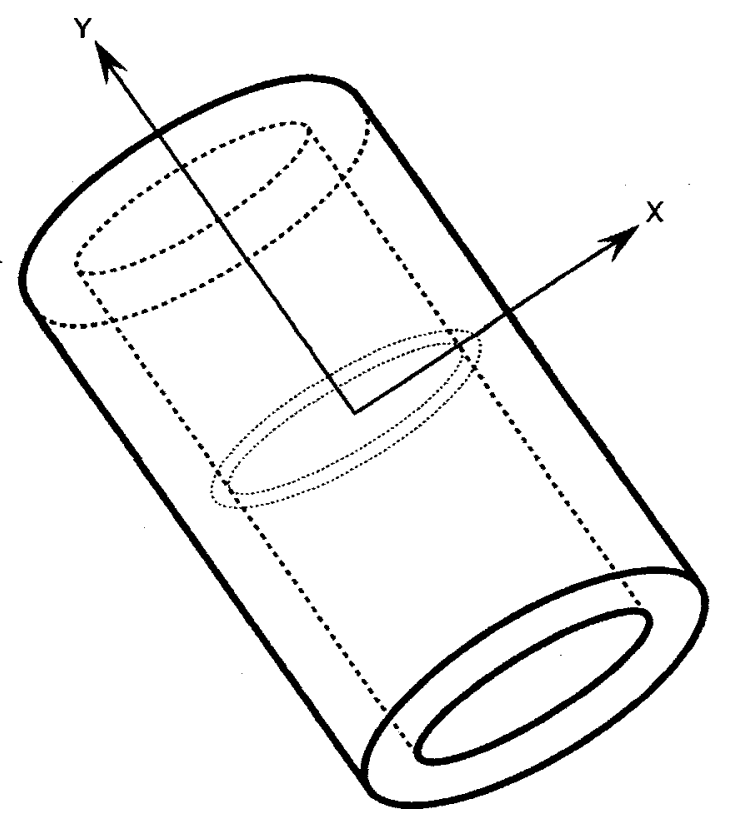

Figure 3.1: Three Dimensional View of Circumferentially Cracked Hollow Cylinder 


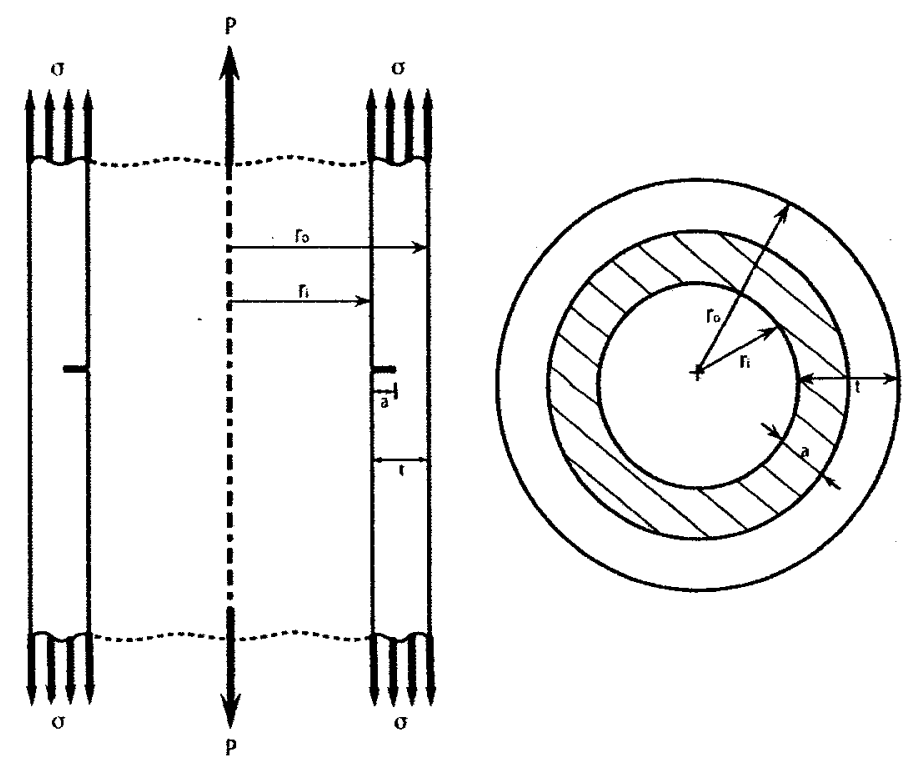

Figure 3.2: Cross-Sectional View of Cracked Geometry 


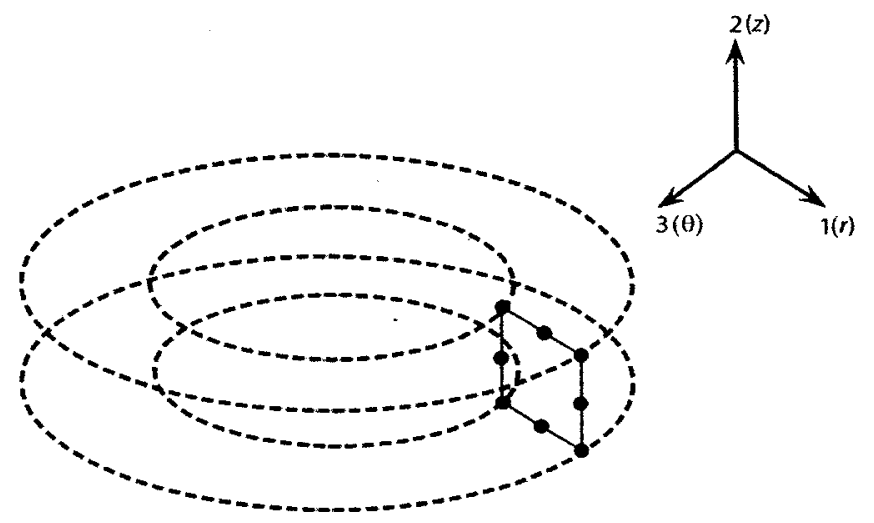

Figure 3.3: Axisymmetric Element CAX8 


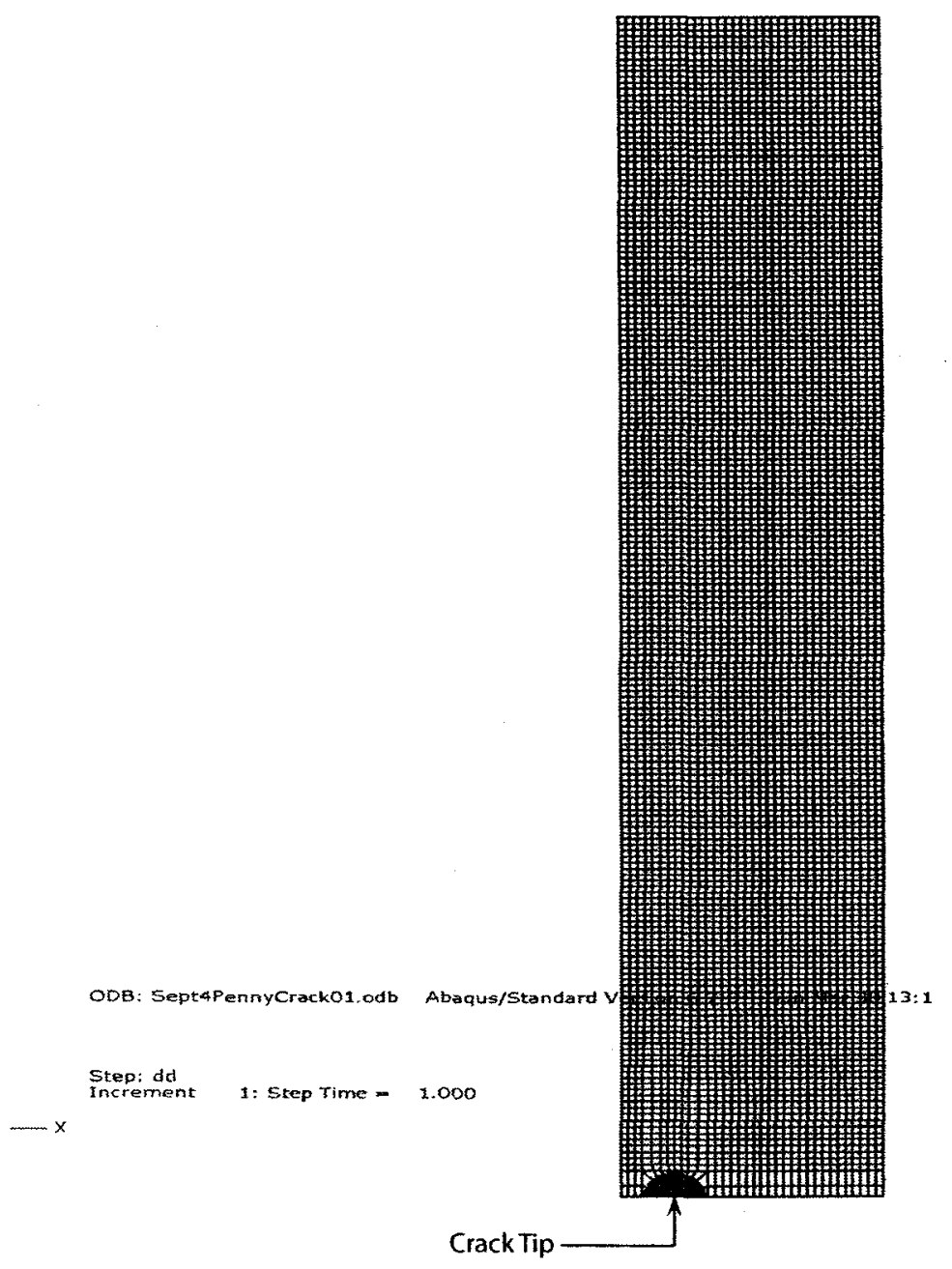

Figure 3.4: ABAQUS FEM Model of Cracked Cylinder Under Tension 


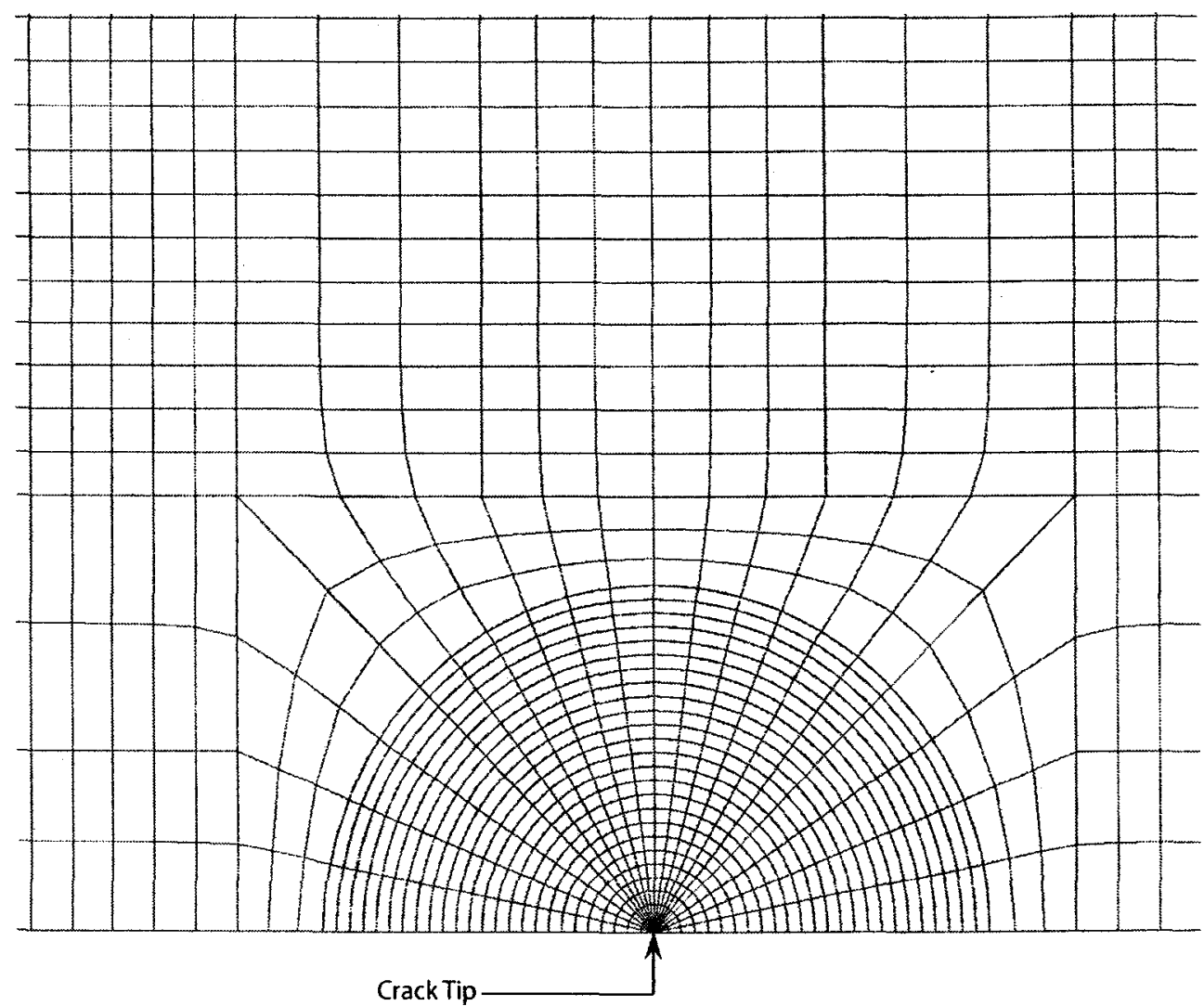

Figure 3.5: Close-Up View of FEM Model of Crack Tip 


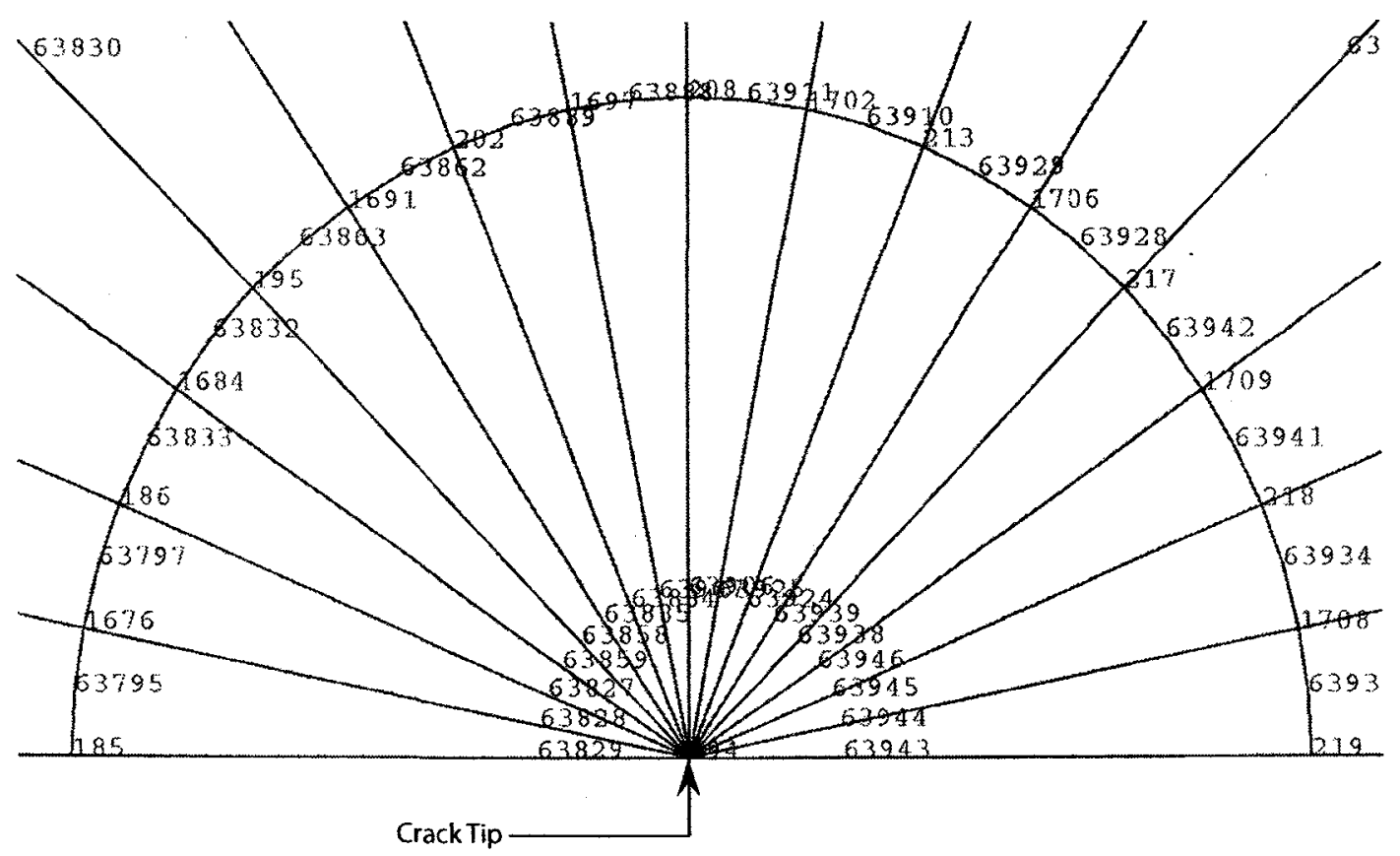

Figure 3.6: Nodal Position of Collapsed Quadrilateral at Vicinity of Crack Tip 


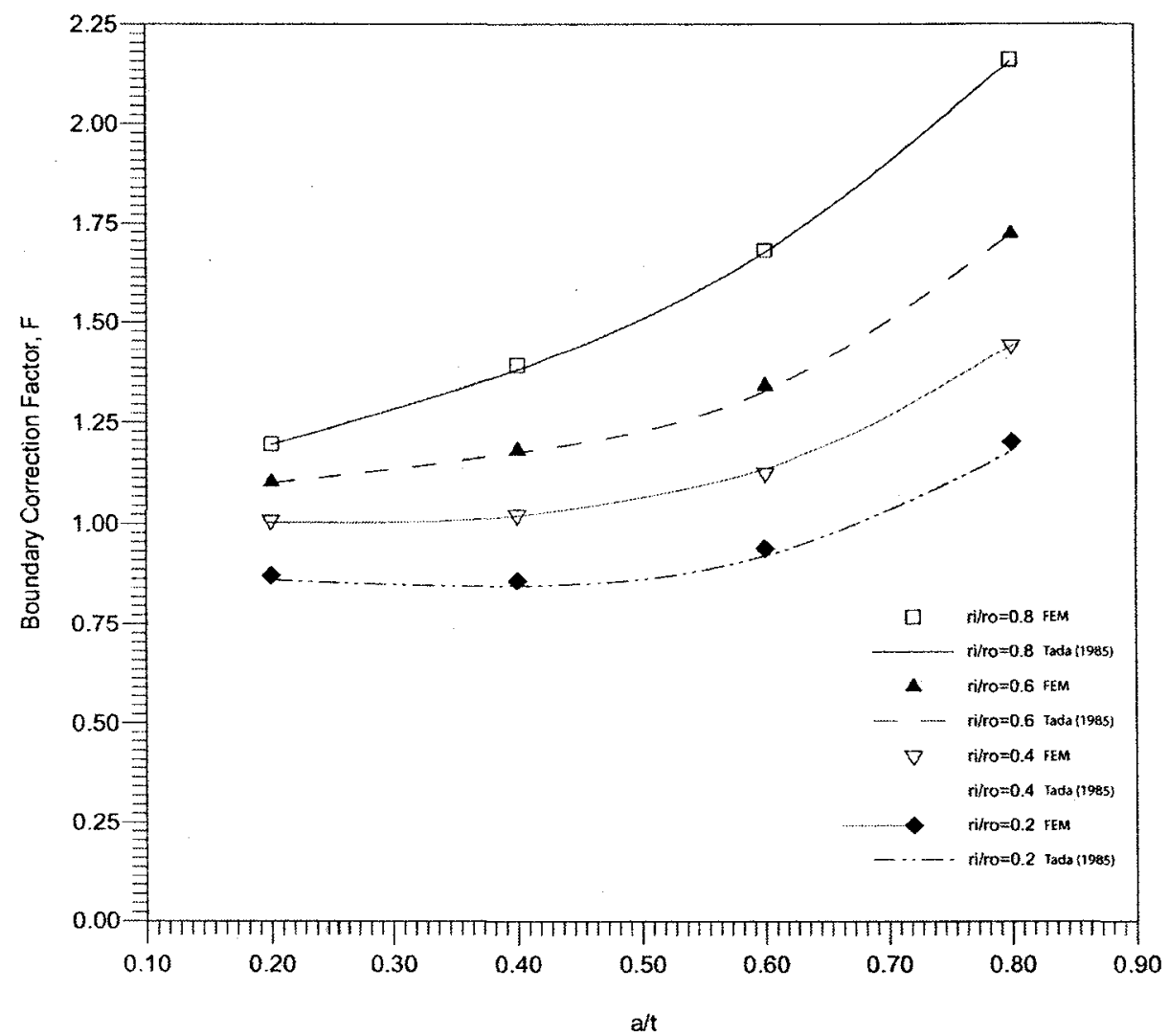

Figure 3.7: Verification of Boundary Correction Factor for Cracked Cylinder From Established Results (Tada, 1985) 


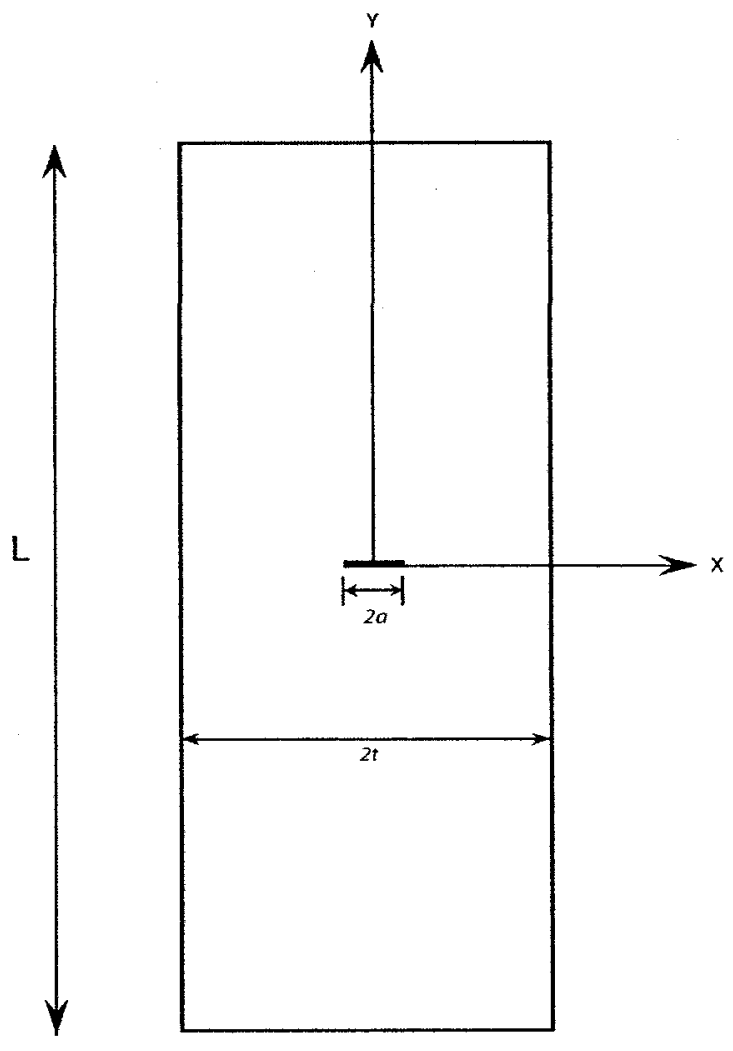

Figure 3.8: Geometry of Penny-Shaped Crack 


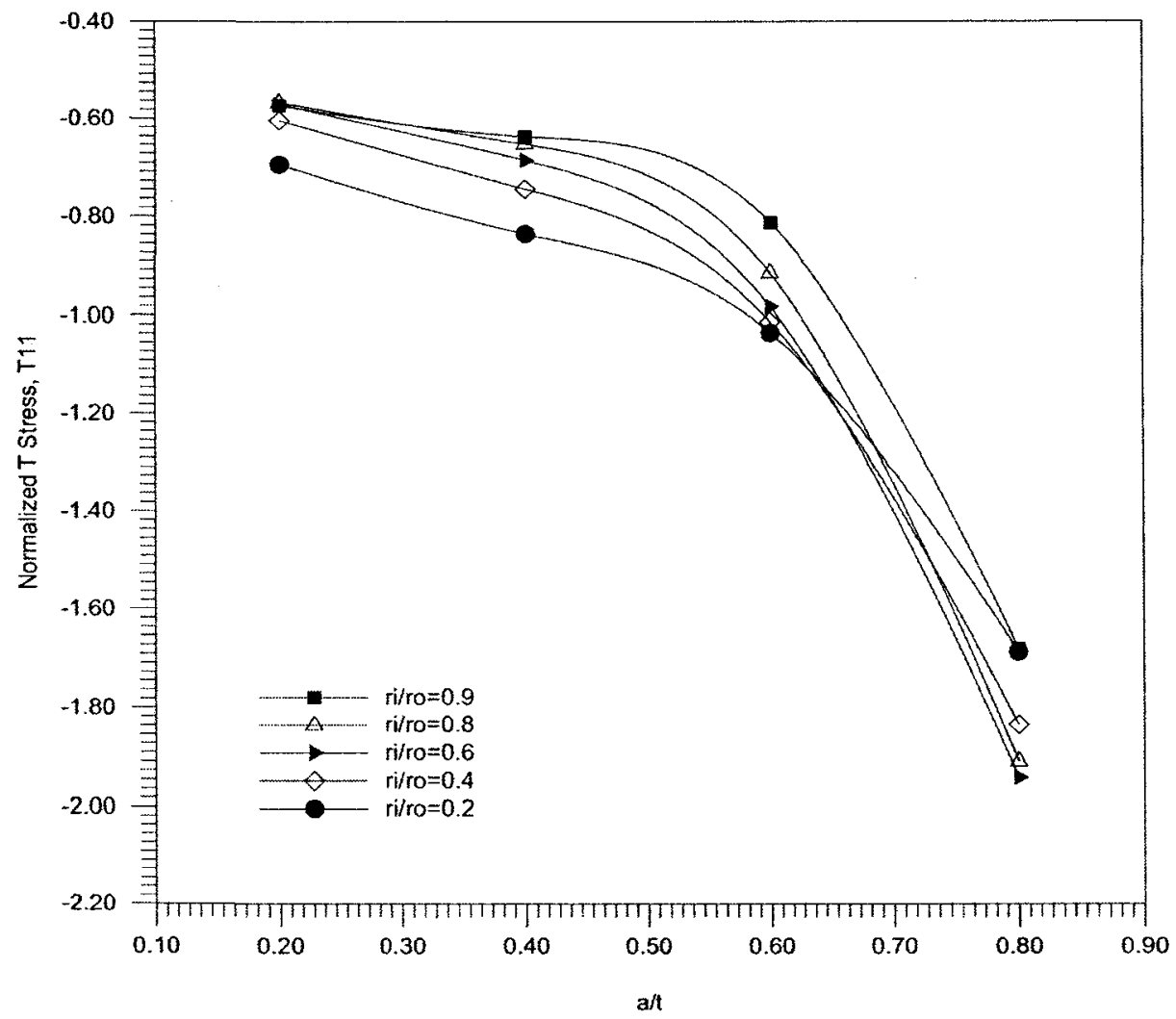

Figure 3.9: Normalized T-stress Solutions for Crack Cylinder Under Uniform Tension 


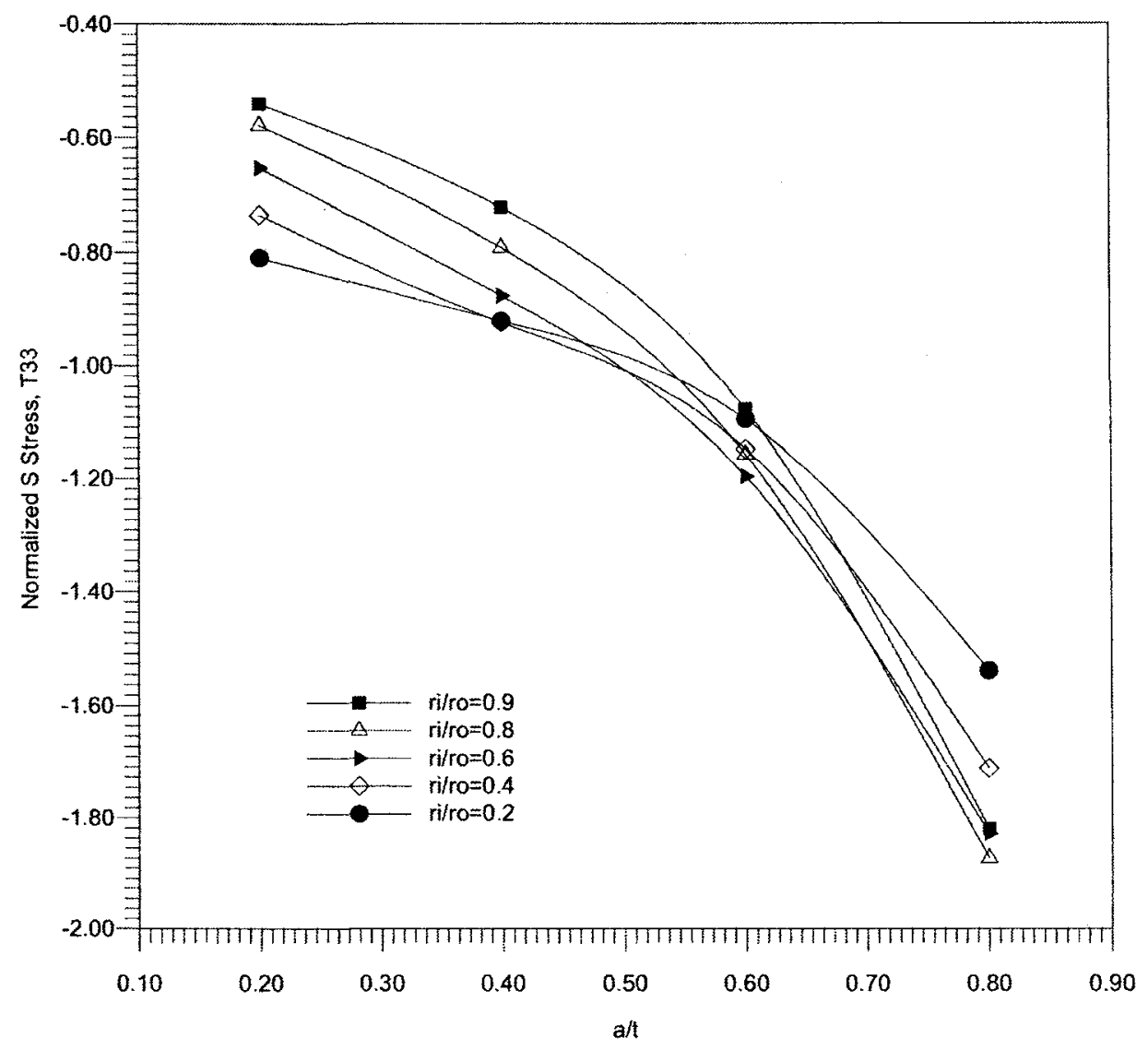

Figure 3.10: S-stress Solutions for Cracked Cylinder Under Uniform Tension 


\section{Chapter 4}

\section{Solution of Fully Plastic J-Integral for Hollow Cylinder}

The purpose of chapter 4 is to determine the fully plastic J-integral for cracked hollow cylinders under tension. The material properties of the cylinder studied follows that of a Ramberg-Osgood power law hardening coefficient of $n=3,5$, and 10 . The fully plastic geometry factor, $h_{l}$ extracted from the fully plastic J-integral solutions, can be used as a parameter in failure assessment. Limited solutions have been established for fully plastic J-integral for circumferential cracked hollow cylinders with $r_{i} / r_{o}=0.83,0.9$ and 0.95 (Anderson, 1991). This chapter will determine the solutions of fully plastic J-integral for thicker cylinders of $r_{i} / r_{o}=0.2,0.4,0.6$ and 0.8 .

\subsection{Finite Element Analysis}

\subsubsection{Cracked Geometry}

In this chapter extensive FEM analyses are conducted to determine the fully plastic $\mathrm{J}$ integral. The geometry studied is that of a cracked hollow cylinder shown in Figure 4.1 with varying $r_{i} / r_{o}=0.2,0.4,0.6$, and 0.8 and $a / t=0.2,0.4,0.6$, and 0.8 . Uniaxial tensile load is applied to the ends of the cylinder. 


\subsubsection{FEM Model}

The cracked cylinder is modeled using the FEM software, ABAQUS 6.7.3 (ABAQUS User Manual, 2004). The model is simplified to a quarter of the cracked cylinder. The element used is a CAX8R, which is an axisymmetric 8-node quadrilateral with reduced integration. The domain integral method was used to solve the J-integral of the FEM model and reduced integration was used on the Gaussian points in the quadratic element as seen in Figure 4.2. Reduced integration helps reduce numerical difficulties that can occur when the incompressible conditions of fully plastic deformation which places volumetric constraints on the elements (Dodds, 1991). At the tip of crack, the quadrilateral elements were collapsed on one side but not constrained to move together to produce the $1 / r$ singularity at the crack tip as seen in Figure 4.3. Good contour independences of the J-integrals are obtained. A total of seven contours were taken in the analysis and the results of the outer three contours were averaged and used. An FEM model of the cracked cylinder is shown in Figure 4.4.

\section{Load Application}

In nonlinear analysis, the solution is determined by applying the loads gradually and in increments to reach a final solution. ABAQUS asks that the initial load, increment and maximum load be inputted. ABAQUS then divides the simulation into a number of load increments and finds the approximate equilibrium configuration at the end of each load increment. Each iteration brings the analysis closer to the equilibrium solution. The settings in ABAQUS were set so that the iteration stopped as soon as the entire model reached equilibrium. For the analyses presented in this thesis, external loads were increased gradually until the plastic zone covered the entire model, which corresponds to fully plastic conditions. 


\section{Material Properties}

For all FEM calculations of the cracked cylinders, the material properties were set to $\alpha=$ 1, $E=207 \mathrm{GPa}, \sigma_{o}=200 \mathrm{MPa}$, and $v=0.3$. The material used follows the RambergOsgood model as given in Eq. (2.15) of chapter 2. Three $n$ values were used in the calculations as follows, $n=3,5$, and 10 . The range of $n$ values represents both low and high strain hardening materials. A stress strain graph for the three $n$ values is shown in Figure 4.5 and given by

$$
\frac{\varepsilon}{\varepsilon_{o}}=\frac{\sigma}{\sigma_{o}}+\alpha\left(\frac{\sigma}{\sigma_{o}}\right)^{n}
$$

Extracting the Fully Plastic J-integral from FEM

The J-integral calculated in the FEM software is the total J-integral at a particular load increment. The total J-integral is the sum of two components: the elastic and plastic Jintegral,

$$
J=J_{e l}+J_{p l}
$$

To obtain the plastic component of the J-integral, the elastic component was first calculated from a linear elastic model assuming $n=1$. The elastic component of Jintegral is subtracted from the total J-integral solution to obtain the plastic J-integral. It was noticed through extensive verification that when the material became fully plastic, the elastic component of the J-integral was very small. The extracted plastic J-integral 
made up 95 percent of the total $\mathrm{J}$-integral and so the total $\mathrm{J}$-integral was taken as an approximate value of the fully plastic J-integral. Once the fully plastic J-integral was determined for all the geometries, the fully plastic $h_{I}$ factor was determined from equation

$$
J_{p l}=\alpha \sigma_{o} \varepsilon_{o} c h_{1}\left(\frac{P}{P_{o}}\right)^{n+1}
$$

Where $\alpha$ is the dimensionless constant of the Ramberg-Osgood equation, $\sigma_{o}$ is the yield stress, $\varepsilon_{o}$ is the yield strain, and $n$ is the Ramberg-Osgood constant. The term $c$ is the remaining uncracked segment, $P$ is the load and $P_{o}$ is the load at collapse. For the present crack geometry, the load at collapse was summarized by Anderson (1991) and given as

$$
P_{o}=\frac{2}{\sqrt{3}} \pi\left(r_{o}^{2}-\left(r_{i}+a\right)^{2}\right) \sigma_{o}
$$

It is important to note that once $J_{p l}$ is normalized, it is independent of the material constants of $\alpha, E$, and $\sigma_{o}$, and is only dependent on geometry and the strain-hardening coefficient, $n$. 


\subsubsection{Verification of Fully Plastic J-Integral for Cracked Cylinders}

Two verifications were performed to determine the validity of the fully plastic J-integral calculations produced from the FEM model before continuing with the FEM model of the cylindrical crack geometry.

\section{Verification using a Penny-shaped Cracked Solution}

A penny-shaped crack in an infinite body under uniaxial loading is calculated to verify the finite element model for determination of the fully plastic J-integral of the 3D crack problem. This penny-shaped crack problem was analyzed extensively by $\mathrm{He}$ and Hutchinson (1981). The normalized fully plastic J-integral solutions are given as follows

$$
J_{p l}=h_{1} \alpha \sigma_{o} \varepsilon_{o} a\left(\frac{\sigma_{\infty}}{\sigma_{o}}\right)^{n+1}
$$

where $a$ is the radius of the crack, and $\sigma_{\infty}$ is the remote tensile stress. Table 4.1 presents the results form the FEM model for $n=3,5$, and 10 . The calculated results are very close to established results of $\mathrm{He}$ and Hutchinson (1981) with a maximum of $3.97 \%$ difference. 


\section{Verification using Circumference Crack Cylinder Solution for $r_{i} / r_{o}=0.83$}

Limited data have been produced for the fully plastic J-integral for very thin circumferentially cracked cylinders. Anderson (1991) summarized results for cylinders with $r_{i} / r_{o}=0.83,0.9$, and 0.95 . The purpose of this section is to determine the fully plastic J-integral for the geometry $r_{i} / r_{o}=0.83$. The calculated FEM solutions will be used to determine the $h_{l}$ factor, which will then be compared to the established $h_{l}$ factor. For verification purpose the models the $a / t$ is set to 0.5 and $n=3,5$, and 10 .

Table 4.2 presents the $h_{l}$ calculated in FEM as well as the $h_{l}$ from established results. Figure 4.6 shows the plotted values of the $h_{l}$ factor calculated and the $h_{l}$ factor from established results summarized by Anderson (1991). The results in Figure 4.6 show excellent agreement with one another. There is a maximum difference of $7.63 \%$ between the calculated $h_{1}$ factor and the $h_{1}$ factor from established results. Through these verifications, the present finite element procedures are considered acceptable for the calculations of fully plastic J-integral for the circumferential crack in hollow cylinders.

\subsection{Determination of Fully Plastic J-Integral Solution}

Results of Fully Plastic J-integral Solutions for Cracked Cylinders

Once the fully plastic J-integrals were determined for each set of crack cylinder geometry, the $h_{l}$ factor was calculated using the following normalization 


$$
J_{p l}=\alpha \sigma_{o} \varepsilon_{o} c h_{1}\left(\frac{P}{P_{o}}\right)^{n+1}
$$

Tables 4.3, 4.4, 4.5, and 4.6 summarize the data of the calculated $h_{l}$ factor for the cracked cylinder of $r_{i} / r_{o}=0.2,0.4,0.6$, and 0.8 respectively. Figures $4.7,4.8,4.9$, and 4.10 shows the plots of four sets of data for $r_{i} / r_{o}=0.2,0.4,0.6$, and 0.8 . Each set of data contains three graphs corresponding to the three strain hardening coefficients, $n=3,5$, and 10 .

\subsubsection{Discussion of Results}

From Figures 4.7, 4.8, 4.9, and 4.10, the trend can be seen that the $h_{1}$ factor increases as the size of the crack decreases for all thickness of cracked cylinders. It is important to note that in general, the $h_{l}$ factor increases with the increase in strain hardening coefficient. However, for thinner cracked cylinders such as $r_{i} / r_{o}=0.6$ and 0.8 , the $h_{1}$ factor decreased with increase in strain hardening coefficient, $n$.

\subsection{Application of the EPRI J-integral Estimation Scheme}

The EPRI J-integral estimation scheme states that the total J-integral solution for any cracked geometry can be determined by the summation of the two components of the elastic and plastic components as described in section 2.3.1 and given as

$$
J=J_{e l}+J_{p l}
$$


Equipped with the $h_{I}$ factor, one can determine the J-integral for a cracked geometry at any given load. The elastic portion of J-integral can be determined through the relationship of J-integral and stress intensity factor as giving in

$$
J_{e l}=\frac{K^{2}}{E}
$$

The plastic J-integral is determined by inserting the $h_{I}$ factor into Eq. (2.21). Once the two components are determined, the total J-integral can be calculated for any particular load. This estimation procedure is applied for the crack geometry of $r_{i} / r_{o}=0.8, a / t=0.2$ and $n=3,5$, and 10. Figures 4.11, 4.12, and 4.13 shows the load vs. J-integral plot for the two methods of determining the total J-integral. The plots of the J-integral calculated using FEM and the J-integral calculated using the EPRI estimation scheme are almost identical with a maximum difference of $2.6 \%$, proving that the EPRI estimation scheme is a good approximation method to determine the J-integral at any given load level using the $h_{l}$ factor and the stress intensity factor.

\subsection{Summary}

The elastic plastic analysis of the cracked cylinder under tensile loading was performed in chapter 4 . The fully plastic J-integral was calculated for the tensile loading condition. Two verifications were made for similar geometries. The corresponding $h_{l}$ factor was determined from the fully plastic J-integral. Application of the EPRI estimation scheme was demonstrated by calculating the elastic and plastic components of the J-integral for increment load levels and comparing the total J-integral to that of the total J-integral calculated using FEM. 


\begin{tabular}{|c|c|c|c|}
\hline \multicolumn{4}{|c|}{ Fully Plastic Factor, $h_{l}$} \\
\hline $\begin{array}{c}\text { Strain Hardening } \\
\text { Coefficient }\end{array}$ & $h_{1}$ & $\begin{array}{c}\text { He and } \\
\text { Hutchinson } \\
(1981)\end{array}$ & Difference \\
$(n)$ & Present & $\%)$ \\
\hline 3 & 1.40 & 1.35 & 3.7 \\
\hline 5 & 1.57 & 1.51 & 3.97 \\
\hline 10 & 1.75 & 1.71 & 2.34 \\
\hline
\end{tabular}

Table 4.1: Verification of fully plastic $h_{1}$ factor for penny-shaped crack

\begin{tabular}{|c|c|c|c|}
\hline \multicolumn{4}{|c|}{ Fully Plastic Factor, $h_{l}$. } \\
\hline $\begin{array}{c}\text { Strain Hardening } \\
\text { Coefficient } \\
\text { (n) }\end{array}$ & $\begin{array}{c}\quad h_{I} \\
\text { Present }\end{array}$ & $\begin{array}{c}h_{l} \\
\text { Anderson } \\
\text { (1991) }\end{array}$ & $\begin{array}{c}\text { Difference } \\
\qquad \%)\end{array}$ \\
\hline 3 & 4.94 & 4.59 & 7.63 \\
\hline 5 & 3.98 & 3.79 & 5.01 \\
\hline 10 & 2.34 & 2.28 & 2.63 \\
\hline
\end{tabular}

Table 4.2: Verification of fully plastic $h_{l}$ factor for cracked cylinder $r_{i} / r_{o}=0.83, a / t=0.5$ 


\begin{tabular}{|c|c|c|c|c|}
\hline \multicolumn{5}{|c|}{ Normalized Fully Plastic Factor, $h_{1}$ : Finite Element Method, Cracked } \\
Cylinder, $r_{i} / r_{o}=0.2$ \\
$\begin{array}{c}\text { Stain } \\
\text { Hardening } \\
\text { Coefficient } \\
(n)\end{array}$
\end{tabular}

Table 4.3: Results for normalized fully plastic factor, $h_{l}$ for cracked cylinder $r_{i} / r_{o}=0.2$

\begin{tabular}{|c|c|c|c|c|}
\hline \multicolumn{3}{|c|}{ Normalized Fully Plastic Factor, $h_{1}$ : Finite Element Method, Cracked } \\
Cylinder, $r_{i} / r_{0}=0.4$ \\
\hline $\begin{array}{c}\text { Stain } \\
\text { Hardening } \\
\text { Coefficient } \\
(n)\end{array}$
\end{tabular}

Table 4.4: Results for normalized fully plastic factor, $h_{l}$ for cracked cylinder $r_{i} / r_{o}=0.4$ 


\begin{tabular}{|c|c|c|c|c|}
\hline \multicolumn{5}{|c|}{ Normalized Fully Plastic Factor, $h_{1}$. Finite Element Method, Cracked } \\
Cylinder, $r_{i} / r_{o}=0.6$ & & \\
\hline $\begin{array}{c}\text { Stain } \\
\text { Hardening } \\
\text { Coefficient } \\
(n)\end{array}$ & $a / t=0.2$ & $a / t=0.4$ & $a / t=0.6$ & $a / t=0.8$ \\
\hline 3 & 1.38 & 1.09 & 0.73 & 0.44 \\
\hline 5 & 1.69 & 1.12 & 0.61 & 0.35 \\
\hline 10 & 2.40 & 1.07 & 0.40 & 0.31 \\
\hline
\end{tabular}

Table 4.5: Results for normalized fully plastic factor, $h_{I}$ for cracked cylinder $r_{i} / r_{o}=0.6$

\begin{tabular}{|c|c|c|c|c|}
\hline \multicolumn{5}{|c|}{ Normalized Fully Plastic Factor, $h_{l}$ : Finite Element Method, Cracked } \\
Cylinder, $r_{i} / r_{0}=0.8$ \\
\hline $\begin{array}{c}\text { Stain } \\
\text { Hardening } \\
\text { Coefficient } \\
(n)\end{array}$
\end{tabular}

Table 4.6: Results for normalized fully plastic factor, $h_{l}$ for cracked cylinder $r_{i} / r_{o}=0.8$ 


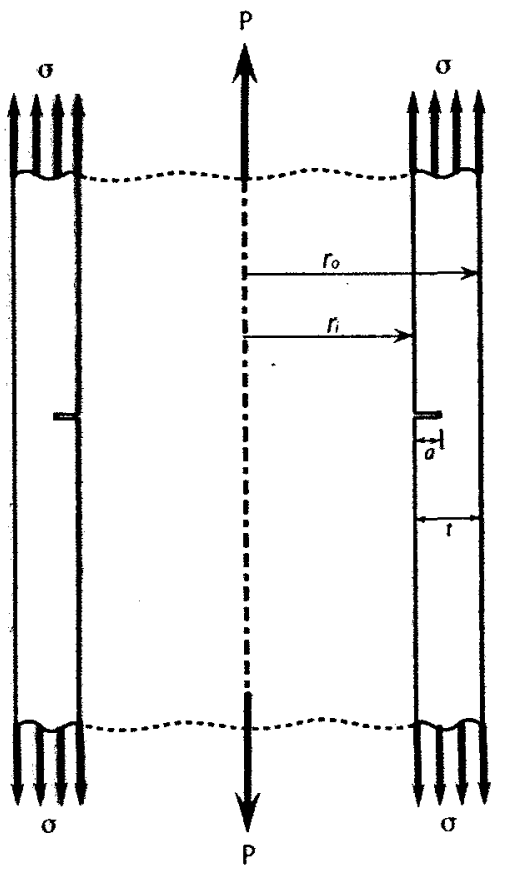

Figure 4.1: Cross-Sectional View of Cracked Geometry 


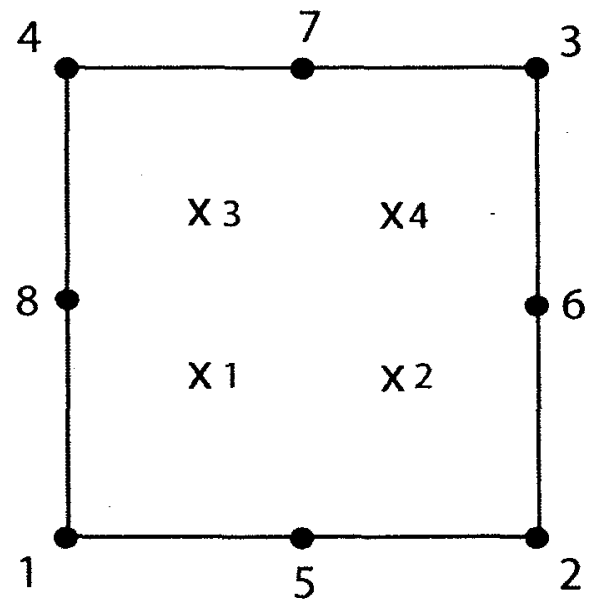

Figure 4.2: Location of Gauss Points in Quadrilateral Element With Reduced Integration 

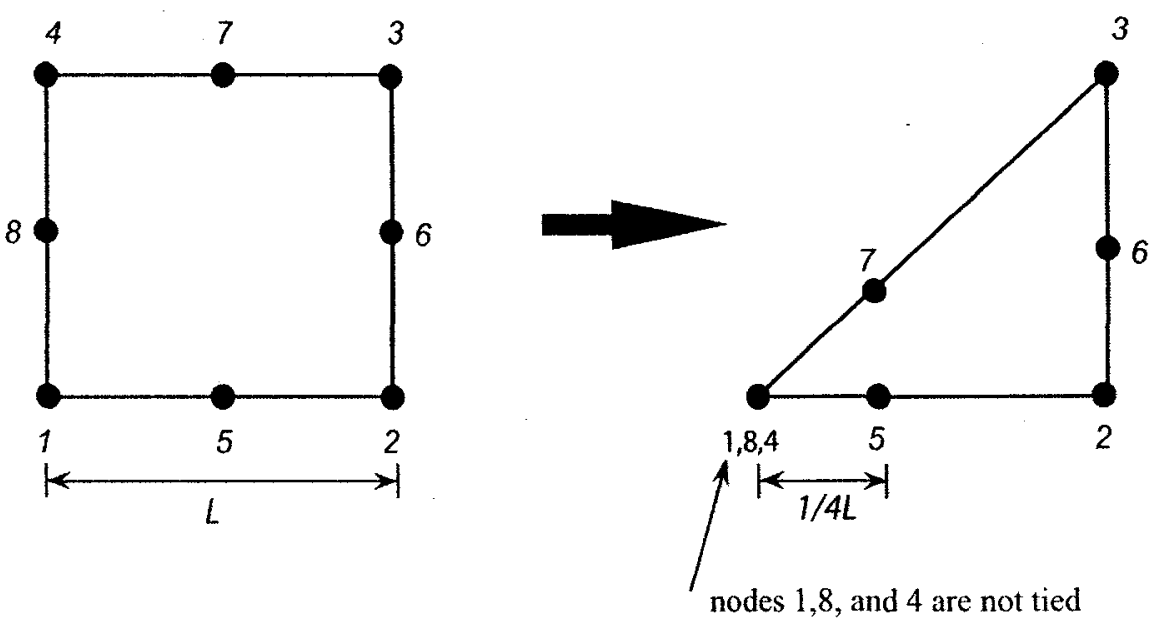

Figure 4.3: Collapse of 8-node Element at One Side to Model Stress Tip Singularity 


\section{DSImULA}
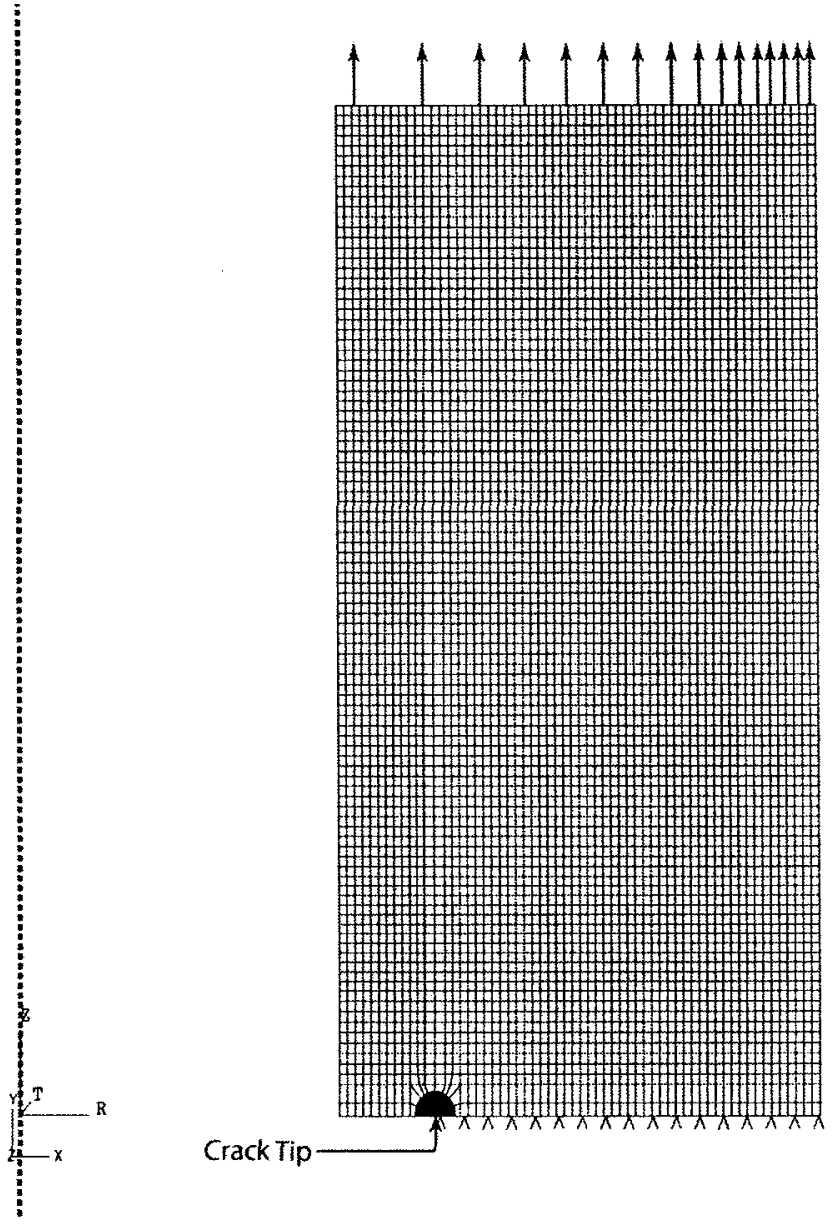

Figure 4.4: Quarter FEM Model of Elastic Plastic Cracked Cylinder Under Tensile Load 


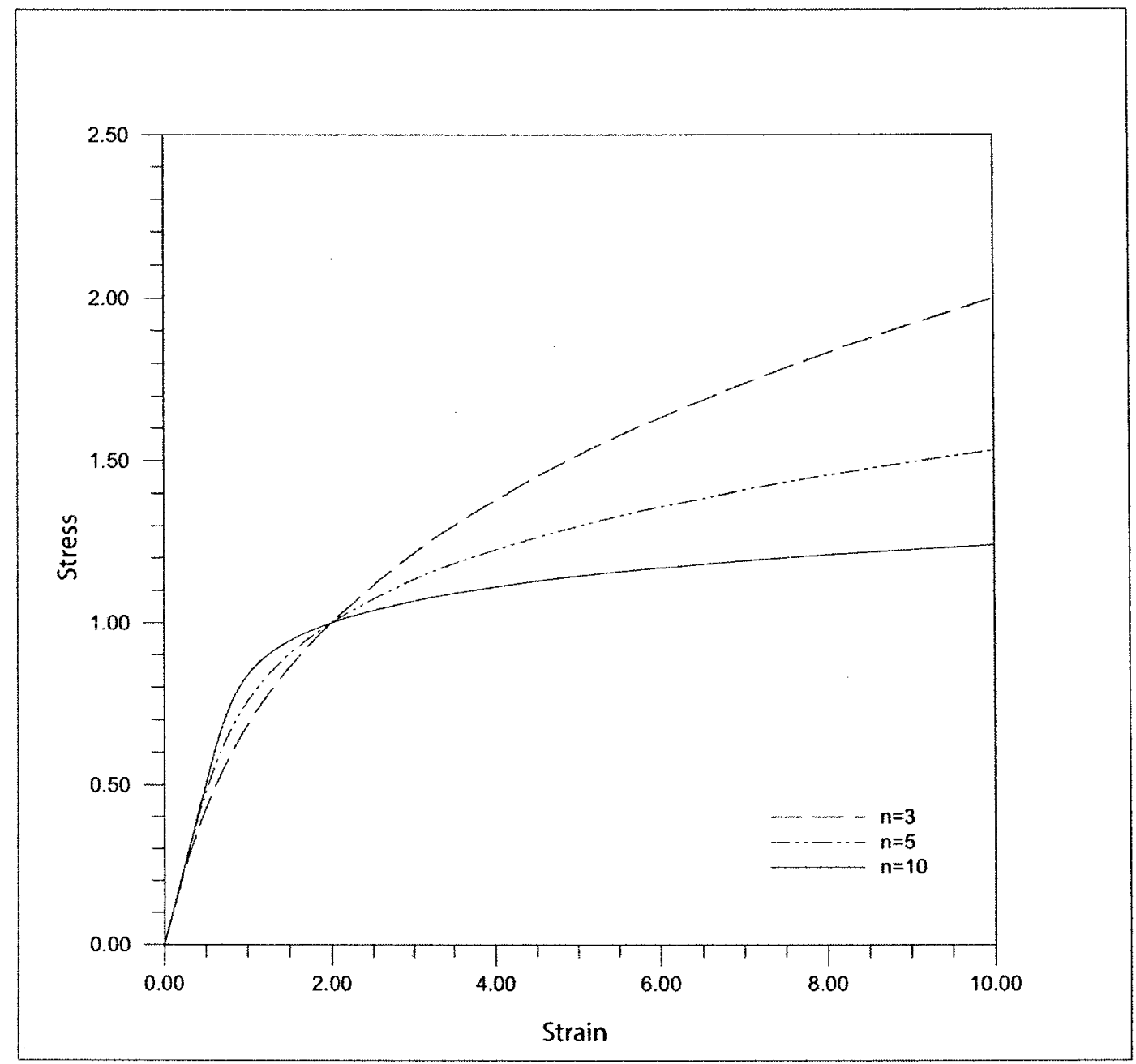

Figure 4.5 Stress Strain Curves for Strain Hardening Material $n=3,5$, and 10 


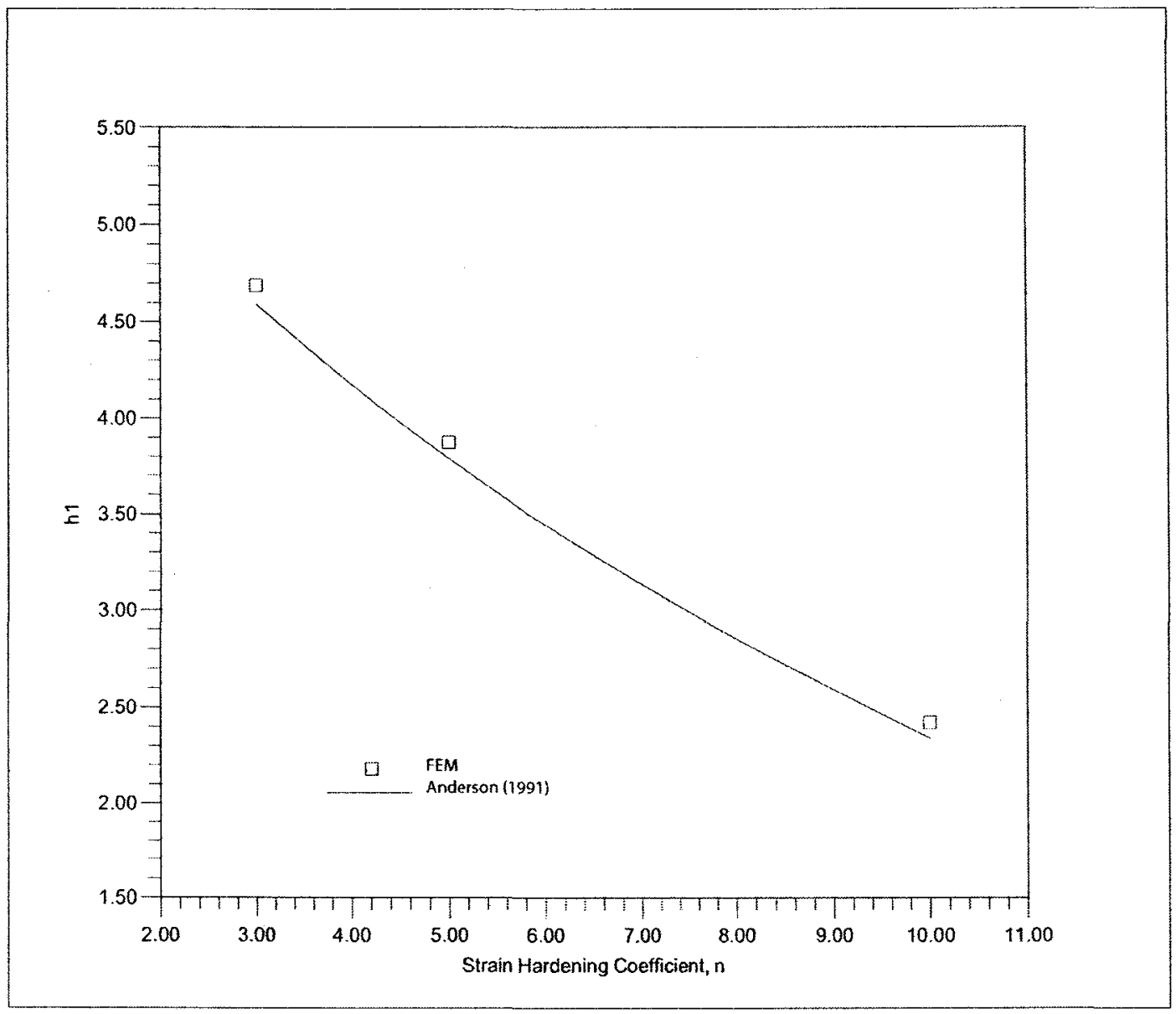

Figure 4.6: Verification of $h_{1}$ Factor for Cracked Cylinder $r_{i} / r_{o}=0.83$ with Established Results (Anderson,1991) 


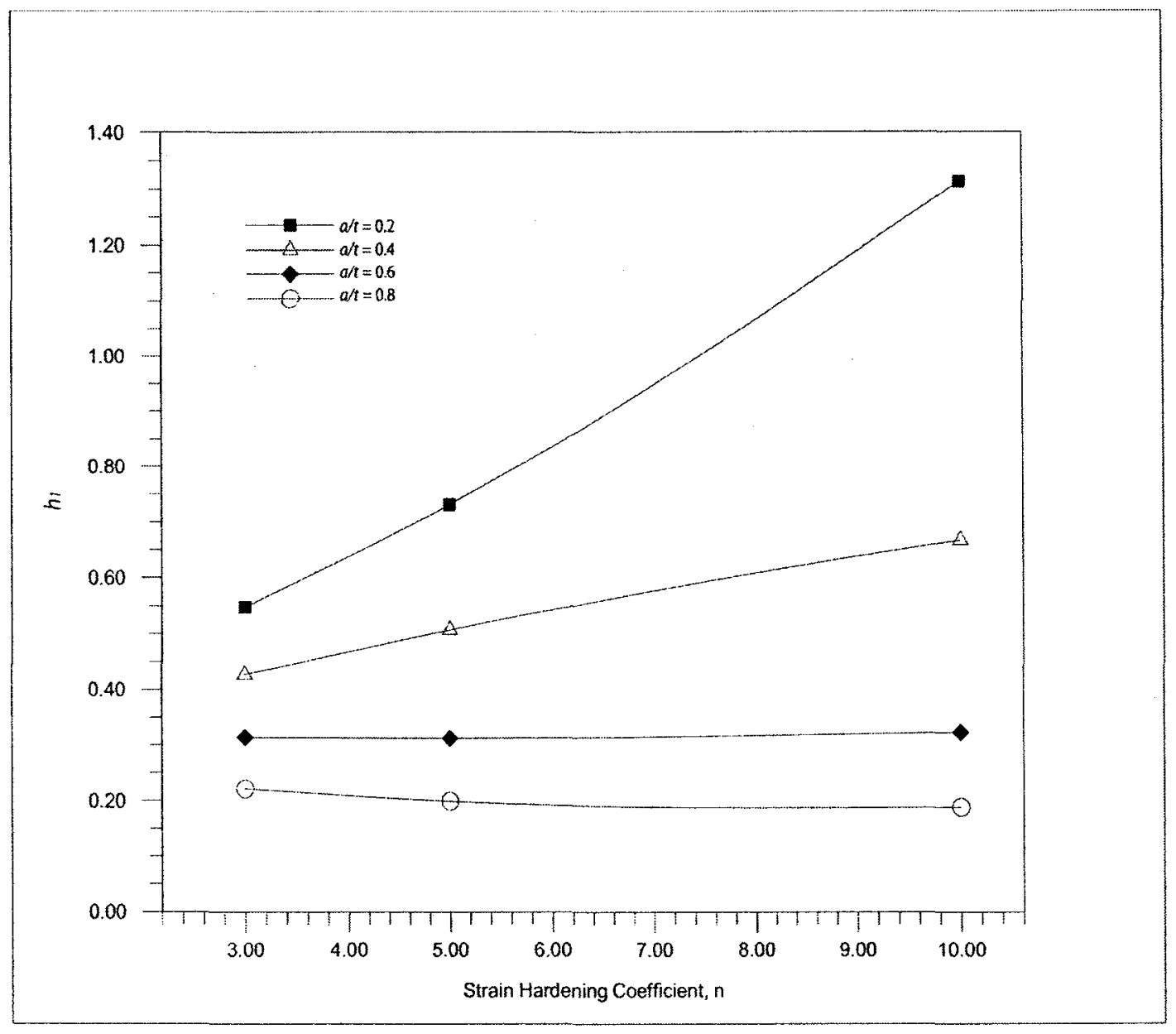

Figure 4.7: $h_{l}$ Factor for Cracked Cylinder $r_{i} / r_{o}=0.2, n=3,5$, and 10 


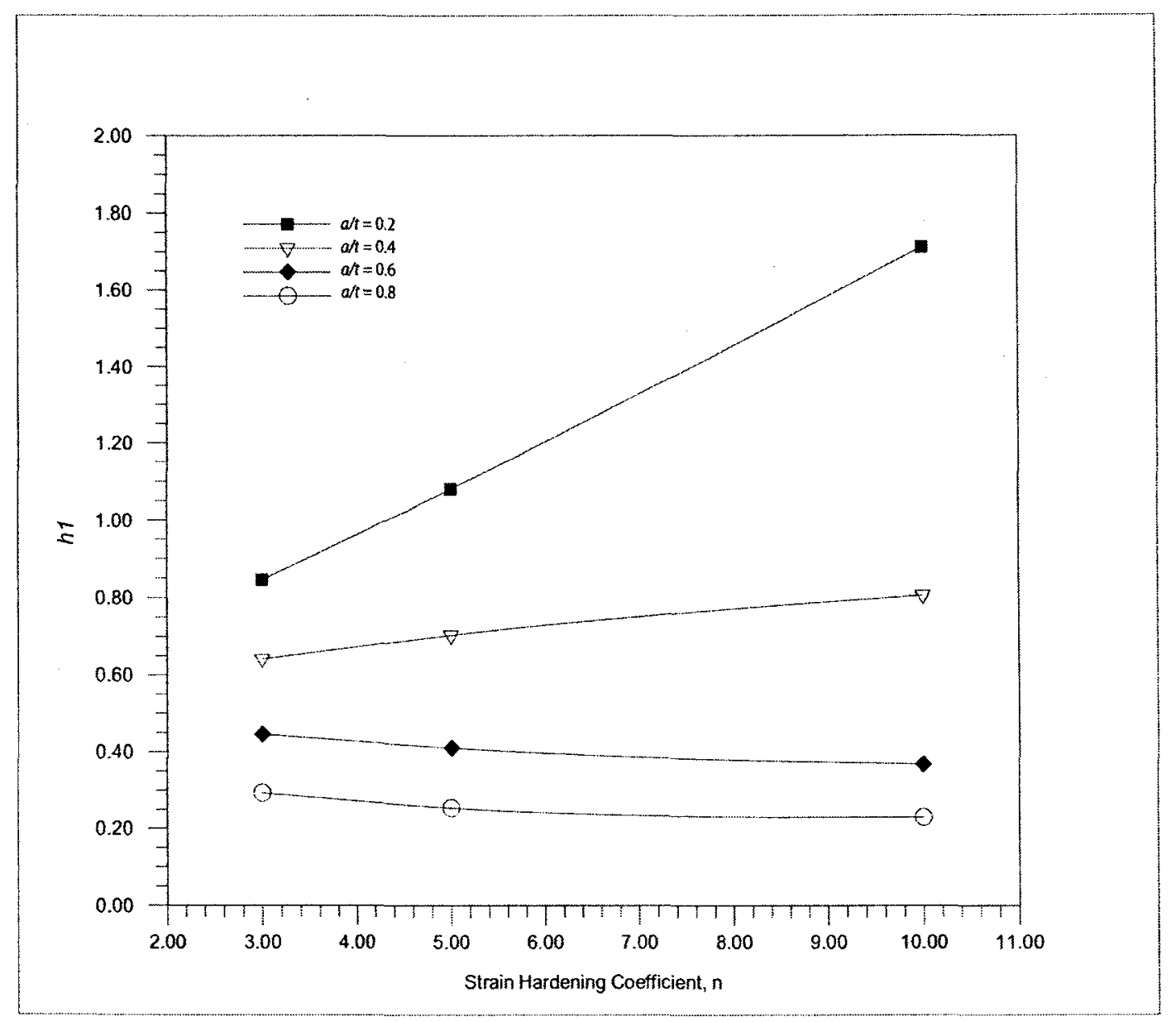

Figure 4.8: $h_{1}$ Factor for Cracked Cylinder $r_{i} / r_{o}=0.4, n=3,5$, and 10 


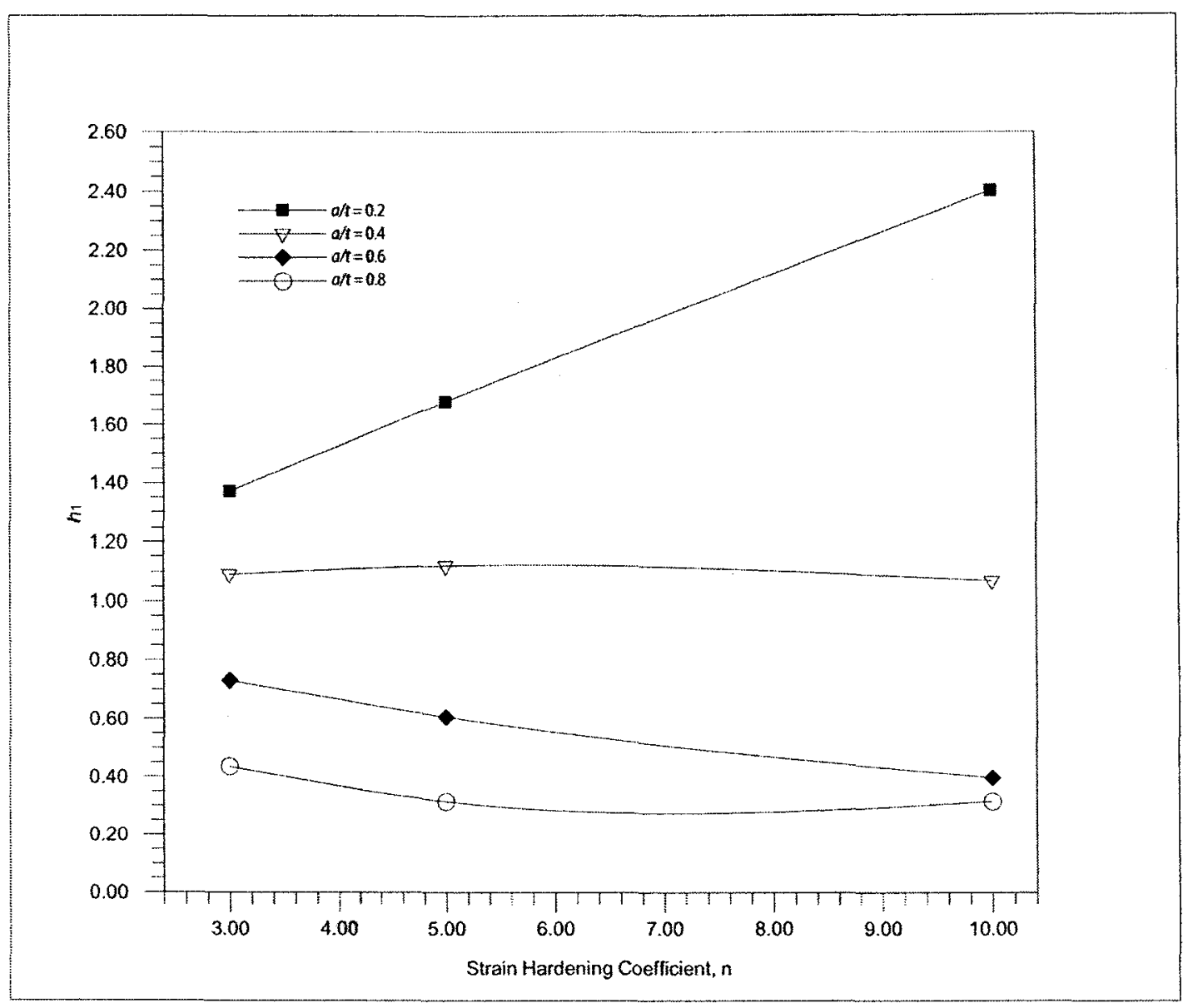

Figure 4.9: $h_{1}$ Factor for Cracked Cylinder $r_{i} / r_{o}=0.6, n=3,5$, and 10 


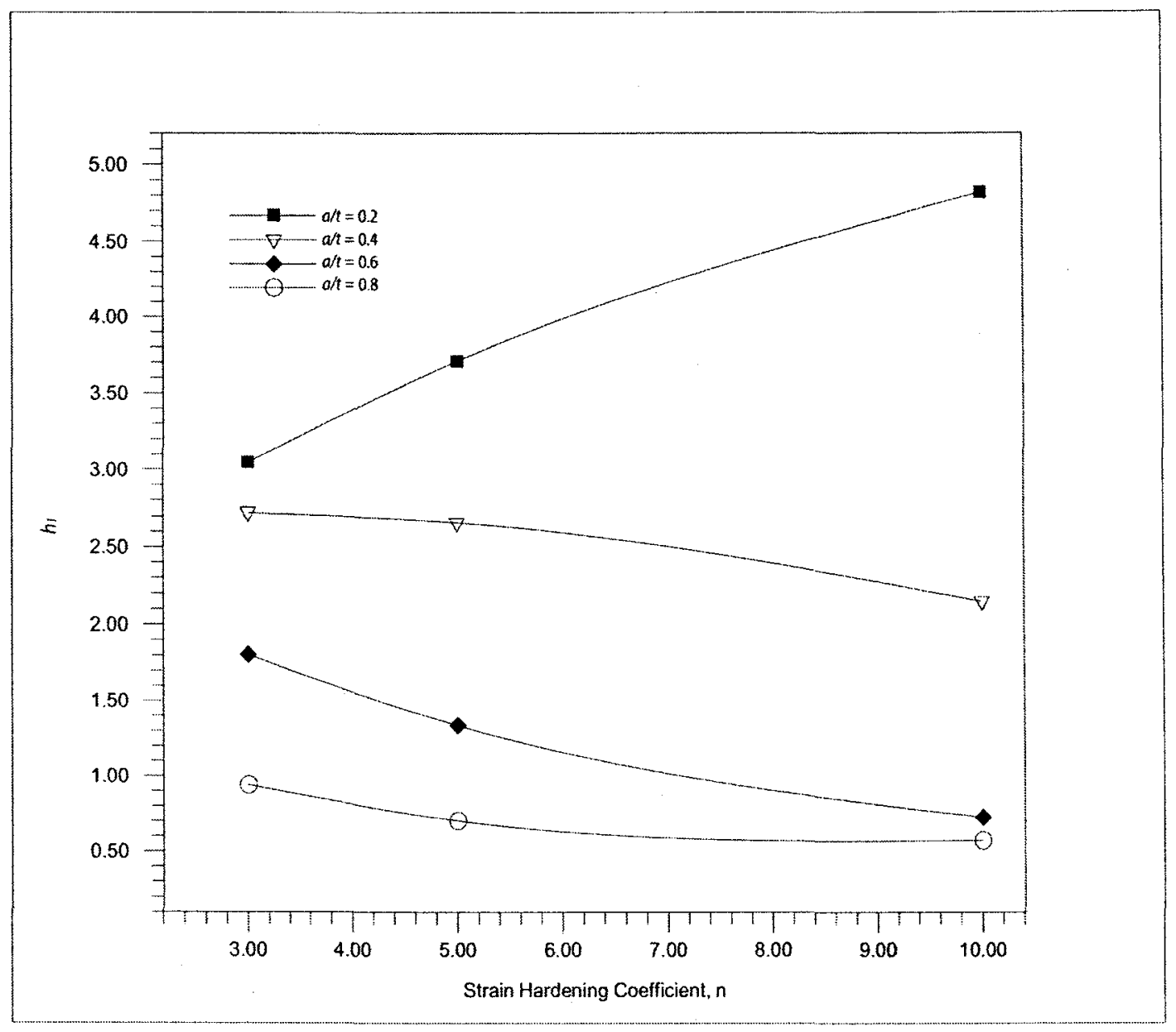

Figure 4.10: $h_{1}$ Factor for Cracked Cylinder $r_{i} / r_{o}=0.8, n=3,5$, and 10 


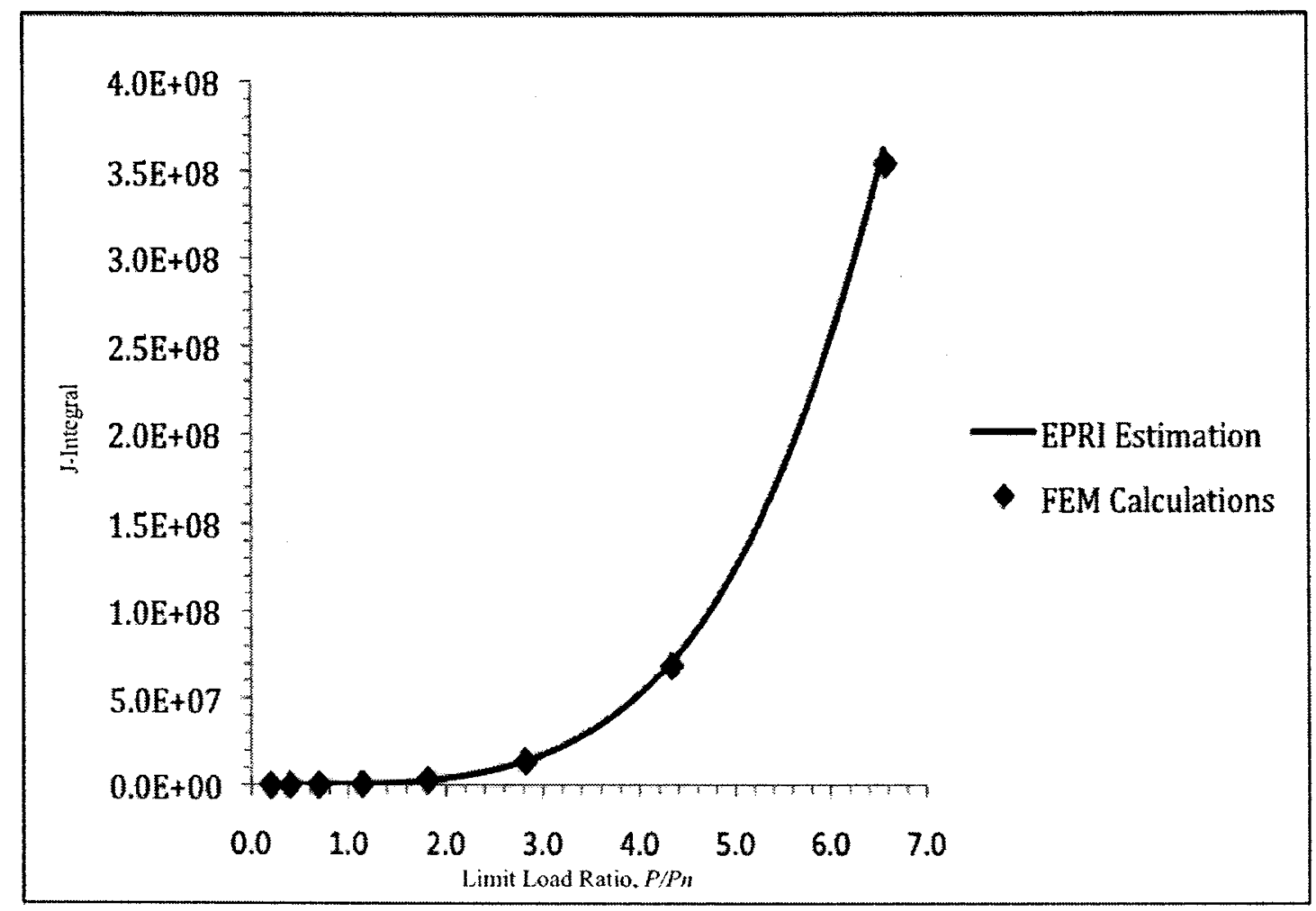

Figure 4.11: Application of EPRI Estimation for J-Integral with Cracked Cylinder, $n=3$ 


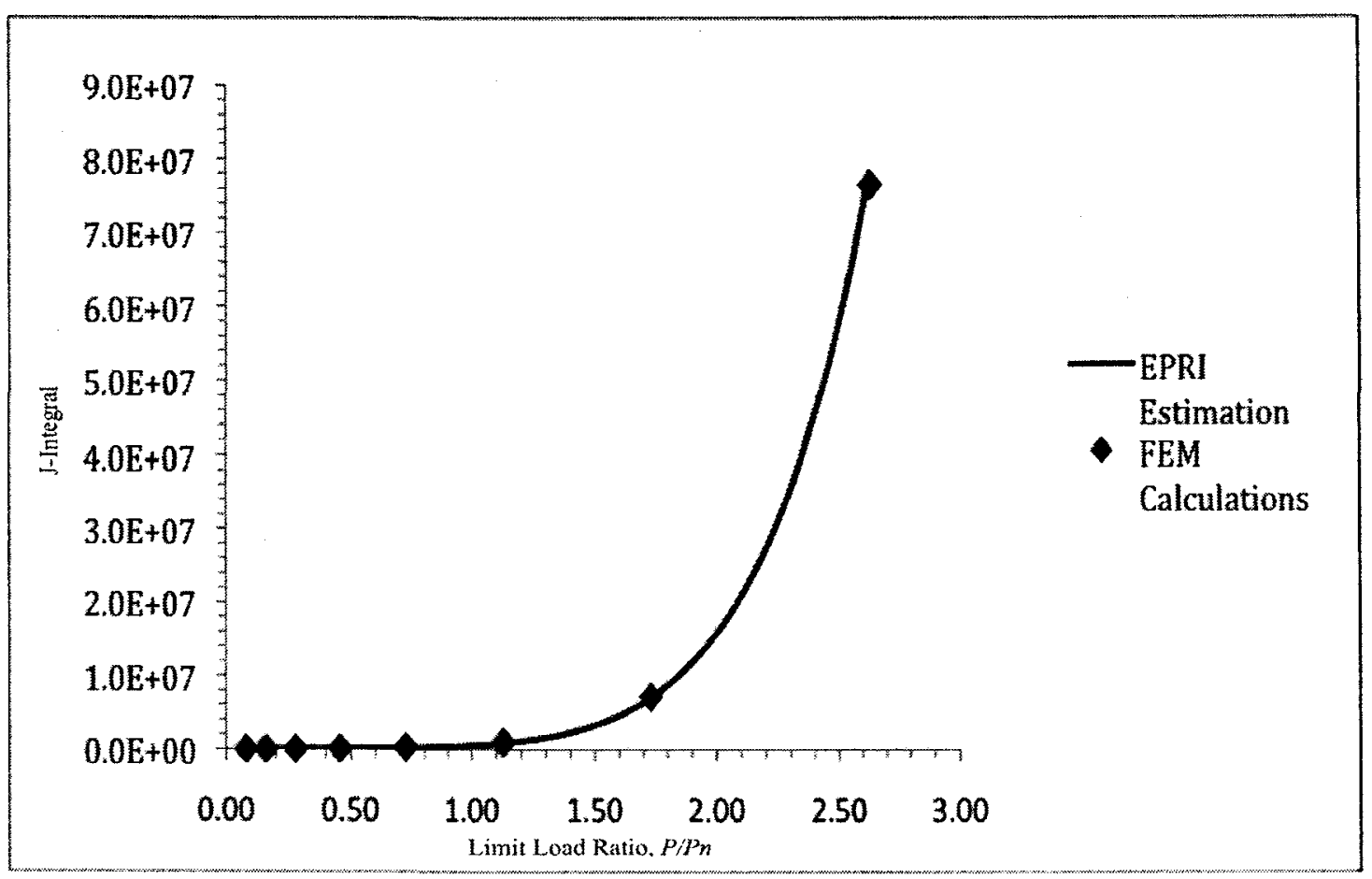

Figure 4.12: Application of EPRI Estimation for J-Integral with Cracked Cylinder, $n=5$ 


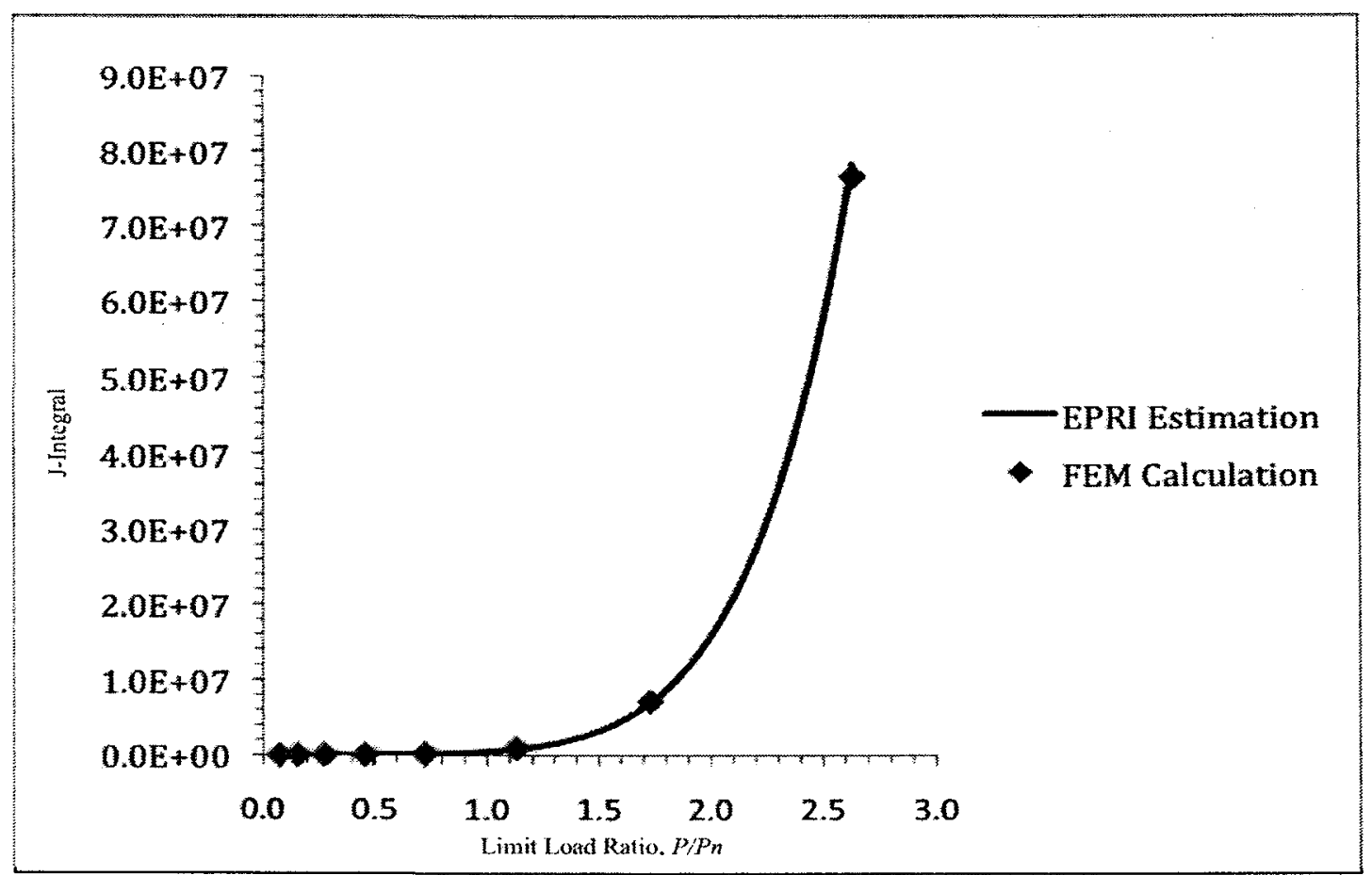

Figure 4.13: Application of EPRI Estimation for J-Integral with Cracked Cylinder, $n=10$ 


\section{Chapter 5}

\section{Failure Assessments of Cracked Cylinders}

In Chapters 3 and 4, the elastic T-stress and J-integral solutions for a cracked cylinder under tension were determined. Application of these T-stress and J-integral solutions to conduct a two-parameter, constraint-based failure assessment is presented in this chapter. Constraint-based failure assessments involve generating FADs and determining the maximum load carrying capacity for each crack geometry. Both constraint-based lower bound FAD and J-T based FAD analyses will be conducted.

\subsection{Constraint-Based Failure Assessment Diagrams}

As discussed in section 2.4.1, the conventional failure assessment diagrams that are used in PD 6493 (1991) can be overly conservative if a cracked geometry is under conditions of low constraint. A constraint-based FAD allows a more accurate fracture assessment of low constrained cracked geometry by predicting a higher maximum load carrying capacity than that of the conventional failure assessment methods would yield. The following section will look at two different constraint-based FADs. The first FAD is the lower bound FAD that is modified by constraint effects and the second is the J-T FAD modified by constraint effects.

\subsubsection{Constraint-Base Lower Bound FADs}

The first constraint-based failure assessment diagram is based on the lower bound FAD and elastic T-stress as discussed in section 2.4.2 (Ainsworth and O'Dowd, 1995). 
The conventional failure assessment diagram uses a single fracture parameter of stress intensity factor which, is determined by calculating the two parameters of $K_{r}$, and $L_{r}$ given as

$$
\begin{gathered}
K_{r}=\frac{K_{I}}{K_{I C}} \\
L_{r}=\frac{\sigma}{\sigma_{L}}
\end{gathered}
$$

Failure of the cracked geometry is avoided if the calculated point $\left(K_{r}, L_{r}\right)$ lies within the failure assessment curve given as $K_{r}=f\left(L_{r}\right)$. Another condition that must be met is that $L_{r}$ cannot exceed the cut-off value of $L_{r}$ given as $L_{r}^{\max }$. The lower bound failure assessment diagram approach that is used in this thesis is based on Level 3 of PD 6493 (1991) in which a FAD curve, $K_{r}=f\left(L_{r}\right)$, is generated that is independent of geometry and the material stress strain curve given as

$$
K_{r}=\left(1-0.14 L_{r}^{2}\right)\left(0.3+0.7 \exp \left(-0.65 L_{r}^{6}\right)\right)
$$

For the constraint-based failure assessment diagrams, a fracture resistance of $K^{C}{ }_{m a t}$ is used to modify the failure assessment diagram of Eq. (2.27).

$$
K_{r}=f\left(L_{r}\right)\left(\frac{K_{m a t}^{c}}{K_{I C}}\right)
$$

Betegon and Hancock (1991) and O'Dowd and Shih (1991) determined though experimental analysis that the increase in fracture toughness can be represented by 


$$
\begin{array}{ll}
K_{m a t}^{c}=K_{I C}\left[1+\alpha\left(-\beta L_{r}\right)^{m}\right] & \text { for } \beta<0 \\
K_{m a t}^{c}=K_{I C} & \text { for } \beta \geq 0
\end{array}
$$

where $\alpha$, and $m$ are material dependent constants which relates the dependence of fracture toughness on constraint. $\beta$ is the normalized constraint parameter relating to the T-stress given by

$$
\beta=\frac{T}{\sigma_{o} L_{r}}
$$

where $T$ is the elastic T-stress and $\sigma_{o}$ is the yield stress of the material. Substituting Eq. (2.29) into Eq. (2.28) the failure assessment curve is modified to account for constraint effects and given as

$$
\begin{array}{ll}
K_{r}=f\left(L_{r}\right)\left[1+\alpha\left(-\beta L_{r}\right)^{m}\right] & \text { for } \beta<0 \\
K_{r}=f\left(L_{r}\right) & \text { for } \beta \geq 0
\end{array}
$$

substituting Eq. (2.32) into Eq. (2.27) the failure assessment curve becomes

$$
\begin{array}{ll}
\left.K_{r}=\left(1-0.14 L_{r}{ }^{2}\right)\left[0.3+0.7 \exp \left(-0.65 L_{r}^{6}\right)\right] 1+\alpha\left(-\beta L_{r}\right)^{m}\right] & \text { for } \beta<0 \\
K_{r}=\left(1-0.14 L_{r}{ }^{2}\right)\left[0.3+0.7 \exp \left(-0.65 L_{r}^{6}\right)\right] & \text { for } \beta \geq 0
\end{array}
$$


The first equation in Eq. (5.1) is the constraint-based failure assessment diagram. Similar to the conventional failure assessment diagrams, failure is avoided if the calculated point $\left(K_{r}, L_{r}\right)$ lies within the failure assessment curve and that $L_{r}$ cannot exceed the cut-off value of $L_{r}$ given as $L_{r}^{\max }$.

In order to generate a constraint-based failure assessment diagram, $K$, T-stress and $P_{L}$ have to be determined. The first is the stress intensity factor that is calculated by Eq. (3.1). The stress intensity factor for a given load level can be calculated by

$$
K_{I}=F\left(\frac{r_{i}}{r_{o}}, \frac{a}{t}\right) \sigma \sqrt{\pi a}
$$

Using the boundary correction factor, $F$ for a given crack length, the stress intensity factor for various load levels can be determined.

The second parameter that is needed is the elastic T-stress solutions; the equation to determined the T-stress solutions are outlined in section 2.4.3 The T-stress is normalized by

$$
V=\frac{T}{\sigma_{o}}
$$

The third parameter is the limit stress. The limit load is calculated using Eq. (4.1) but in this chapter, the limit load with respect to FAD is given as $P_{L}$. 


$$
P_{L}=\frac{2}{\sqrt{3}} \pi\left(r_{o}^{2}-\left(r_{i}+a\right)^{2}\right) \sigma_{o}
$$

The limit stress is determined by dividing the limit load over the cross sectional area of the cracked cylinder.

\section{Failure Assessment of Cracked Cylinders}

Using the three parameters that were discussed, the constraint-based failure assessment diagrams can now be carried out. The failure assessment diagrams are generated for circumferentially cracked cylinders with thickness ratios of $r_{i} / r_{o}=0.2,0.4,0.6$, and 0.8 and crack ratios of $a / t=0.2,0.4,0.6$, and 0.8 . The load applied to the cylinder is remote tensile loading.

The material that was selected for the analysis is A533B, a typical pressure vessel low alloy steel ASME (1992). The tensile yield stress of the steel is $471 \mathrm{MPa}$ and the ultimate strength is $591 \mathrm{MPa}$ at $70^{\circ} \mathrm{C}$. The Young's modulus of the material is 196.5 GPa. The initiation toughness of the material, $J_{I C}$ is $0.38 \mathrm{MJ} / \mathrm{m}^{2}$ (Phaal et al., 1995). The material's fracture toughness of $286 \mathrm{MN} / \mathrm{m}^{3 / 2}$ is determined from $J_{I C}$. The material properties are taken from ASME Boiler \& Pressure Vessel Code (1992). The constraint constants $\alpha=1.5$ and $m=1$ (Ainsworth, and O'Dowd, 1995). The cut-off load ratio for C-Mn Steel is 1.2 (PD 6493, 1991). For this analysis, since the flow stress can be calculated as

$$
\sigma_{f}=0.5\left(\sigma_{y}+\sigma_{u}\right)
$$


The cut-off stress ratio that is used in the thesis is $\sigma_{f} / \sigma_{y}=1.12$.

\section{Constraint-Based Failure Assessment Diagrams}

The constraint-based failure assessment diagrams for the cracked geometry are generated using Eq. (5.1) based on the calculated fracture parameters and material properties of A533B. A conventional FAD curve is plotted along with constraint-based FAD for each cylinder thickness ratio, $r_{i} / r_{o}$ and various crack length ratios, $a / t$. Figures 5.1, 5.2, 5.3, and 5.4 show the FAD generated for $r_{i} / r_{o}=0.2,0.4,0.6$, and 0.8 respectively. From the failure assessment diagrams, a failure assessment line was plotted as shown in Figure 5.5. The failure assessment line is constructed by incrementally increasing the load for a given material and a $\left(K_{r}, L_{r}\right)$ line was plotted. The applied stress, $\sigma$ from the $L_{r}$ value of the intersection of the failure assessment line and failure assessment curve was obtained and the maximum load carrying capacity was determined as

$$
P_{n}=\frac{\sigma}{\sigma_{f}}
$$

where $\sigma_{f}$ is the flow stress given by Eq. (5.3). The $P_{n}$ results for $r_{i} / r_{o}=0.2$ and 0.8 are summarized in Tables 5.1 and 5.2. Both conventional and constraint base FADs are presented in Figures 5.6, and 5.7. 


\section{Results and Discussion}

From Figures 5.1, 5.2, 5.3 and 5.4 it can be seen that the FAD curve of the constraintbased lower bound FADs are higher than that of the conventional lower bound FAD curve. This is due to the low constraint condition in which T-stress is negative. Figure 5.6 corresponds to the maximum load carrying capacities of cylinder thickness, $r_{i} / r_{o}=$ 0.2 and Figure 5.7 corresponds to the maximum load carrying capacities of cylinder thickness, $r_{i} / r_{o}=0.8$. Both Figures 5.6 and 5.7 shows that the maximum normalized axial stress, $P_{n}$ for the cracked cylinder is higher for the constraint-based FAD than that of the conventional FAD for every crack length. From Figure 5.6 with $r_{i} / r_{o}=0.2$ (thick cylinder), the crack depth ratio that exhibited the most increase in maximum load carrying capacity was that of $a / t=0.8$ (thick crack) with an increase of $52.81 \%$. The trend in Figure 5.6 was that the amount of increase in load carrying capacity decreases with the increase in the crack length. From Figure 5.7 with $r_{i} / r_{o}=0.8$ (thin cylinder), the crack depth ratio that exhibited the most increase in maximum load carrying capacity was that of $a / t=0.2$ with an increase of $56.80 \%$. Figure 5.7 shows that there is less of an increase in maximum load carrying capacity than that of Figure 5.6 corresponding to a thick cylinder. The results of this analysis demonstrate that using the constraint-based failure assessment diagrams based on $K$ and $\mathrm{T}$-stress, the maximum load carrying capacity for the cracked cylinder can increase significantly compared to the conventional lower bound and overly conservative FAD methods.

\subsubsection{J-T Constraint-Based Failure Assessment Diagrams}

The second constraint-based failure assessment method is based on the J-integral and Tstress parameters as discussed in section 2.4. Fracture assessment is more accurate using this method because it is dependent on geometry and the material's stress strain curve. As 
discussed in section 2.5.2, the conventional J-integral FAD diagrams are determined using Eq. (2.27) Ainsworth and O’Dowd (1995).

$$
K_{r}=\sqrt{\frac{J_{e l}}{J}}
$$

$J_{e l}$ is calculated using Eq. (2.18). The total J-integral is determined by adding the calculated $J_{e l}$ value with the $J_{p l}$ value. $J_{p l}$ is calculated by inserting the $h_{l}$ factor into Eq. (2.21). Failure is assumed to be prevented if the $\left(K_{r}, L_{r}\right)$ point lies within the failure assessment curve and less than the cut-off value of $L_{r}{ }^{m a x}$.

The constraint-based failure assessment diagrams are generated similar to that of Eq. (5.1) except the first part of Eq. (5.1) is substituted with Eq. (2.28) and is given as

$$
\begin{array}{ll}
K_{r}=\sqrt{\frac{J_{e l}}{J}}\left[1+\alpha\left(-\beta L_{r}\right)^{m}\right] & \text { for } \beta<0 \\
K_{r}=\sqrt{\frac{J_{e l}}{J}} & \text { for } \beta \geq 0
\end{array}
$$

\section{Failure Assessment of Cracked Cylinders}

Using Eq. (2.28) and Eq. (2.33), the FADs are generated for both the J-based methods and J-T based methods. The failure assessment diagrams are generated for circumferentially cracked cylinders with thickness ratios of $r_{i} / r_{o}=0.8$ and crack ratios of $a / t=0.2$, and 0.6 . The load applied to the cylinder is remote tensile loading. A hardening coefficient of $n=10$ was used to simulate a ductile metal similar to that of A533B. The 
materials properties were that of the pressure vessel steel, A533B as stated in section 5.1.1. Two sets of FADs are plotted, the first set is based on the lower bound and constraint-based lower bound FAD and the second set of curves are based on the J-based FAD and J-T based FAD. Figure 5.8 show the two sets of FAD curves for $r_{i} / r_{o}=0.8, a / t$ $=0.2$ and Figure 5.9 show the two sets of FAD curves for $r_{i} / r_{o}=0.8, a / t=0.6$. From the J-based and J-T constraint-based FAD curves, the maximum load carrying capacities were also determined.

\section{Results and Discussion}

The results of the maximum load carrying capacities based on the J-integral and $\mathrm{T}$-stress are presented in Table 5.3. From Figure 5.8 which is the FAD curve for $r_{i} / r_{o}=0.8, a / t=$ 0.2 , it can be seen that the FAD curve for the J-based method is greater than the FAD of the lower bound method. For the constraint-based FAD, the J-T FAD curve is also greater than the constraint-based lower bound. The increase in maximum load carrying capacity of the J-T constraint-based FAD is $51.34 \%$ with respect to conventional $\mathrm{J}$ based FAD.

Figure 5.9 which is that FAD curve for $r_{i} / r_{o}=0.8, a / t=0.6$ shows similar trend to that in Figure 5.8. The increase in maximum load carrying capacity of the J-T constraint-based FAD is $39.76 \%$ with respect to conventional J-based FAD. The increase in maximum load carrying capacity for $a / t=0.6$ is less than that of $a / t=0.2$.

Figures 5.10 and 5.11 show the bar graphs for the comparison of maximum load carrying capacities of the conventional lower bound FAD, constraint-based lower bound FAD, Jbased FAD, and J-T based FAD for $r_{i} / r_{o}=0.8, a / t=0.2$ and 0.6 respectively. Figure 5.10 
and Figure 5.11 show the benefits of using J-T based FAD because the maximum load carrying capacity is the highest of the four methods.

\subsection{Summary}

The purpose of chapter 5 was to generate both conventional FADs and constraint-based FADs by two different methods. The first method was based on the lower bound FAD, and the second method was based on the J-integral. From the FADs of both methods, the maximum load carrying capacities were determined for the specific material and compared. It was shown that the maximum load carrying capacities for the constraintbased lower bound method was greater than that of the conventional lower bound method based of $K$. Similar increases were observed comparing the J-T based method with the J-based method. 


\begin{tabular}{|c|c|c|c|}
\hline \multicolumn{4}{|c|}{ Maximum Load Carrying Capacity, $P_{n}$} \\
\hline \multirow{2}{*}{$a / t$} & $\begin{array}{c}\text { Conventional } \\
\text { Lower Bound } \\
\text { FAD }\end{array}$ & $\begin{array}{c}\text { Constraint-Based } \\
\text { Lower Bound } \\
\text { FAD }\end{array}$ & $\begin{array}{c}\text { Percent } \\
\text { Increase } \\
(\%)\end{array}$ \\
\hline 0.2 & 0.377 & 0.503 & 33.42 \\
\hline 0.4 & 0.235 & 0.315 & 34.04 \\
\hline 0.6 & 0.159 & 0.211 & 32.70 \\
\hline 0.8 & 0.089 & 0.136 & 52.81 \\
\hline
\end{tabular}

Table 5.1: Maximum load carrying capacity for cracked cylinder, $r_{i} / r_{o}=0.2$ using lower bound FAD methods

\begin{tabular}{|c|c|c|c|}
\hline \multicolumn{4}{|c|}{ Maximum Load Carrying Capacity, $P_{n}$} \\
\hline$a / t$ & $\begin{array}{c}\text { Conventional } \\
\text { Lower Bound } \\
\text { FAD }\end{array}$ & $\begin{array}{c}\text { Constraint-Based } \\
\text { Lower Bound } \\
\text { FAD }\end{array}$ & $\begin{array}{c}\text { Percent } \\
\text { Increase } \\
(\%)\end{array}$ \\
\hline 0.2 & 0.250 & 0.392 & 56.80 \\
\hline 0.4 & 0.199 & 0.266 & 33.67 \\
\hline 0.6 & 0.154 & 0.192 & 24.68 \\
\hline 0.8 & 0.098 & 0.139 & 41.84 \\
\hline
\end{tabular}

Table 5.2: Maximum load carrying capacity for cracked cylinder, $r_{i} / r_{o}=0.8$ using lower bound FAD methods 


\begin{tabular}{|c|c|c|c|}
\hline \multicolumn{4}{|c|}{ Maximum Load Carrying Capacity, $P_{n}$} \\
\hline \multirow{3}{*}{$a / t$} & J-Based FAD & $\begin{array}{c}\text { P-T based } \\
\text { FAD }\end{array}$ & $\begin{array}{c}\text { Increase } \\
(\%)\end{array}$ \\
\hline 0.2 & 0.411 & 0.622 & 51.34 \\
\hline 0.6 & 0.166 & 0.232 & 39.76 \\
\hline
\end{tabular}

Table 5.3: Maximum load carrying capacity for cracked cylinder, $r_{i} / r_{o}=0.8, n=10$ using J-Based FAD 


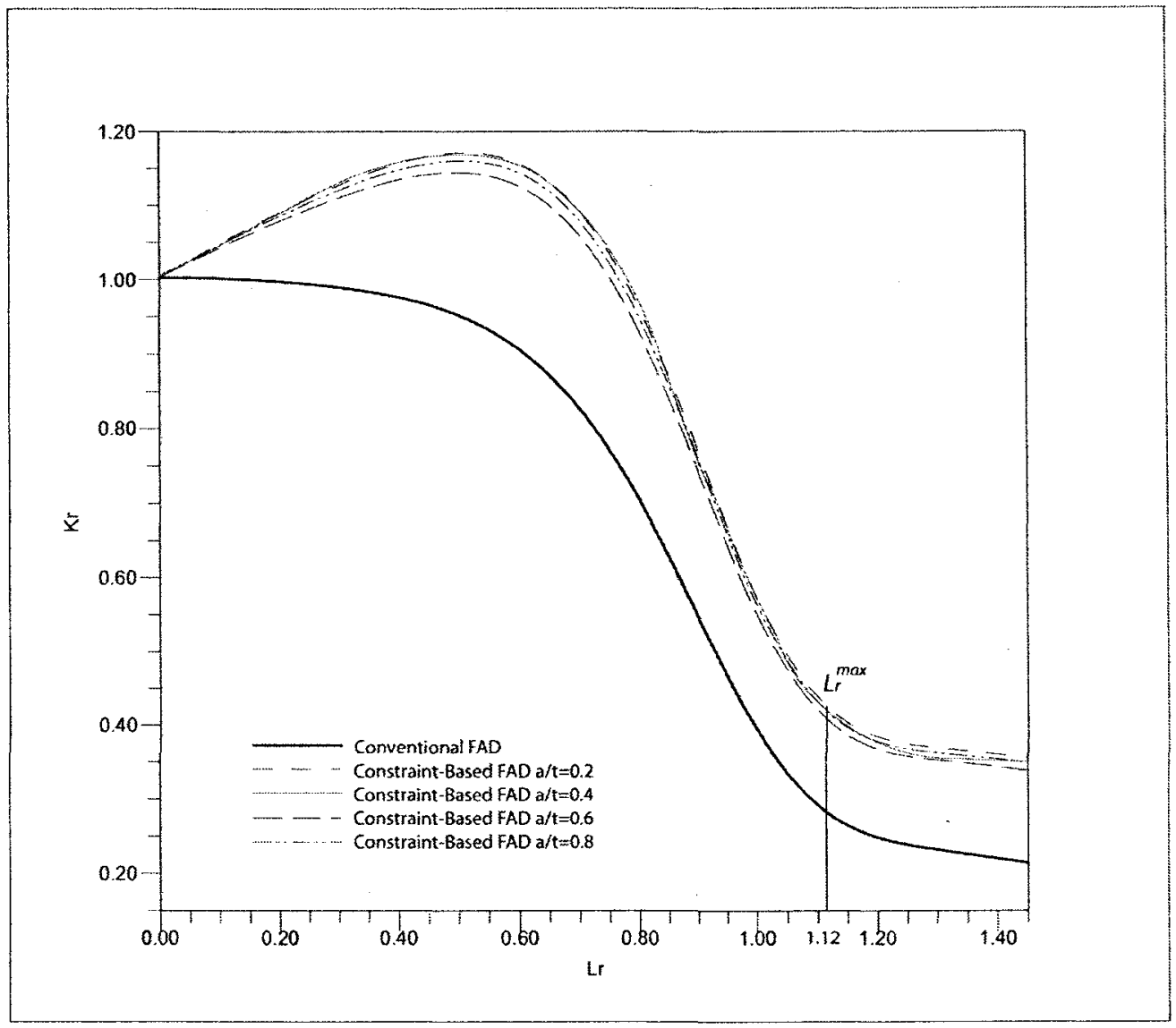

Figure 5.1: FAD of Cracked Cylinder with $r_{i} / r_{o}=0.2$ 


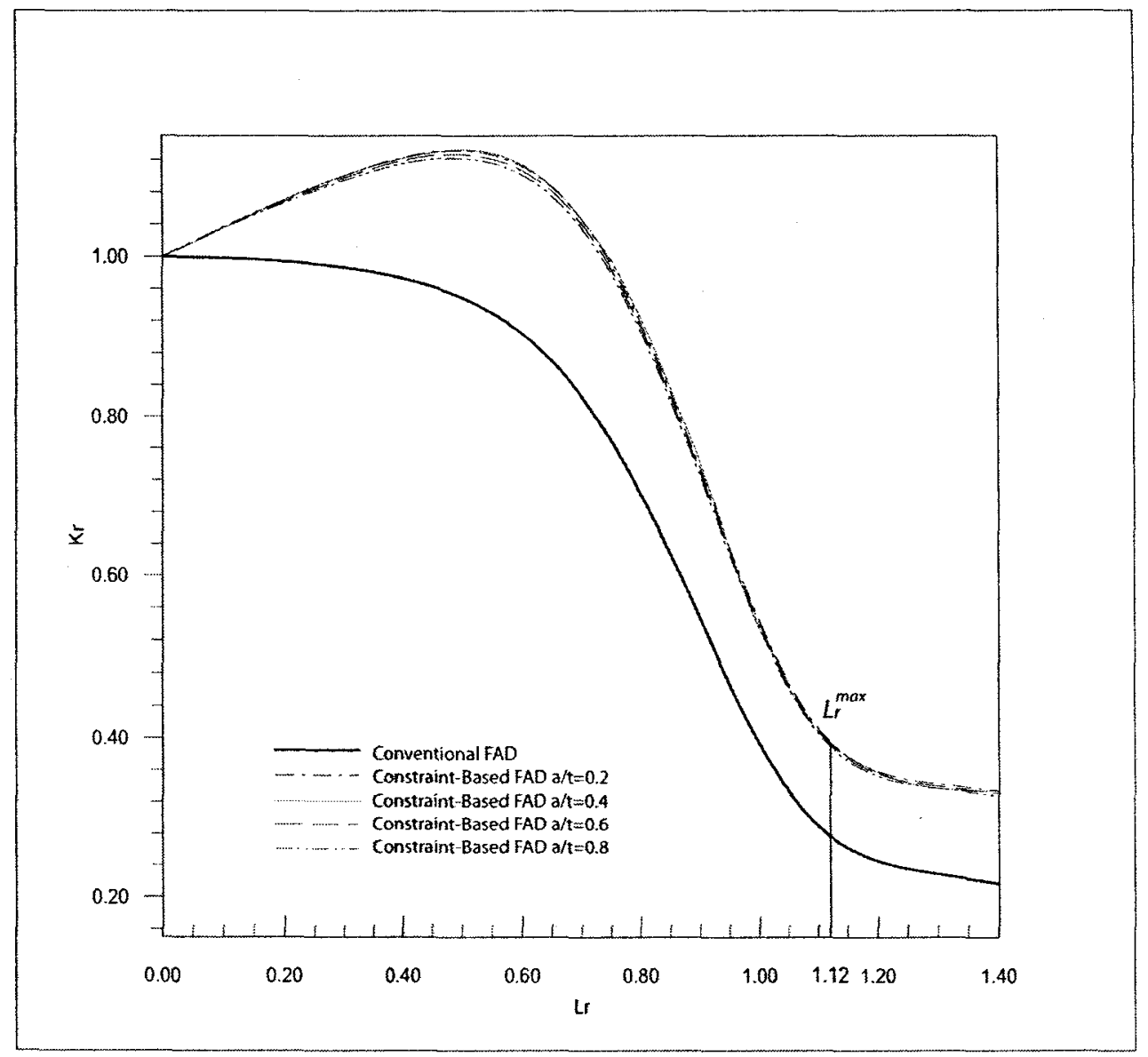

Figure 5.2: FAD of Cracked Cylinder with $r_{i} / r_{o}=0.4$ 


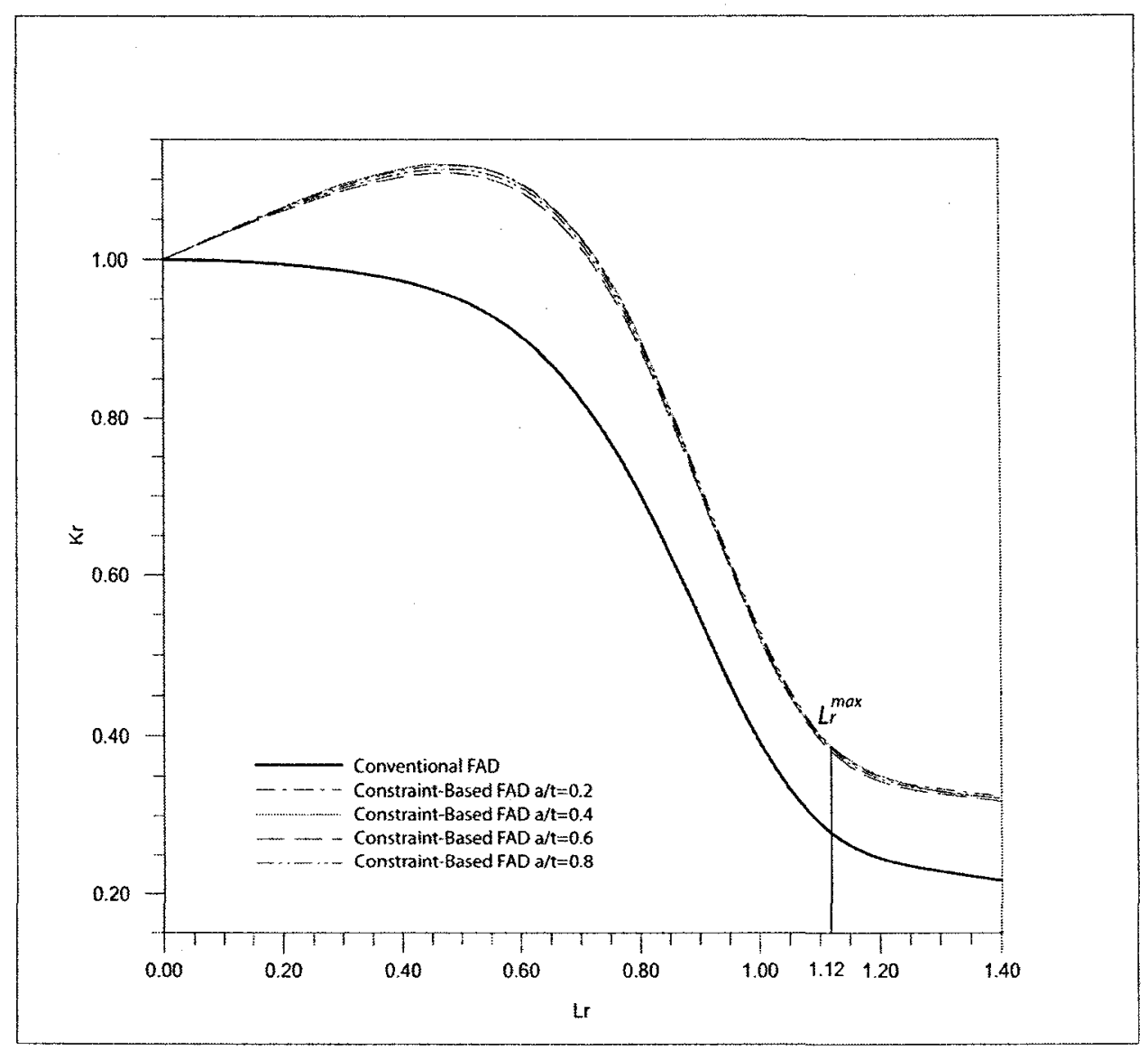

Figure 5.3: FAD of Cracked Cylinder with $r_{i} / r_{o}=0.6$ 


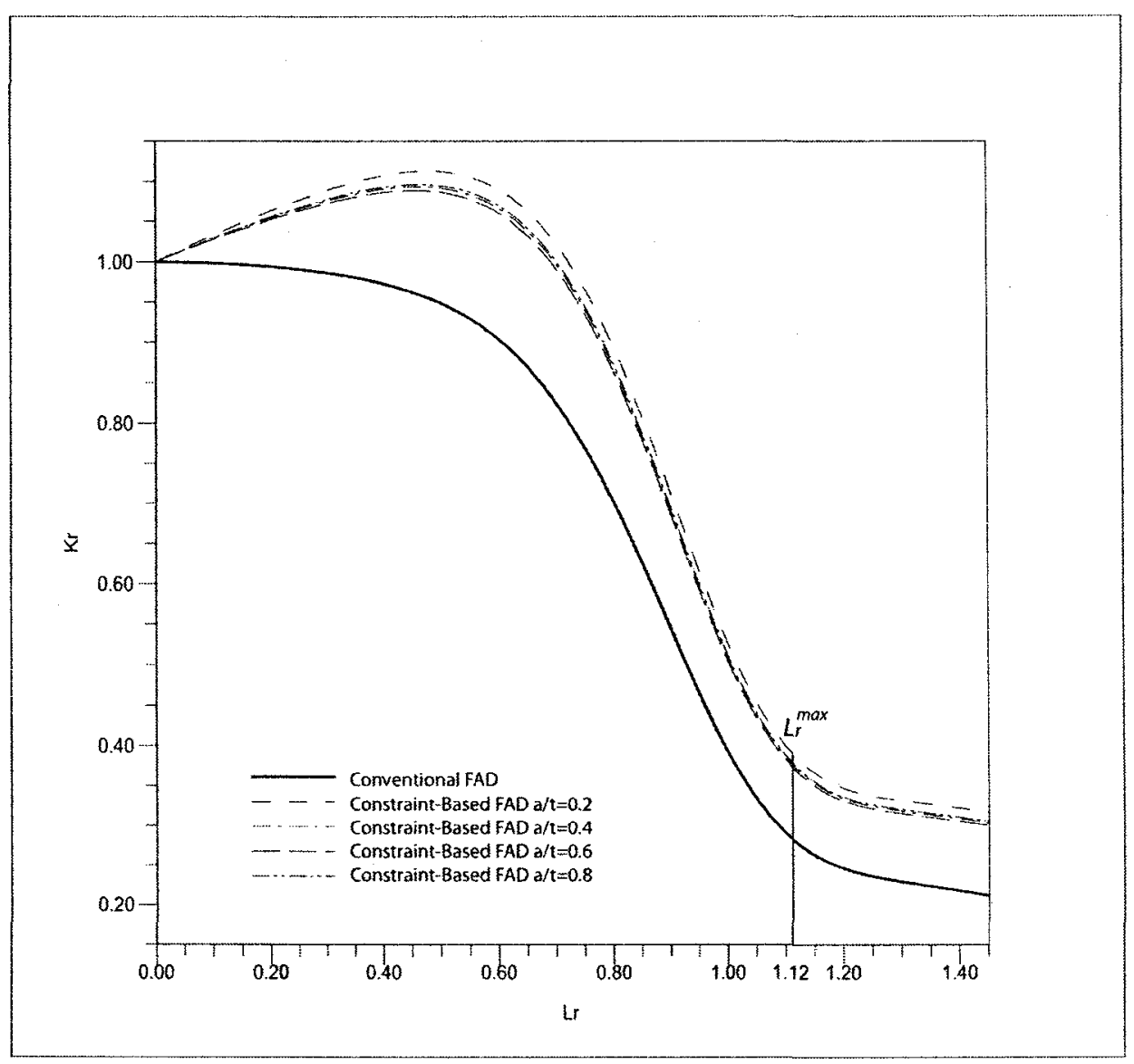

Figure 5.4: FAD of Cracked Cylinder with $r_{i} / r_{o}=0.8$ 


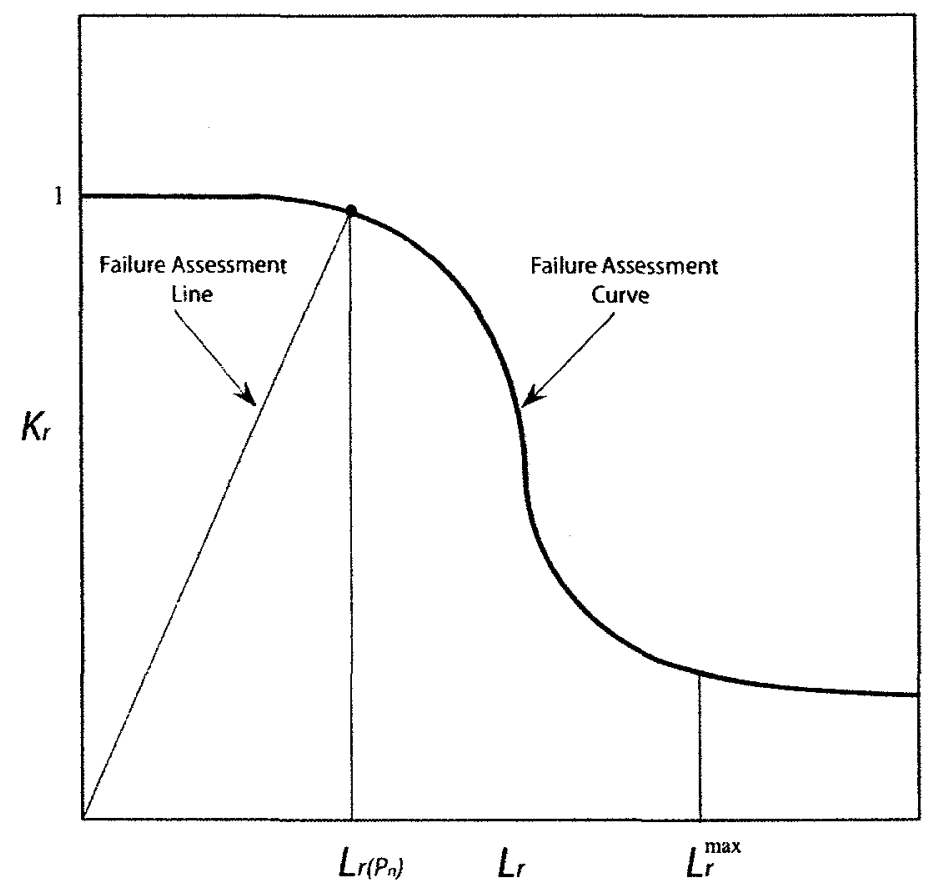

Figure 5.5: Failure Assessment Line Used To Determine Maximum Load Carrying Capacity 


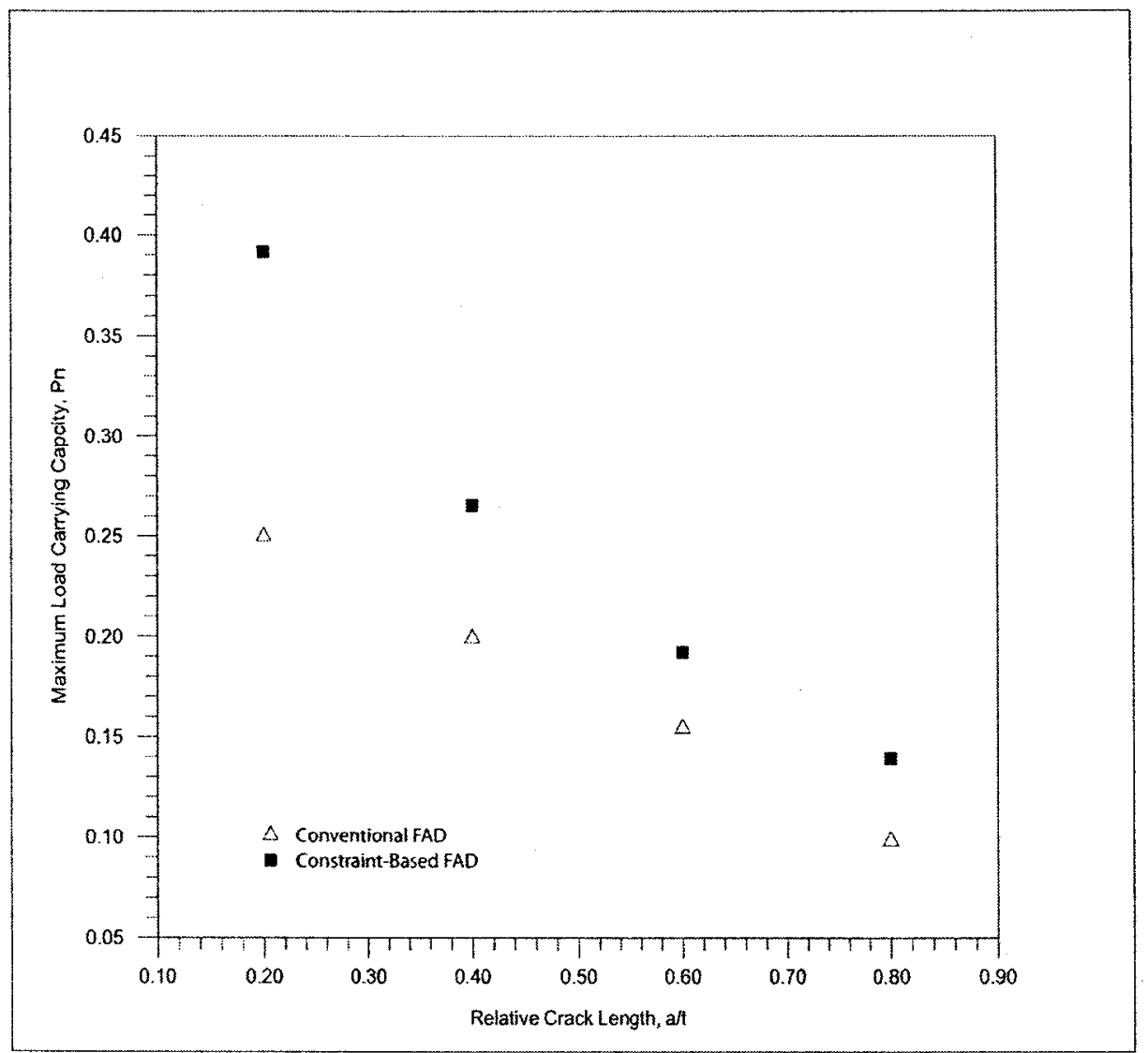

Figure 5.6: Comparison of Conventional FAD and Constraint-Based FAD Cracked Thick Cylinder $r_{i} / r_{o}=0.2$ 


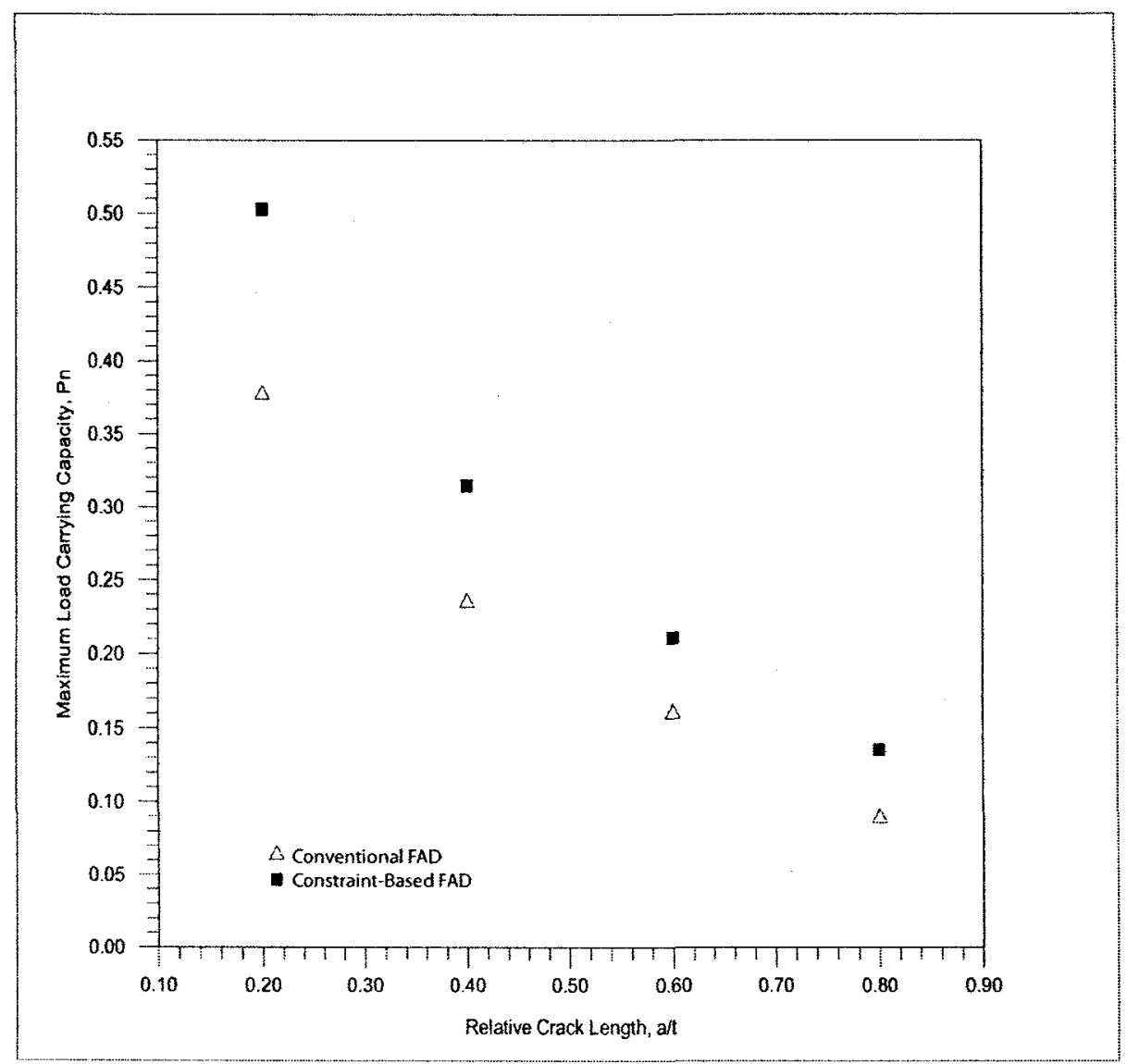

Figure 5.7: Comparison of Conventional FAD and Constraint-Based FAD Cracked Thin Cylinder $r_{i} / r_{o}=0.8$ 


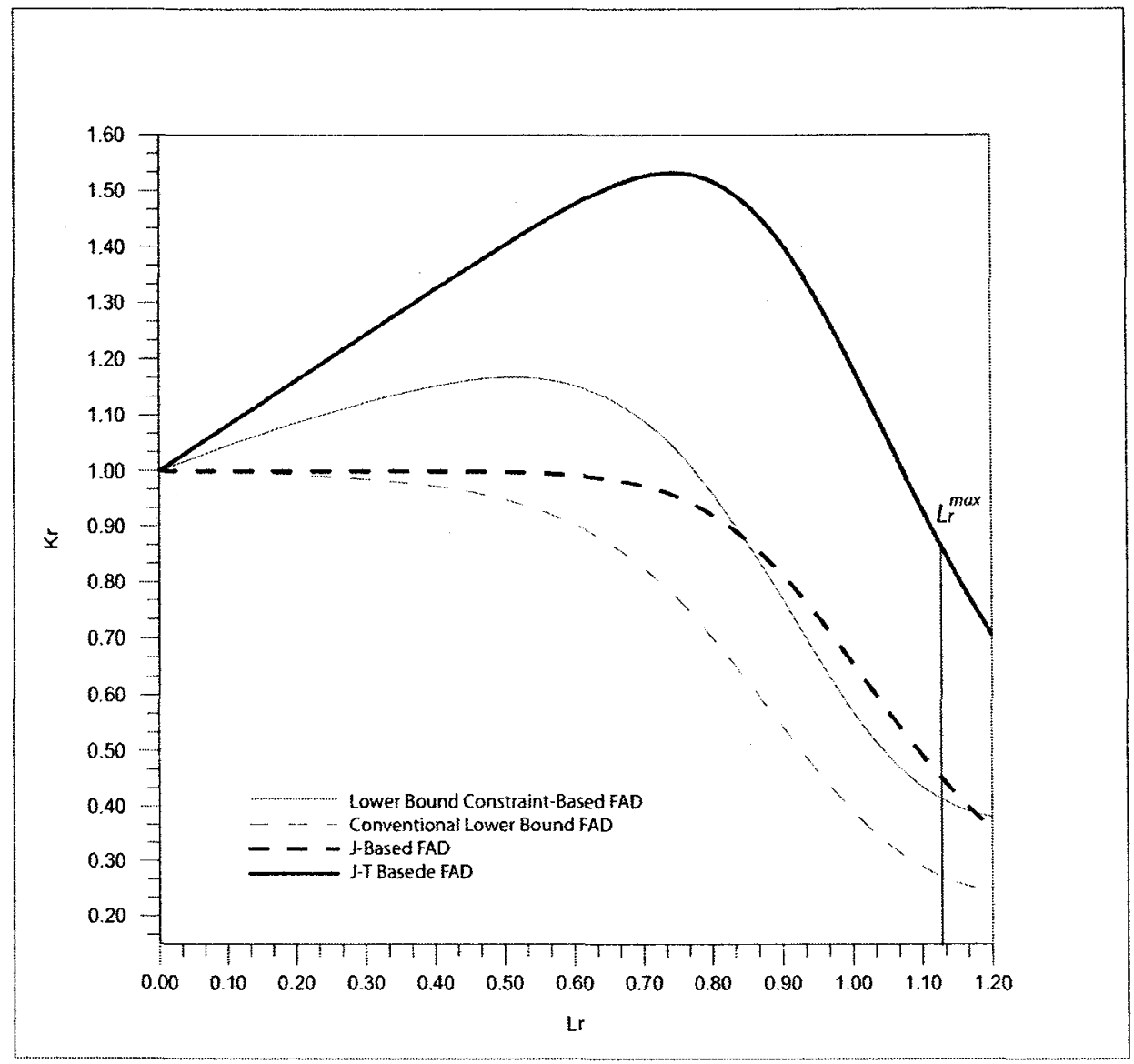

Figure 5.8: J-Based FAD of Cracked Cylinder with $r / r_{o}=0.8, a / t=0.2, n=10$ 


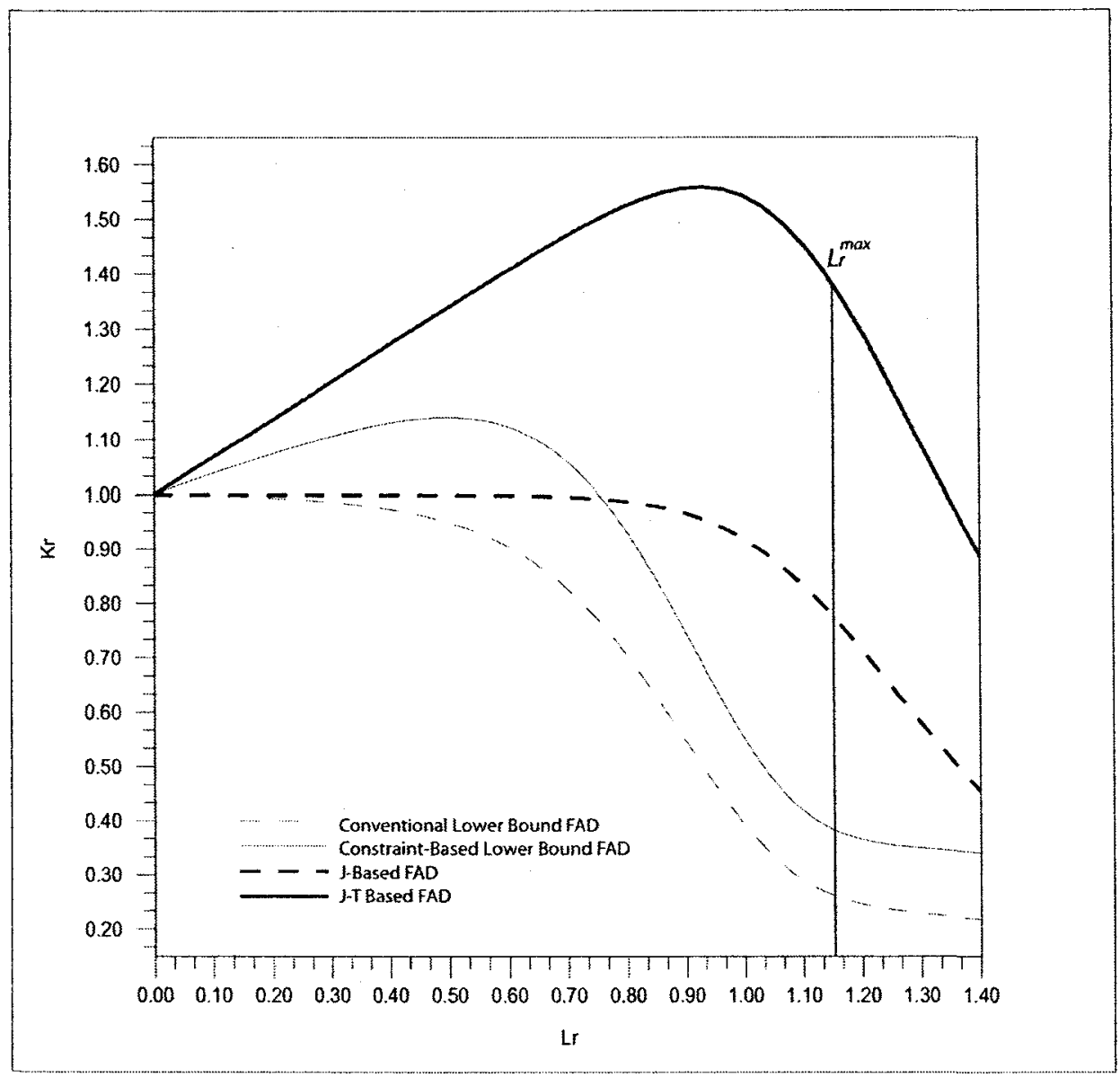

Figure 5.9: J-Base FAD of Cracked Cylinder with $r_{i} / r_{o}=0.8, a / t=0.6, n=10$ 


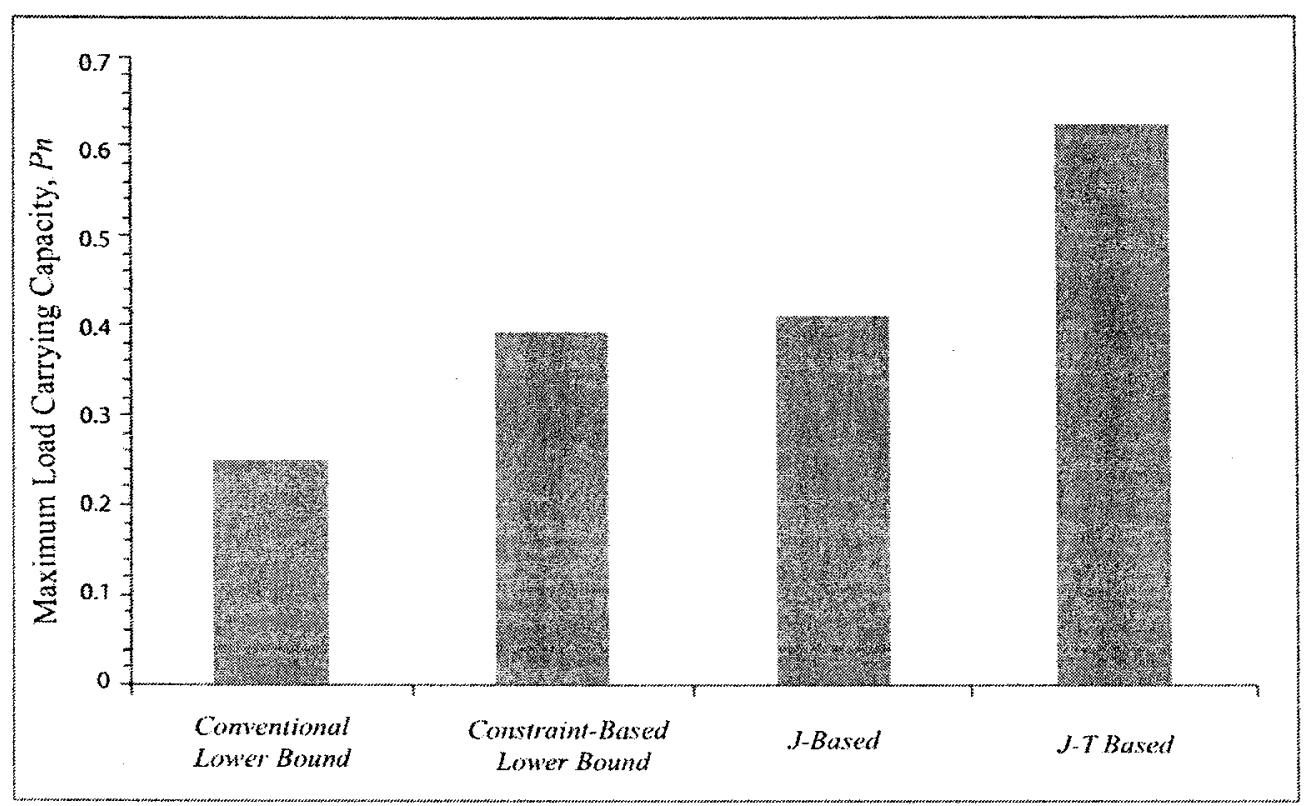

Figure 5.10: Comparison of Increase in $P_{n}$ for K-Based and J-Based FAD $r_{i} / r_{o}=0.8, a / t=0.2, n=10$

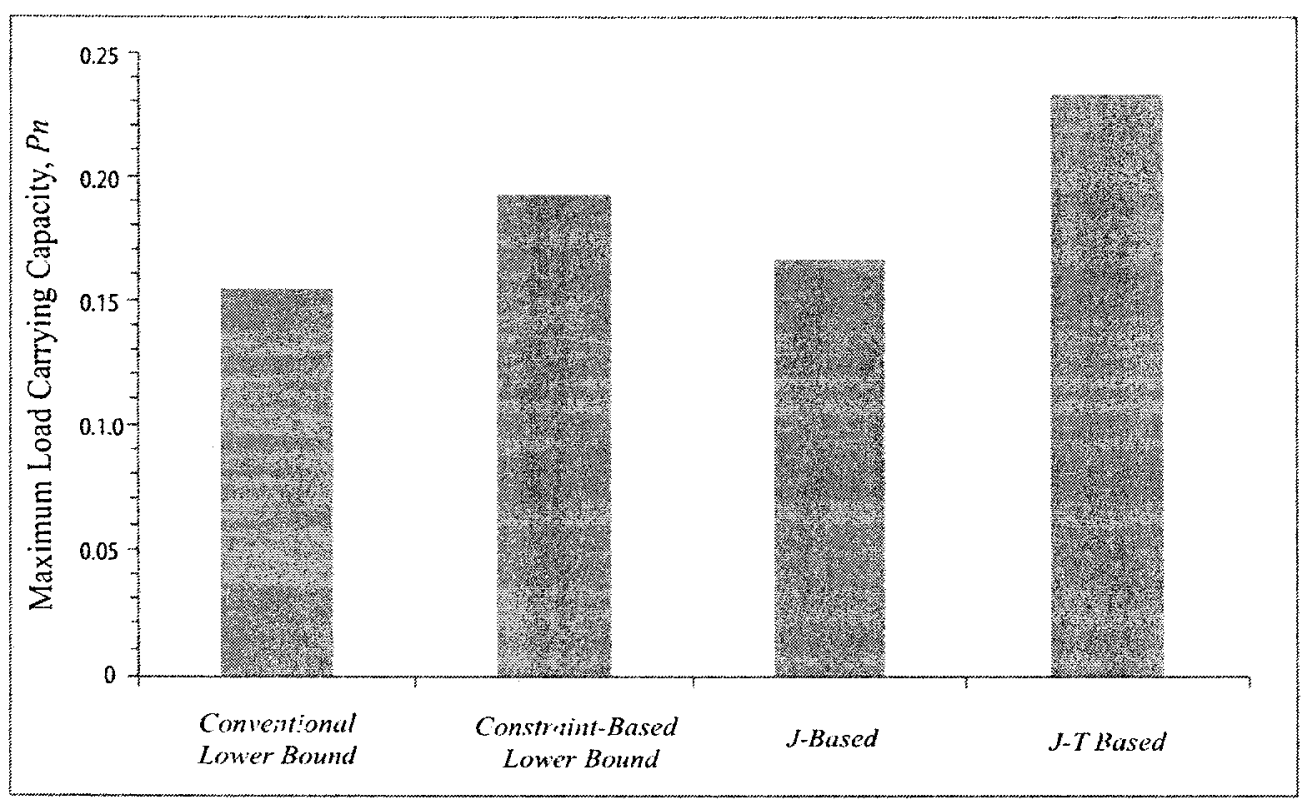

Figure 5.11: Comparison of Increase in $P_{n}$ for K-Based and J-Based FAD $r_{i} / r_{i}=0.8, a / t=0.6, n=10$ 


\section{Chapter 6}

\section{Conclusions and Recommendations}

\subsection{Conclusions}

Linear elastic analyses were conduced for circumferential cracked cylinders. The stress intensity factors for the cracked cylinder with thickness ratio of $r_{i} / r_{0}=0.2,0.4,0.6$ and 0.8 and $a / t=0.2,0.4,0.6$ and 0.8 were determined. From the stress intensity factor calculations, the boundary correction factors were determined and verified with established results from Tada et al. (1985). Axisymmetric finite element models were used to model these cracked geometries. The elastic $\mathrm{T}$-stress solutions were determined.

Elastic plastic analyses were conducted for the same cracked cylinder geometry. The fully plastic $J$-integrals were determined for materials with strain hardening coefficient, $n$, of 3,5 , and 10 . From the fully plastic J-integral, the fully plastic factors, $h_{I}$ were calculated. An application of the EPRI estimation scheme was conducted on crack geometry of $r_{i} / r_{0}=0.8$, and $n=3,5$, and 10 using the calculated $h_{1}$ factors. The $h_{1}$ factors enable the determination of J-integral for these cracked cylinders under any given load.

Conventional lower bound as well as a constraint-based lower bound failure assessment diagrams were developed using the stress intensity factors and T-stress solutions. The maximum load carrying capacities for the two methods were determined. The increase in load carrying capacities after accounting for the constraint effects is demonstrated. 
A conventional J-based as well as a $\mathrm{J}$-T based failure assessment diagram were also developed using calculated J-integral and T-stress solutions for crack geometry of $r_{i} / r_{o}=$ 0.8 and $a / t=0.2$, and 0.6 , with $n=10$. The maximum load carrying capacity was determined. The load carrying capacity increased using the J-T based FAD.

The fracture mechanics parameter solutions of T-stress, J-integral obtained and the constraint-based failure assessment procedures demonstrated in this thesis will enable a more realistic fracture assessment for circumferentially cracked hollow cylinders.

\subsection{Recommendations}

The current thesis studied the circumferential crack in cylinders under uniform tensile loading. It is possible for cracked cylinder to undergo other types of loading such as bending or torsion conditions. Further elastic/elastic plastic analyses of cylinders under these loading conditions could be investigated such as a circumferential crack cylinder under internal pressure loading.

The linear elastic analysis of this thesis used the FEM to determine the various fracture parameters. The stress intensity factor determined in this thesis is based on a single loading condition. To get the stress intensity factor for various crack lengths and other loading conditions, multiple computations of FEM are needed. The weight function is another method that could be used to determine the stress intensity factor and elastic Tstress, Bueckner (1970). The weight function is dependent on the crack geometry and once it is known, the stress intensity factor and T-stress can be determined for various loading conditions. 
A service life study could have been performed on the cracked geometry based on the failure assessments to determine the extension in service life of a cracked cylinder under constraint-based failure assessment conditions. The benefits of this study would further show the importance of conducting the constraint-based FADs. 


\section{References}

ABAQUS User Manual, 2004, Version 6.7.3, Hibbit, Karlsson \& Sorensen, Inc.

Ainsworth, R.A. and O'Dowd, N.P., 1995, "Constraint in the Failure Assessment Diagram Approach for Fracture Assessment", ASME Journal of Pressure Vessel Technology, Vol. 117, pp. 260-267.

Anderson, T.L., 1991, "Fracture Mechanics: Fundamentals and Applications", Boca Raton: CRC Press.91, pp. 283-298.

Ayatollahi, M.R., and Pavier, M.J., 1998, "Determination of T-stress from Finite Element Analysis for Mode 1 and Mixed Mode Loading", International Journal of Fracture, Vol. 91, pp. 283-298.

Barsoum, R.S., 1977, "Triangular quarter-point elements as elastic and perfectly-plastic crack tip elements", International Journal for Numerical Methods in Engineering, Vol.11, pp. 85-98.

Barsom, J.M., and Rolfe, S.T., 1999, "Fracture and Fatigue Control in Structures", Third Edition, ASTM., pp. 16-19, 31-39, 54-57, 101. 
Betegon, C. and Hancock, J.W., 1991, "Two-parameter characterization of elastic-plastic crack tip fields", ASME Journal of Applied Mechanics, Vol. 58, pp.104-110.

Bilby, B.A., Cardew, G.E., Goldthorpe, M.R. and Howard, I.C., 1986, "A finite element investigation of the effect of specimen geometry on the fields of stress and strain at the tips of stationary cracks", In: Size Effect in Fracture. London: Mechanical Engineering Publications Limited, pp. 37-46.

Bloom, J.M., 1980, "Prediction of Ductile Tearing of Compact Fracture Specimens Using the R-6 Failure Assessment Diagram", International Journal of Pressure Vessel and Piping, Vol. 8, pp. 215-231.

Broek, D., 1988,“The Practical Use of Fracture Mechanics, Kluwer.

Bueckner, H.F., 1970, "A novel principle for the computation of stress intensity factors", Mathematic Mechanics, Vol. 50, pp. 129-146.

Dodds, R.H., Anderson, T.L., Kirk, M.T., 1991, "A framework to correlate a/w ratio effect on elastic-plastic fracture toughness $\left(J_{c}\right)$, International Journal of Fracture, Vol. 48 , pp. 1-22.

Du, Z.Z., and Hancock, J.W., 1991, "The effect of non-singular stresses on crack tip constraint", Journal of Mechanical Physics and Solids, Vol. 39, pp. 555-567. 
Eshelby, J.D., 1974, "Calculation of energy release rate", In Prospects of Fracture Mechanics, pp.69-84.

Ewalds, H.L., and Wanhill, R.J.H., 1984, "Fracture Mechanics", Edward Arnold, pp. 1731, 76-79, 118-127.

Griffith, A.A., 1920, "The Phenomena of Rupture and Flow in Solids", Philosophical Transactions of the Royal Society, A221, pp.163-198.

He, M.Y., and Hutchinson, J.W., 1981, "The penny-shaped crack and the plane strain crack in an infinite body of power-law material", ASME Journal of Application Mechanics, Vol. 48, pp.830-840.

Hutchinson, J.W., 1968, "Singular behaviour at the end of a tensile crack in a hardening material", Journal of Mechanical Physics and Solids, Vol. 16, pp. 13-31.

Irwin, G.R., 1957, "Analysis of stresses and strains near the end of a crack traversing a plate", Journal of Applied Mechanics, Vol. 24, pp. 361-364.

Janssen, M., Zuidema, J., and Wanhill, R., 2004, "Fracture Mechanics", Second Edition, Boca Raton: Spon Press., pp. 8-15, 133-146, 191-196.

Kannappan, S., 1986, "Introduction to Pipe Stress Analysis", Wiley-Interscience Publications, pp. 1-7, 22, 171. 
Kfouri, A.P., 1986, "Some evaluation of the elastic T-term using Eshelby's method", International Journal of Fracture, Vol. 30, pp.; 301-315.

Larsson, S.G., and Carlsson, A.J., 1973, "Influence of non-singular stress terms and specimen geometry on small-scale yielding at crack-tip in elastic-plastic materials", Journal of Mechanical Physics and Solids, Vol. 21, pp. 263-277.

Miller, K.J., and Kfouri, A.P., 1974, "An Elastic-plastic finite element analysis of crack tip fields under biaxial loading conditions", International Journal of Fracture, Vol. 10, pp.393-404.

Mullen, R.L., and Dickerson, R., 1983, "An Isoparametric Finite Element With Decreased Sensitivity to Midside Node Location", Computers and Structures, Vol. 17, pp.611-615.

Nakamura, T. and Parks, D.M., 1992, "Determination of elastic T-stress along three dimensional crack fronts using an interaction integral", International Journal of Solids and Structure, Vol. 29, pp. 1597-1611.

O'Dowd, N.P., and Shih, C.F., 1991, "Family of crack tip field characterized by triaxality parameter-I. Structure of fields', Journal of Mechanical Physics and Solids, Vol. 39, pp. 989-1015.

PD 6493, 1991, "Guidance on some methods for the derivation of acceptance levels for defects on fusion welded joints", British Standards Institution. 
Parker, A.P., 1981, “The Mechanics of Fracture and Fatigue”, Spon Ltd., pp.117-120.

Phaal, R., Andrews, R.M., Gardwood, S.J., 1995, "TWI Biaxial Test Program: 19841994", International Journal of Pressure Vessel and Piping, Vol. 64, pp.177-199.

R6, 1997, "Assessment of the integrity of structures containing defects, procedure R6, Revision 3", Nuclear Electric Ltd, Gloucester, U.K.

Rice, J.R., 1968, "A path independent integral and the approximate analysis of strain concentration by notches and cracks", Journal of Applied Mechanics, Vol. 35, pp. 379386.

Rice, J.R., 1974, "Limitation to the small scale yielding approximation for crack tip plasticity", Journal of Mechanical Physics and Solids, Vol. 22, pp. 17-26.

Rice, J.R., and Rosengren, G.F., 1968, "Plane strain deformation near a crack tip in a power law hardening material", Journal of Mechanical Physics and Solids, Vol. 16, pp. $1-12$.

Shames, I.H., 1986, "Introduction to Solids Mechanics", Second Edition, Prentice Hall, pp. 74-77. 631-638.

Sherry, A.H. France, C.C., and Goldthorpe, 1995, "Compendium of T-stress Solutions for Two and Three Dimensional Cracked Geometries", Fatigue Fracture Engineering Material Structure, Vol. 18, pp. 141-155. 
Shih, C.F., German, M.D., and Kumar, V., 1981, "An Engineering Approach for Examining Crack Growth and Stability in Flawed Structures", International Journal for Pressure Vessels and Piping, Vol. 9, pp. 159-196.

Shih, G.C., 1973, "Handbook of the stress intensity factors", Ins. of Fracture and Solid Mechanics, Lehigh University.

Sladeck, J. and Sladeck, V., 2000, "Evaluation of the Elastic T-stress in ThreeDimensional Crack Problems Using and Integral Formula", International Journal $f$ Fracture, Vol. 101, L47-L52.

Tada, H., Paris, P.C., and Irwin, G.R., 1985, "The Stress Analysis of Cracks Handbook", Second Edition, Paris Production Inc.

Varfolomeyev, I.V., Busch, M.P., 1998, "Stress intensity factors for internal circumferential cracks in thin and thick walled cylinders", Engineering Fracture Mechanics, Vol. 60, pp. 491-500.

Wang, X., 2002a, "Elastic T-stress for in test specimens subjected to non-uniform stress distributions", Engineering Fracture Mechanics, Vol. 69, pp. 1339-1352.

Wang, X., 2002b, "Determination of weight functions for elastic T-stress from reference T-stress solutions", Fatigue and Fracture of Engineering Materials and structures, Vol. 25, pp. 965-973. 
Wang, X., 2002c, "Elastic T-stress solutions for semi-elliptical surface cracks in finite thickness plates", Engineering Fracture Mechanics, Vol. 70, pp. 731-756.

Wang, X., 2004, "Elastic T-stress solutions for penny-shaped cracks under tension and bending", Engineering Fracture Mechanics, Vol. 71, pp. 2283-2298.

Wang, X., 2006, "Fully Plastic J-integral solutions for surface cracked plates under biaxial loading", Engineering Fracture Mechanics, Vol. 73, pp. 1582-1584.

Wang, X., Qu, J., 2006, "Solutions of T-stress for quarter-elliptical corner cracks in finite thickness plates subjected to tension and bending", International Journal of Pressure Vessels and Piping, Vol. 83, pp. 593-606.

Williams, M.L., 1957, "On the stress distribution at the base of a stationary crack", ASME Journal of Applied Mechanics, Vol. 24, pp. 109-114. 